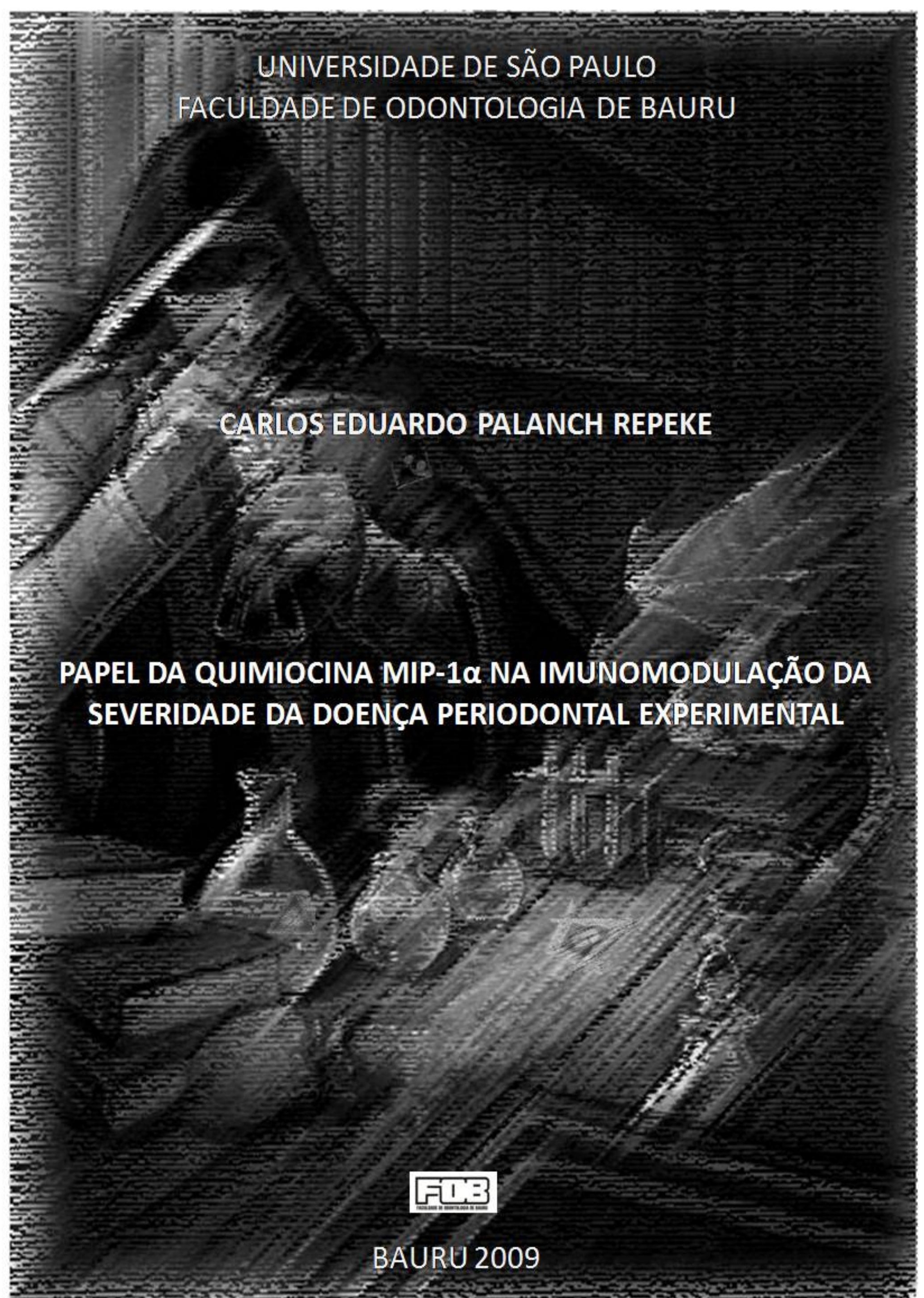





\section{PAPEL DA QUIMIOCINA MIP-1 $\alpha$ NA IMUNOMODULAÇÃO DA SEVERIDADE DA DOENÇA PERIODONTAL EXPERIMENTAL}

\section{CARLOS EDUARDO PALANCH REPEKE}

Dissertação apresentada à Faculdade de Odontologia de Bauru, da Universidade de São Paulo, como parte dos requisitos necessários para obtenção do título de MESTRE em Odontologia, área de Biologia Oral

Orientador: Prof. Dr. Gustavo Pompermaier Garlet 


\begin{tabular}{|c|c|}
\hline & Repeke, Carlos Eduardo Palanch \\
\hline R299p & $\begin{array}{l}\text { Papel da quimiocina MIP-1 } 1 \alpha \text { na imunomodulação da } \\
\text { severidade da doença periodontal experimental / } \\
\text { Carlos Eduardo Palanch Repeke -- Bauru, } 2009 \text {. } \\
102 \text { p. : il. ; } 30 \mathrm{~cm} \text {. }\end{array}$ \\
\hline & $\begin{array}{l}\text { Dissertação (Mestrado) }-- \\
\text { Odontologia de Bauru. Universidade de São Paulo. }\end{array}$ \\
\hline \multicolumn{2}{|c|}{ Orientador: Prof. Dr. Gustavo Pompermaier Garlet } \\
\hline
\end{tabular}

Autorizo, exclusivamente pra fins acadêmicos e científicos, a reprodução total ou parcial desta tese, por processos fotocopiadores e/ou meios eletrônicos.

Assinatura do autor:

Data:

Comitê de Ética no Ensino e Pesquisa em Animais da FOBUSP: projeto de pesquisa aprovado em 13 de setembro de 2007.

Número do protocolo: 15/2007 


\section{Carlos Eduardo Palanch Repeke}

10 de janeiro de 1982

$2000-2005$

$2007-2009$

Associações
Nascimento

São Paulo - São Paulo

Curso de Graduação em Odontologia na Pontifícia Universidade Católica do Paraná

Mestrado em Biologia Oral na Faculdade de Odontologia de Bauru, Universidade de São Paulo

Conselho Regional de Odontologia de Santa Catarina

Sociedade Brasileira de Pesquisa Odontológica 

Dedico inteiramente este trabalho à Iracy Vanin Palanch, um exemplo de amor e perfeição. 


\section{AGRADECIMENTOS}

Aos meus pais Claudemir Repeke (meu amigão) e Marisa Palanch Repeke (minha velhinha), responsáveis por me ensinarem o que eu levo de mais precioso. Tenho muito orgulho de ser filho dos dois.

Ao meu amigo, parceiro e irmão Henrique Palanch Repeke, a quem deposito toda minha confiança e admiração.

À Roberta Santos Domingues, minha companheira em tudo, de noites de estudos a momentos de felicidade. Você torna minha vida fácil e divertida.

Ao meu orientador Gustavo Garlet, pela amizade, paciência e ensinamentos. Tem meu respeito por ser um profissional extremamente diferenciado e um ótimo orientador. The big BOSS.

Ao Prof. Dr. Luis Fernando Pereira (PUC-PR), por despertar em mim a vontade de fazer ciência e me mostrar o verdadeiro papel de um mestre.

Ao Prof. Dr. João Santana da Silva, do laboratório de Imunoparasitologia da FMRP/USP, por participar diretamente de nossos estudos e por fornecer os camundongos MIP-1aKO, agradeço a colaboração.

Ao Prof. Dr. Mário Júlio Ávila Campos, do Laboratório de Anaeróbios do ICB/USP, que por muito tempo tem colaborado com nosso grupo, fornecendo as cepas do periodontopatógeno utilizado no desenvolvimento de nossos estudos.

Ao Prof. Dr. Fernando Queiroz Cunha, do Laboratório de Farmacologia da FMRP/USP, pelas análises de MPO e por toda atenção e profissionalismo.

À Marcela Claudino, a quem devo grande parte da minha vida científica, obrigado pelo carinho, amizade e todo ensinamento que me proporcionou.

Aos amigos do laboratório de histologia Elcia Varize Silveira, Gabriela Gennaro, Francine Mariana Raimundo, Isabela Souza Nunes, Priscila Maria Colavite, Kelly Cristina Rodrigues de Moura, Maria Clara Venturini, Pamella Angélica Lisbôa Rodrigues, Isabel Cristina Meneghetti, Angélica Cristina de Oliveira Martins e em especial Samuel Ferreira Jr, pela parceria no mundo das quimiocinas.

Aos Amigos de mestrado Aroldo, Marcus Gustavo, Luis Rapucci, Geraldo Rosa, Luis (Basquete), Leslie Casas, Hayana Lima, Carla Sipert, Mileni Fernandes, Aline Leite, Ana Morandini e Mônica Lobo e em especial aos amigos Bruno Furquim e Erivan Ramos Jr por 24 horas de convivência, amizade e por dividirem um apartamento minúsculo e bagunçado.

Aos profs. Dr. Gerson Francisco de Assis, Dr. Rumio Taga, Dr. Dagoberto Sottovia Filho e técnicas/equipe Patrícia Germino, Daniele Santi Ceolin, Tânia Mary Cestari , Ivânia Komatsu, Beonildes Teresinha Ruiz Correia e Aldivina Mendes, pela ajuda diária e convivência. 
Aos amigos Anthon P. Cechelero, Raul M. Martins, Jefferson Hirt, Fabiano J. Alves, Henrique Kenji e todo pessoal de Piçarras/SC, Pedro e Caio Salvador, Raphael Mori de Almeida, Francisco Fronza, Carlo Arashiro, Igor Alisson, em especial Fernando Koike, a quem devo muito da minha formação, conhecimento em odontologia e pela grande amizade e parceria.

Aos trabalhadores da Acácia (Itajaí) e da Luz de Curitiba, pela amizade, torcida e paciência da minha ausência nos trabalhos.

Aos familiares e amigos, Juliana, Renata e Cidinha Repek, Nilzete Brito, Dulce, Renata e Roberto Domingues, Edson Spinello, Patrícia Leichsenring, Zé Roberto Lucon, Carlos Boldati e Drica Palanch Repeke, pelo carinho e amor.

À Lilian Palanch e André Boldati, agradeço por sempre estarem ao meu lado.

À FAPESP, cujo auxílio na forma de minha bolsa de mestrado (2007/01705-7) e de auxílio pesquisa (2006/00534-1) possibilitou a realização desta dissertação.

Carlos Eduardo Palanch Repeke. 


\section{From Hell, Jack "the Ripper"}

(O papel de MIP-1a na doença periodontal)

Esse tipo de "trabalho" não é como nos livros. Esse "trabalho" é um evento humano localizado tanto no espaço quanto no tempo e que tem um campo imaginário completamente não circunscrito por conceitos. Possui significado e forma, mas não solução. A incerteza quântica, incapaz de determinar tanto a localização de uma partícula quanto a sua natureza, necessita que nós mapeemos todos os possíveis estados da partícula: sua superposição. Jack não é Gull ou Druitt. Jack é uma superposição.

Adaptado de: Do Inferno (From Hell) Alan Moore e Eddie Campbell 1989, 1999. 


\section{RESUMO}

O desenvolvimento da doença periodontal (DP) é influenciado pela resposta imunológica do hospedeiro frente ao desafio bacteriano. Apesar da função protetora de tal resposta frente à infecção, a mesma leva à destruição dos tecidos periodontais. Neste estudo, analisamos o papel de MIP-1 $\alpha$ na imunomodulação da DP experimental em camundongos. Camundongos C57B1/6 (WT) infectados com A. actinomycetemcomitans desenvolveram uma intensa reação inflamatória e severa reabsorção óssea alveolar, associada a uma alta expressão de MIP-1 $\alpha$ e uma intensa migração de células CCR5+ e CCR1+ para os tecidos periodontais. Além disso, verificamos que uma intensa expressão de citocinas inflamatórias (TNF- $\alpha$ ) e do tipo Th1 (IFN- $\gamma$ ), RANKL e MMPs estava associada à progressão da doença. Entretanto, camundongos geneticamente modificados para não expressar MIP-1 $\alpha$ (MIP-1 $\alpha \mathrm{KO})$, quando infectados com A. actinomycetemcomitans, apresentaram um padrão de resposta muito semelhante aos animais WT. De fato, a ausência de MIP-1 $\alpha$ não interferiu na migração de células inflamatórias para os tecidos periodontais e na reabsorção óssea alveolar nos camundongos infectados. Semelhantemente, a expressão de citocinas (TNF- $\alpha$, IFN- $\gamma$ e IL-10), dos fatores osteoclastogênicos (RANKL e OPG) e das MMPs e seus inibidores (MMP-1, MMP-2, MMP-3, TIMP-1 e TIMP-3) foram similares entre os camundogos das linhagens WT e MIP-1 $\alpha$ KO. Além disso, a ausência de MIP-1 $\alpha$ não interferiu no controle da infecção por $A$. actinomycetemcomitans como demonstrado pela similaridade na quantidade de carga bacteriana presente nos tecidos e nos níveis de MPO e iNOS. Os resultados obtidos podem ser explicados pela relativa redundância no sistema quimiocinas/receptores de quimiocinas, onde mais de uma quimiocina pode ligar-se ao mesmo receptor. De fato quimiocinas como MIP-1 $\beta$ e RANTES, que utilizam os mesmos receptores de MIP-1 $\alpha$ (CCR5 e CCR1), apresentaram-se intensamente expressas nos tecidos periodontais dos camundongos infectados com $A$. actinomycetemcomitans, independentemente da ausência de MIP-1 $\alpha$. De fato, camundongos tratados com Met-RANTES, um antagonista específico dos CCR5 e CCR1, resultou em uma redução significativa no influxo de células inflamatórias e perda óssea alveolar quando comparados com os camundongos não tratados. Nossos resultados demonstraram que a ausência de MIP-1 $\alpha$ não afeta o desenvolvimento da doença periodontal experimental em camundongos, provavelmente pela presença de quimiocinas homólogas que suprem sua ausência. 
Palavras-chave: QUIMIOCINAS, PERIODONTITE, IMUNOLOGIA, CAMUNDONGOS, A. ACTINOMYCETEMCOMITANS. 


\section{ABSTRACT}

\section{The role of MIP-1 $\alpha$ on the immunomodulation of experimental periodontal disease in mice}

Periodontal disease (PD) development is highly influenced by the host immune response to the bacterial challenge. Despite the protective role of this response against infectious agents it leads to periodontal tissues destruction. In this study, we analyzed the role of chemokine MIP-1 $\alpha$ on the immunomodulation of experimental PD in mice. C57B1/6 (WT) mice infected with A. actinomycetemcomitans developed an intense inflammatory reaction and severe alveolar bone resorption, associated with a high expression of MIP-1 $\alpha$ and the migration of CCR5+ and CCR1+ cells to the periodontal tissues. In addition, an intense expression of Th1 (IFN- $\gamma$ ) and inflammatory (TNF- $\alpha$ ) cytokines, RANKL and MMPs are associated with the disease progression. However, mice genetically deficient of MIP-1 $\alpha$ (MIP-1 $\alpha \mathrm{KO})$, when infected with A. actinomycetemcomitans, developed a very similar response pattern to that observed for WT strain. Indeed, the absence of MIP-1 $\alpha$ does not interfere in inflammatory cells migration to periodontal tissues and alveolar bone resorption in response to A. actinomycetemcomitans infection. Similarly, the expression of cytokines (TNF$\alpha$, IFN- $\gamma$ and IL-10), osteoclastogenic factors (RANKL and OPG) and MMPs and its inhibitors (MMP-1, MMP-2, MMP-3, TIMP-1 and TIMP-3) was similar between WT and MIP- $1 \alpha \mathrm{KO}$ strains. Furthermore, the lack of MIP-1 $\alpha$ does not interfere in the control of $A$. actinomycetemcomitans infection as demonstrated by the similar bacterial load, and similar levels of the antimicrobial MPO and iNOS. Such results can be explained by the relative redundancy of chemokine system, where more than one chemokine can bind to the same receptor. Indeed, chemokines, such as MIP-1 $\beta$ and RANTES, which use the same receptors used by MIP-1 $\alpha$ (CCR1 and CCR5), are intensely expressed in periodontal tissues of mice infected with A. actinomycetemcomitans, regardless of the absence of MIP-1 $\alpha$. In accordance, the treatment of mice with Met-RANTES, a specific antagonist of the receptors CCR5 and CCR1, resulted in a significant reduction in the influx of inflammatory cells and alveolar bone loss when compared with untreated mice. Our results demonstrate that the absence of MIP-1 $\alpha$ does not affect the development of experimental periodontitis in mice, probably due to the presence of homologous chemokines that overcome the absence of this chemokine. 
Keywords: CHEMOKINES. PERIODONTITIS. IMUNNOLOGY. MICE, A. ACTINOMYCETEMCOMITANS. 


\section{LISTA DE ILUSTRAÇÕES}

\section{- FIGURAS}

Figura 1 Cinética de expressão da quimiocina MIP-1a nos tecidos periodontais de camundongos infectados com $A$. actinomycetemcomitans

Figura 2 Cinética de migração de células CCR5+ e CCR1+ para os tecidos periodontais de camundongos infectados com A. actinomycetemcomitans

Figura 3 Análise fenotípica das células CCR5+ e CCR1+ extraídas dos tecidos periodontais de camundongos infectados com $A$. actinomycetemcomitans

Figura 4 Papel de MIP-1a na modulação da reação inflamatória e perda óssea alveolar induzida por $A$. actinomycetemcomitans

Figura 5 Papel de MIP-1a na migração de células CCR5+ e CCR1+ extraídas dos tecidos periodontais de camundongos infectados com $A$. actinomycetemcomitans

Figura 6 Papel de MIP-1a na cinética de migração de células RANKL+ nos tecidos periodontais de camundongos infectados com $A$. actinomycetemcomitans

Figura 7 Papel de MIP-1a na modulação da expressão de RANKL e OPG nos tecidos periodontais de camundongos infectados com $A$. actinomycetemcomitans

Figura 8 Papel de MIP-1a na modulação da produção de RANKL e OPG nos tecidos periodontais de camundongos infectados com $A$. actinomycetemcomitans

Figura 9 Papel de MIP-1a na modulação da expressão de citocinas nos tecidos periodontais de camundongos infectados com $A$. actinomycetemcomitans

Figura 10 Papel de MIP-1a na modulação da expressão de metaloproteinases (MMPs) e seus inibidores (TIMPs) nos tecidos periodontais de camundongos infectados com $A$. actinomycetemcomitans

Figura 11 Papel de MIP-1 $\alpha$ na modulação da infecção experimental por $A$. actinomycetemcomitans 
Figura 12 Papel de MIP-1 $\alpha$ nos níveis de expressão de óxido nítrico sintase induzível (iNOS) nos tecidos periodontais de camundongos infectados com $A$. actinomycetemcomitans

Figura 13 Papel de MIP-1a na modulação dos níveis de mieloperoxidase (MPO) nos tecidos periodontais de camundongos infectados com $A$. actinomycetemcomitans

Figura 14 Cinética de expressão das quimiocinas MIP-1 $\mathrm{e}$ RANTES nos tecidos periodontais de camundongos infectados com $A$. actinomycetemcomitans

Figura 15 Efeito de MetRANTES na migração de células inflamatórias e perda óssea alveolar induzida por $A$. actinomycetemcomitans 


\section{LISTA DE ABREVIATURAS E SÍMBOLOS}

AA = Aggregatibacter actinomycetemcomitans

$\mathrm{AR}=$ Artrite reumatóide

$\mathrm{CCR}=$ Receptor de quimiocina da família CC

cDNA = Ácido desoxirribonucléico complementar

$\mathrm{COA}=$ Crista óssea alveolar

$\mathrm{CXCR}=$ Receptor de quimiocina da família CXC

$\mathrm{DP}=$ Doença periodontal

ELISA = Ensaio imunoenzimático (enzyme-linked immunosorbent assay)

FACS = Citômetro de fluxo (fluorescence activated cell sorter)

FITC = Isotiocianato de fluoresceína (fluorescein isothiocyanate)

FSC $=$ Parâmetro de análise celular por tamanho (forward scatter)

$\mathrm{IFN}=$ Interferon

$\mathrm{IL}=$ Interleucina (interleukin)

iNOS = Enzima óxido nítrico sintetase induzível (inducible nitric oxide synthase)

JAC $=$ Junção amelo cementária

$\mathrm{KO}=$ Animal geneticamente deficiente (Knock-Out)

LPS $=$ Lipopolissacarídeo

MMP = Metaloprotease de matriz (matrix metalloproteinase)

MPO = Mieloperoxidase (myeloperoxidase)

mRNA $=$ Acido ribonucléico mensageiro

$\mathrm{NFkB}=$ Fator nuclear $\kappa \mathrm{B}($ nuclear factor $\kappa \mathrm{B})$

$\mathrm{NK}=$ Natural Killer

$\mathrm{NO}=$ Óxido nítrico (nitric oxide)

$\mathrm{OPG}=$ Osteoprotegerina (osteoprotegerin)

PBS = Solução salina tamponada com fosfato

$\mathrm{PCR}=$ Reação em cadeia da polimerase (polymerase chain reaction)

$\mathrm{PE}=$ Ficoeritrina (phycoeritrin)

PI = Pós-infecção

$\mathrm{PG}=$ Porphyromonas gingivalis

$\mathrm{RANK}=$ Receptor ativador do NF-kB (receptor activator of NF- $k B$ )

$\mathrm{RANKL}=$ Ligante do receptor ativador do NF-kB (receptor activator of NF- $k B$ 
ligand)

RealTimePCR $=$ Reação em cadeia da polimerase quantitativa

$\mathrm{RT}=$ Transcrição reversa (reverse transcription)

$\mathrm{SD}=$ Desvio padrão (standard deviation)

SSC = Parâmetro de análise celular em citometria de fluxo por granulosidade

(side scatter)

$\mathrm{Th}=$ Linfócito $\mathrm{T}$ auxiliar (T helper lymphocyte)

TIMP = Inibidor tecidual de metaloprotease (tissue inhibitor of

metalloproteinase)

$\mathrm{TNF}=$ Fator de Necrose Tumoral (tumor necrosis factor)

$\mathrm{UAA}=$ Unidade arbitrária de área

$\mathrm{WT}=$ Camundongo selvagem (wild-type) 


\section{SUMÁRIO}

1 INTRODUÇÃO

2 PROPOSIÇÃOO 35

3 MATERIAL E MÉTODOS 39

3.1 Animais de experimentação $\quad 41$

3.2 Protocolo de indução de doença periodontal 41

3.3 Coleta de amostras $\quad 41$

3.4 Avaliação da reabsorção óssea alveolar 42

3.5 Análise quantitativa do infiltrado inflamatório 42

3.6 Extração de RNA e transcrição reversa 43

3.7 Reações de Real Time PCR 43

3.8 Detecção e quantificação de A. actinomycetemcomitans 44

$\begin{array}{lll}3.9 & \text { ELISA } & 45\end{array}$

3.10 Dosagem de mieloperoxidase (MPO) 45

3.11 Tratamento dos animais com MetRANTES 46

$\begin{array}{lll}3.12 & \text { Análise estatística } & 46\end{array}$

4 RESULTADOS $\quad 47$

4.1 Cinética de expressão da quimiocina MIP-1a nos tecidos periodontais 49 de camundongos infectados com $A$. actinomycetemcomitans

4.2 Cinética de migração de células CCR5+ e CCR1+ para os tecidos 49 periodontais de camundongos infectados com $A$. actinomycetemcomitans

4.3 Análise fenotípica das células CCR5+ e CCR1+ extraídas dos tecidos 50 periodontais de camundongos infectados com $A$. actinomycetemcomitans

4.4 Papel de MIP-1a na modulação da reação inflamatória e perda óssea 51 alveolar induzida por $A$. actinomycetemcomitans 
4.5 Papel de MIP-1a na migração de células CCR5+ e CCR1+ extraídas 53 dos tecidos periodontais de camundongos infectados com $A$. actinomycetemcomitans

4.6 Papel de MIP-1a na cinética de migração de células RANKL+ nos tecidos periodontais de camundongos infectados com $A$. actinomycetemcomitans

4.7 Papel de MIP-1a na modulação da expressão de RANKL e OPG nos tecidos periodontais de camundongos infectados com $A$. actinomycetemcomitans

4.8 Papel de MIP-1a na modulação da produção de RANKL e OPG nos 56 tecidos periodontais de camundongos infectados com $A$. actinomycetemcomitans

4.9 Papel de MIP-1a na modulação da expressão de citocinas nos tecidos periodontais de camundongos infectados com $A$. actinomycetemcomitans

4.10 Papel de MIP-1a na modulação da expressão de metaloproteinases (MMPs) e seus inibidores (TIMPs) nos tecidos periodontais de camundongos infectados com $A$. actinomycetemcomitans

4.11 Papel de MIP-1a na modulação da infecção experimental por $A$. actinomycetemcomitans

4.12 Papel de MIP-1a nos níveis de expressão de óxido nítrico sintetase induzível (iNOS) nos tecidos periodontais de camundongos infectados com $A$. actinomycetemcomitans

4.13 Papel de MIP-1a na modulação dos níveis de mieloperoxidase (MPO) 62 nos tecidos periodontais de camundongos infectados com $A$. actinomycetemcomitans

4.14 Cinética de expressão das quimiocinas MIP-1 $\beta$ e RANTES nos tecidos periodontais de camundongos infectados com $A$. actinomycetemcomitans

4.15 Efeito de MetRANTES na migração de células inflamatórias e perda óssea alveolar induzida por $A$. actinomycetemcomitans

5 DISCUSSÃO

6 CONCLUSÕES

REFERÊNCIAS 


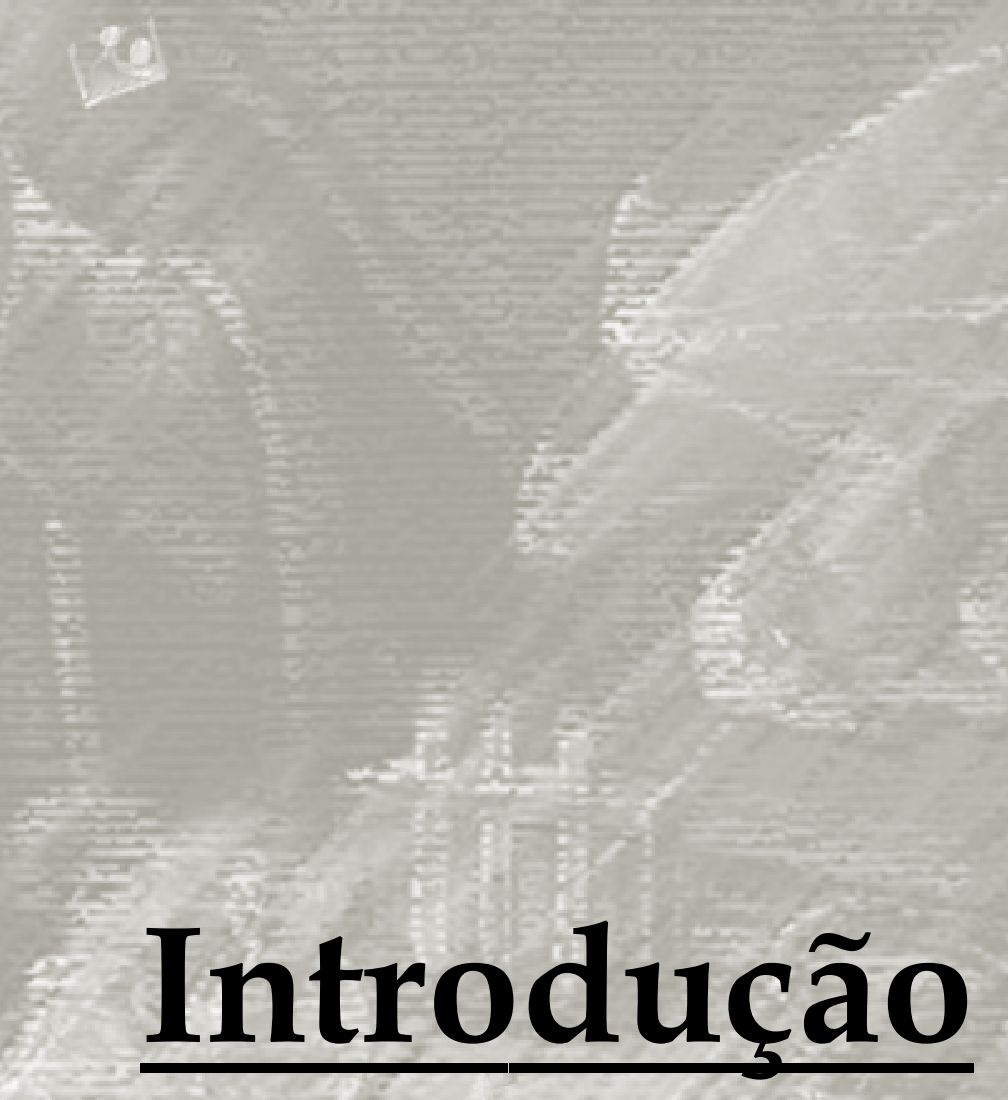





\section{Introdução}

Doenças periodontais (DPs) são alterações inflamatórias dos tecidos de proteção e sustentação do dente, cuja etiologia está relacionada à placa dental bacteriana. Em termos epidemiológicos, quase a totalidade da população sofre de alguma das modalidades das doenças periodontais, sendo a principal causa da perda dental entre adultos e podendo ser modificadora da saúde sistêmica (Loesche, 1993; Kinane e Lappin, 2001).

Mesmo em condições clínicas de saúde, há um constante desafio de microrganismos potencialmente patogênicos que, até certo ponto, convivem em harmonia com os tecidos periodontais. Com o desenvolvimento do biofilme bacteriano e com alterações no número e na microflora da placa estabelece-se um desequilíbrio, aumentando os produtos microbianos gerados e a carga antigênica no sulco gengival, resultando em uma resposta inflamatória mais intensa, o que constitui o início da resposta imune (Loesche, 1993; Engebretson, Lamster et al., 1999; Kinane e Lappin, 2001; Kinane, Demuth et al., 2007).

Embora o início e a progressão da doença periodontal dependam da presença de microrganismos periodontopatogênicos, e que produtos destas bactérias possam causar diretamente dano tecidual, observações histológicas em tecidos periodontais nos mostram que os sítios lesados na doença periodontal estão distantes da fronte de ataque bacteriano, o que sugere uma lesão indireta causada pelas bactérias através da resposta imunológica exacerbada (Craig, Yip et al., 2003). É geralmente aceito que, apesar do processo inflamatório na doença periodontal ser caracterizado por um infiltrado de leucócitos cujo papel é limitar a invasão bacteriana, a natureza e a magnitude da resposta imune do hospedeiro possam modular a severidade da destruição tecidual (Ebersole e Taubman, 1994; Baker, 2000). De fato, diversos estudos experimentais sugerem que a inibição de determinados fatores da resposta imune, como citocinas, reduzem marcadores clínicos e biológicos do aumento da severidade da doença periodontal (Garlet, Cardoso et al., 2007; Garlet, Cardoso et al., 2008). Por outro lado, a inibição destes fatores causa um prejuízo na eliminação e no controle bacteriano, supostamente envolvendo alterações na saúde sistêmica (Garlet, Cardoso et al., 2007; Garlet, Cardoso et al., 2008). A falta de um completo entendimento da resposta imune na DP configura um quadro paradoxal entre o benefício promovido pelo controle da infecção e o efeito destrutivo desencadeado, e torna a modulação desta resposta uma ferramenta 
importante na paralisação ou diminuição da severidade de tal patologia, porém a ser utilizada com cautela.

Controvérsias à parte, um fato concreto é que a permanência de um foco infeccioso em íntima associação aos tecidos periodontais leva a manutenção de uma reação inflamatória local (Loesche, 1993; Baker, Evans et al., 1994; Genco, Van Dyke et al., 1998). Tal resposta leva a destruição tecidual através de mecanismos que incluem a produção de enzimas envolvidas na degradação de tecido conjuntivo e a expressão de fatores osteoclastogênicos (de diferenciação e ativação de osteoclastos) (Assuma, Oates et al., 1998; Baker, 2000; Cheng, Kinosaki et al., 2003; Craig, Yip et al., 2003; Ejeil, Igondjo-Tchen et al., 2003). Fatores osteoclastogênicos esses diretamente responsáveis pela reabsorção óssea alveolar, um evento chave nas DPs. A integridade do tecido ósseo depende da manutenção de um delicado equilíbrio entre a reabsorção óssea pelos osteoclastos e a formação óssea pelos osteoblastos. RANKL (ligante do receptor de ativação do fator nuclear $\kappa B$ ), seu receptor celular RANK (receptor de ativação do fator nuclear kB), e osteoprotegerina (OPG), que atua como receptor “decoy" de RANKL, foram recentemente identificados como os componentes moleculares do sistema de remodelação óssea (Suematsu e Takayanagi, 2007; Takayanagi, 2007; Nakashima e Takayanagi, 2008). A ligação de RANKL a RANK, expresso nos precursores de osteoclastos, é o principal evento estimulatório para sua diferenciação e posterior ativação. Os efeitos de RANKL são regulados pela $\mathrm{OPG}$, que inibe a reabsorção óssea impedindo a interação entre RANK e RANKL (Teitelbaum, 2000; Katagiri e Takahashi, 2002). Alterações no balanço da expressão de RANKL e OPG estão relacionadas como componentes chaves na patogênese de diversas patologias ósseas (Rodan e Martin, 2000; Romas, Gillespie et al., 2002; Sezer, Heider et al., 2003). Com relação às DPs, estudos recentes têm demonstrado que níveis elevados de RANKL são encontrados no fluido gengival e no tecido periodontal em condições de doença. Tais estudos também sugerem que o balanço entre RANKL e OPG supostamente determina a atividade da doença (Teng, Nguyen et al., 2000; Crotti, Smith et al., 2003; Liu, Xu et al., 2003; Garlet, Martins et al., 2004; Mogi, Otogoto et al., 2004).

Além da reabsorção óssea, a destruição do tecido conjuntivo por proteases está relacionada com a severidade da doença periodontal. Dentre as proteases envolvidas na degradação e remodelação de proteínas da matriz extracelular, estão as metaloproteases de matriz (MMPs), as quais desempenham tal papel tanto em processos físiológicos como patológicos (Li, Mctiernan et al., 2000; Chakraborti, Mandal et al., 2003). A ativação das MMPs é regulada por um grupo de proteínas endógenas, chamado de inibidores teciduas de metaloproteases (TIMPs), capazes de inibir praticamente todos os membros da família das 
MMPs, de forma não específica (Baker, Edwards et al., 2002). Em condições fisiológicas, os TIMPs estão em balanço com as MMPs, sendo a matriz extracelular remodelada de forma extremamente controlada. Contudo, em diversos estados patológicos, se verifica a elevação dos níveis de MMPs sem o concomitante aumento na expressão dos TIMPs, aumentando a atividade proteolítica e levando a destruição tecidual (Dean, Martel-Pelletier et al., 1989; Murphy, Docherty et al., 1991; Reynolds, 1996; Nawrocki, Polette et al., 1997; Li, Mctiernan et al., 2000; Parsons, Bradford et al., 2004). Por outro lado, a elevação dos níveis de TIMPs, ou dimuição dos níveis de MMPs, também está associada a processos patológicos, como por exemplo, a quadros de fibrose (Iredale, 1997).

Diversas MMPs são identificadas em tecidos periodontais e no fluido gengival (MMP1, MMP-2, MMP-13) (Kubota, Nomura et al., 1996; Tervahartiala, Pirila et al., 2000; Alpagot, Bell et al., 2001; Seguier, Gogly et al., 2001; Kiili, Cox et al., 2002; Tuter, Kurtis et al., 2002; Ejeil, Igondjo-Tchen et al., 2003; Reddy, Geurs et al., 2003), sendo encontradas em baixos níveis em tecidos normais, e em altas concentrações em tecidos inflamados (Alpagot, Bell et al., 2001). Diversos TIMPs também são encontrados em tecidos periodontais (TIMP-1, TIMP-2, TIMP-3) (Kubota, Nomura et al., 1996; Seguier, Gogly et al., 2001; Reddy, Geurs et al., 2003), assim como são produzidos por fibroblastos gengivais in vitro (TIMP-1, TIMP-2) (Kut-Lasserre, Miller et al., 2001). Dessa forma, acredita-se que MMPs e TIMPs estejam envolvidos no turnover fisiológico dos tecidos periodontais, assim como na destruição tecidual vista nas DPs (Van Der Zee, Everts et al., 1997; Golub, Mcnamara et al., 2001; Ramamurthy, Xu et al., 2002; Ejeil, Igondjo-Tchen et al., 2003; Reddy, Geurs et al., 2003; Emingil, Atilla et al., 2004). Tanto na produção de fatores osteoclastogênicos quanto fatores de degradação do tecido conjuntivo, há participação de diversas células e moléculas, sendo que a contribuição de tais fatores para o desenvolvimento das DPs, dentro de uma resposta inflamatória e imunológica, necessitam ser mais bem estudadas e compreendidas.

No curso desta reação inflamatória e imunológica, verifica-se a presença de diversos tipos celulares. Inicialmente predominam leucócitos polimorfonucleares, sendo posteriormente o infiltrado inflamatório constituído em sua maioria por macrófagos e linfócitos (Kinane e Lappin, 2001). Porém, pouco se conhece a respeito da importância individual de cada população celular na imunopatogênese das doenças periodontais, muito menos é conhecido sobre os fatores quimiotáticos que desencadeiam a migração, permanência e ativação de tais células no tecido gengival (Ferrante, 1992).

Neutrófilos polimorfonucleares estão presentes nos tecidos periodontais mesmo em condições de saúde, são a população celular predominante no início da reação inflamatória e 
ainda podem ser encontrados em lesões estabelecidas (Teng, 2003). Parecem ser de grande importância no processo de defesa, uma vez que alterações na função e na migração dos neutrófilos estão relacionadas com formas mais severas de doenças periodontais. Além de sua importância na defesa, os neutrófilos são potencialmente perigosos em relação à ocorrência de dano tecidual devido ao conteúdo de seus grânulos. Compondo os grânulos azurófilos dos neutrófilos, há uma enzima chamada mieloperoxidase (MPO) que compõe um dos sistemas mais eficazes de ação antimicrobiana, além do mais, esta enzima é utilizada como um marcador de neutrófilos ativados (Ferrante, 1992).

Já os macrófagos são encontrados em números substanciais nas lesões inflamatórias crônicas dos tecidos periodontais. Eles reagem com componentes bacterianos, particularmente LPS, e são ativados para liberar seus mediadores inflamatórios e citocinas nos tecidos circundantes (Lappin, Kjeldsen et al., 2000; Kinane, Demuth et al., 2007). Também podem apresentar papel regulatório da resposta imune local através da fagocitose e morte de patógenos, seguida da apresentação de antígenos (Chapple, Srivastava et al., 1998; Lappin, Kjeldsen et al., 2000). Outro sistema de defesa do organismo apresentado pelos macrófagos e por células polimorfonucleares (PMN) é a liberação do radical livre óxido nítrico (NO), o qual é produzido por uma isoenzima chamada de enzima óxido nítrico sintetase induzível (iNOS). Esta enzima é expressa em resposta a estímulos inflamatórios, tais como citocinas inflamatórias e LPS, sendo produzida em alta quantidade e por um período longo de tempo (Blix e Helgeland, 1998; Chapple, Srivastava et al., 1998; Aliberti, Machado et al., 1999; Lappin, Kjeldsen et al., 2000; Fukada, Silva et al., 2008).

Acredita-se que a resposta do hospedeiro para o desenvolvimento de doenças periodontais é dependente de linfócitos. Tanto linfócitos $\mathrm{T}$ quanto $\mathrm{B}$ estão presentes em grande número nos tecidos periodontais em condições patológicas. Uma das possíveis vias de regulação da resposta nas DPs seria a produção de citocinas pelas diferentes subpopulações de linfócitos T auxiliares (ou T helper:Th), que atuariam atenuando ou potencializando a reação inflamatória nos tecidos periodontais, e desta forma, determinando a atividade ou latência das lesões periodontais (Berglundh, Liljenberg et al., 2002; Teng, 2003; Yamazaki, Yoshie et al., 2003; Gemmell e Seymour, 2004). As respostas mediadas por linfócitos Th podem exibir um padrão Th1, que consiste predominantemente de uma resposta imune celular e próinflamatória, com a presença característica de citocinas como fator de necrose tumoral- $\alpha$ (TNF- $\alpha$ ) e interferon- $\gamma$ (IFN- $\gamma$ ), ou um padrão do tipo Th2, com características antiinflamatórias, de resposta imune predominantemente humoral e com a presença característica de citocinas como interleucina-10 (IL-10) (Moore, O'garra et al., 1993). Tal 
polarização é determinada por citocinas típicas de cada padrão, envolvendo a participação de quimiocinas e tipos celulares característicos.

Dentre as diversas citocinas implicadas na patogênese das DPs, o TNF- $\alpha$ é provavelmente o fator mais estudado e com papel bem estabelecido. O TNF- $\alpha$ age em diversos passos nos mecanismos de recrutamento de leucócitos e estimula a produção local de quimiocinas, que por sua vez, atuam na manutenção e/ou na amplificação da reação inflamatória local (Offenbacher, Odle et al., 1989; Graves e Jiang, 1995; Jiang, Magli et al., 1999; Graves e Cochran, 2003). Além disso, o TNF- $\alpha$ participa diretamente da estimulação da imunidade inata e da atividade bactericida de fagócitos (Dinarello, 1990; Pfizenmaier, Wajant et al., 1996; Dinarello, 2000). Dessa forma, o TNF- $\alpha$ apresenta importante papel na resistência a infecções por diversos patógenos (Ferrante, 1992; Graves, Chen et al., 2000).

Embora o TNF- $\alpha$ apresente papel essencial na iniciação e efetuação das respostas imune e inflamatória, diversos estudos têm demonstrado que a expressão inadequada de tal citocina pode levar a um significante dano colateral ao hospedeiro. De fato, TNF- $\alpha$ apresenta um evidente papel na patogênese de diversas doenças auto-imunes e inflamatórias, como a artrite reumatóide (AR) (Stashenko, Dewhirst et al., 1987; Ridderstad, Abedi-Valugerdi et al., 1991; Dinarello, 2000; Henderson e Nair, 2003). A inibição de TNF- $\alpha$ na AR leva a um menor recrutamento de células para o sítio de inflamação, regulação negativa da expressão de citocinas pró-inflamatórias e MMPs no tecido sinovial, além de significante redução na reabsorção óssea (Tak, Taylor et al., 1996; Goldring, 2000; Ulfgren, Andersson et al., 2000). Estudos demonstram que a AR compartilha alguns aspectos com as DPs como a natureza crônica da resposta inflamatória, a intensa destruição tecidual e a reabsorção óssea. Além disso, verifica-se uma interessante associação entre DP e AR, uma vez que uma maior prevalência e maior severidade das DPs são verificadas nos pacientes com AR (Mercado, Marshall et al., 2001; Henderson e Nair, 2003; Mercado, Marshall et al., 2003; Miranda, Fischer et al., 2003). Com relação às DPs, TNF- $\alpha$ tem sido identificado em altos níveis em lesões peridontais (Stashenko, Jandinski et al., 1991; Matsuki, Yamamoto et al., 1992; Gorska, Gregorek et al., 2003; Graves e Cochran, 2003; Wang, Ohura et al., 2003) e no fluido gengival de pacientes com DP (Rossomando, Kennedy et al., 1990; Engebretson, Lamster et al., 1999). De fato, em modelos experimentais de DP, o TNF- $\alpha$ está envolvido na migração de leucócitos aos tecidos periodontais, na reabsorção óssea alveolar e na perda de inserção conjuntiva (Assuma, Oates et al., 1998; Graves, Delima et al., 1998; Delima, Oates et al., 2001), além de apresentar papel fundamental no controle da carga bacteriana (Garlet, Cardoso et al., 2007). 
Outra citocina com papel imunoregulador interessante e extensamente estudada é o IFN- $\gamma$. Essa citocina parece ser a principal produzida por células T na DP, e diversos estudos têm demonstrado uma associação entre IFN- $\gamma$ e lesões progressivas ou formas mais severas de DP (Ebersole e Taubman, 1994; Roberts, Mccaffery et al., 1997; Salvi, Brown et al., 1998; Sigusch, Klinger et al., 1998; Kawai, Eisen-Lev et al., 2000; Takeichi, Haber et al., 2000; Ukai, Mori et al., 2001; Gorska, Gregorek et al., 2003). Nesse sentido, estudos prévios de nosso grupo de pesquisa demonstram que pacientes com periodontite agressiva (de caráter mais severo e de progressão mais rápida) apresentam uma resposta predominante do tipo Th1, com intensa expressão de IFN- $\gamma$, correlacionada com uma intensa expressão de MMPs e RANKL (Garlet, Martins et al., 2003; Garlet, Martins et al., 2004; Garlet, Cardoso et al., 2008). Em concordância com tais resultados, estudos demonstram que o IFN- $\gamma$ leva a um aumento da responsividade dos fibroblastos gengivais a ação do LPS, levando a uma maior produção de citocinas inflamatórias (Tamai, Sakuta et al., 2002; Mochizuki, Kobayashi et al., 2004). Além disso, o IFN- $\gamma$ está associado à diminuição na síntese de colágeno e ao aumento na síntese de MMPs por fibroblastos gengivais in vitro (Martelli-Junior, Cotrim et al., 2003). De fato, a inoculação de Porphyromonas gingivalis em animais geneticamente deficientes de IFN- $\gamma$ resulta em uma menor reação inflamatória e reabsorção óssea (Baker, Dixon et al., 1999), sugerindo um importante papel de IFN- $\gamma$ na potencialização da severidade da DP. Ao contrário, certos estudos têm sugerido que altos níveis de IFN- $\gamma$ no tecido gengival estariam envolvidos na atenuação da severidade da doença (Yamazaki, Nakajima et al., 1995; Gemmell, Marshall et al., 1997; Gemmell e Seymour, 1998; Bartova, Kratka-Opatrna et al., 2000; Kobayashi, Nagasawa et al., 2000; Petit, Hovenkamp et al., 2001). Tal hipótese encontra suporte em trabalhos que demonstram que IFN- $\gamma$ está associado à redução na diferenciação e ativação de osteoclastos, principalmente in vitro (Moriyama, Ukai et al., 2002; Takayanagi, Sato et al., 2005; Takayanagi, 2007).

Além de atuar no agravamento da severidade da doença, o IFN- $\gamma$ está potencialmente envolvido no controle da infecção periodontal, uma vez que tal citocina estimula fibroblastos gengivais a produzirem óxido nítrico (NO) (KENDALL et al. 2000, DAGHIGH et al. 2002), envolvido no controle de microrganismos no microambiente periodontal (RAUSCH-FAN et al. 2001, KENDALL et al. 2001). De fato, estudos de DP experimental em camundongos demonstram que a falta de IFN- $\gamma$ contribui para um déficit na resposta imunológica, aumentando assim a carga bacteriana (Garlet, Cardoso et al., 2008).

Além de mediadores de resposta Th1, citocinas envolvidas em respostas Th2 têm sido identificadas em lesões periodontais e também estão potencialmente envolvidas na patogênese 
da doença (Yamazaki, Nakajima et al., 1995; Gemmell, Marshall et al., 1997; Gemmell e Seymour, 1998; Bartova, Kratka-Opatrna et al., 2000; Petit, Hovenkamp et al., 2001). Uma dessas citocinas, a IL-10, apresenta propriedades antiinflamatórias, sendo capaz de reduzir a expressão de moléculas co-estimulatórias em células apresentadoras de antígenos e inibir a síntese de citocinas inflamatórias e Th1 (Rousset, Garcia et al., 1992; Moore, O'garra et al., 1993; Hamilton, Ohmori et al., 1999; Pestka, Krause et al., 2004; Menezes, Garlet et al., 2008). Tal citocina está geralmente associada a uma significante redução na reação inflamatória, mas uma vez que interfere na resposta imune celular mediada por TNF- $\alpha$ e IFN$\gamma$, a produção de IL-10 pode prejudicar a eliminação de agentes infecciosos, levando a latência de infecções (Belkaid, Piccirillo et al., 2002; Mittrucker e Kaufmann, 2004; Sakaguchi, 2004).

As propriedades regulatórias de IL-10 também incluem a inibição da produção de MMPs e de fatores osteoclastogênicos, além de estimular a produção de seus respectivos antagonistas TIMPs e OPG (Mertz, Dewitt et al., 1994; Reynolds, 1996; Bessis e Boissier, 2001; Chakraborti, Mandal et al., 2003; Cheng, Kinosaki et al., 2003; SaidenbergKermanac'h, Cohen-Solal et al., 2004). Tais estudos sugerem que IL-10 pode apresentar um efeito protetor em relação à destruição tecidual nas DPs (Menezes, Garlet et al., 2008).

Nesse sentido, estudos prévios de nosso grupo de pesquisa demonstram que pacientes com periodontite crônica (menos grave e de progressão mais lenta) apresentam uma intensa expressão de IL-10, correlacionada a uma maior expressão de TIMPs e OPG, possivelmente envolvida na atenuação da severidade da doença (Garlet, Martins et al., 2003; Garlet, Martins et al., 2004; Menezes, Garlet et al., 2008). Dados provenientes de modelos experimentais de DP suportam tal hipótese, demonstrando que a ausência de IL-10 leva a uma maior reabsorção óssea alveolar (Sasaki, Hou et al., 2000; Al-Rasheed, Scheerens et al., 2004; Sasaki, Okamatsu et al., 2004), e que células Th2 apresentam papel protetor com relação à severidade da doença (Eastcott, Yamashita et al., 1994).

Não só as citocinas, como uma expressão seletiva de diferentes quimioatraentes nos tecidos periodontais, podem determinar um padrão de resposta imune Th1 ou Th2 (Karpus e Kennedy, 1997). Uma complexa rede de interação entre citocinas e quimiocinas vem sendo descrita, podendo, as citocinas regularem a produção das quimiocinas e vice-versa. Ainda não se sabe exatamente se tal integração entre padrões de resposta e expressão de determinadas quimiocinas e seus receptores apenas se reflete na migração seletiva dos linfócitos polarizados para os sítios de resposta, ou se a expressão e ativação por determinados receptores podem levar a polarização das células no local de expressão das quimiocinas. Provavelmente ambas 
as hipóteses podem ser verdadeiras, uma vez que a quimiocina MIP-1 $\alpha$, que se liga ao receptor de quimiocinas CCR5, promove a diferenciação para um fenótipo Th1, e após a polarização das células sob o estímulo de citocinas, estas passam a expressar determinados receptores (Karpus e Kennedy, 1997; Karpus, Lukacs et al., 1997).

Sabe-se que o processo de migração celular ocorre através de complexas interações de moléculas de adesão e quimioatraentes a seus respectivos receptores, envolvendo inicialmente o endotélio vascular e as células circulantes, e posteriormente, a interação dessas com a matriz extracelular conjuntiva e fatores quimiotáticos nela gerados (Mantovani, 1999). As quimiocinas compreendem uma grande família de citocinas quimiotáticas e são os principais fatores envolvidos na migração de leucócitos. Tais mediadores participam do processo inflamatório promovendo a ativação das integrinas, envolvidas na adesão das células ao vaso (Bokoch, 1995; Graves e Jiang, 1995; Sozzani, Locati et al., 1996; Gale e Mccoll, 1999). Além disso, sua expressão localizada nos tecidos gera gradientes quimiotáticos responsáveis pelo direcionamento da migração celular e pela sua manutenção nos tecidos. Seus efeitos são exercidos pela ligação a uma classe de receptores expressos seletivamente na superfície dos diferentes tipos celulares, os receptores de quimiocinas. De fato, a expressão seletiva de receptores de quimiocinas pelas subpopulações de linfócitos Th leva a uma diferente responsividade destas células a certas quimiocinas (Karpus e Kennedy, 1997; Karpus, Lukacs et al., 1997; O'garra, Mcevoy et al., 1998; Lukacs, Hogaboam et al., 1999; Gamonal, Acevedo et al., 2001; Luther e Cyster, 2001; Yang, Mukai et al., 2002).

Atualmente, um grande número de quimiocinas foi identificado e tem sido classificados em distintas famílias de acordo com a disposição de resíduos conservados de cisteínas presentes em sua região amino terminal. Tal classificação nos leva a quatro famílias de quimiocinas: $\mathrm{CC}, \mathrm{CXC}, \mathrm{C}$ e $\mathrm{CX}_{3} \mathrm{C}$ (Rossi e Zlotnik, 2000). A família das quimiocinas CC (ou ainda denominadas beta quimiocinas) recebe esta denominação por possuírem as duas primeiras cisteínas (CC), próximas ao domínio amino terminal, adjacente uma a outra, enquanto as CXC quimiocinas (ou alfa quimiocinas) apresentam um aminoácido (X) localizado entre as duas primeiras cisteínas próximas ao domínio amino terminal. Um terceiro grupo, designado $\mathrm{C}$ quimiocinas (ou gamma), apresenta apenas um resíduo de cisteína na porção amino terminal. Finalmente, as $\mathrm{CX}_{3} \mathrm{C}$ quimiocinas (ou delta) que na verdade só apresenta um integrante, o qual apresenta três resíduos de aminóacidos separando as duas primeiras cisteínas (Rollins, 1997; Gale e Mccoll, 1999). As quimicinas atuam apartir de um grupo de receptores celulares, denominados de receptores de quimiocinas, caracterizados por apresentar sete domínios transmembrana, e por estarem ligados a proteína $\mathrm{G}$ em sua porção 
carboxi terminal (Saunders e Tarby, 1999). Com a ligação da quimiocina ao seu receptor, a sinalização decorrente é realizada pela proteína G, que através de suas subunidades desencadeia os eventos bioquímicos intracelulares que resultam nos efeitos que as quimiocinas exercem sobre as células (Bokoch, 1995; Saunders e Tarby, 1999; Murdoch e Finn, 2000). A nomenclatura dos receptores de quimiocinas se dá pelo acréscimo da letra $\mathrm{R}$ ao final do nome da classe de quimiocinas a qual o receptor se liga, ou seja, os receptores das CC quimiocinas são denominados CCR, sendo o mesmo válido para as demais famílias. Certos receptores são associados com o fenótipo Th1, principalmente CXCR3 e CCR5, enquanto outros, como CCR3, CCR4 e CCR8 com o fenótipo Th2 (O'garra, Mcevoy et al., 1998). Apesar de certa redundância e promiscuidade na ligação entre quimiocinas e seus receptores, a combinação entre a expressão seletiva dos receptores, e a expressão seletiva de quimiocinas, é crucial para a determinação da especificidade da migração celular (Mantovani, 1999; Rossi e Zlotnik, 2000).

Com relação às DPs, diversas quimiocinas e receptores de quimiocinas têm sido identificados nos tecidos periodontais inflamados, enquanto sua expressão em condições de saúde periodontal é mínima ou inexistente (Gamonal, Bascones et al., 2000; Gamonal, Acevedo et al., 2001) (Tonetti, Imboden et al., 1994; Gemmell, Carter et al., 2001). Um exemplo disto é a quimiocina MIP-1 $\alpha$, recentemente renomeada como CCL3 (Murphy, 2002), a qual é intensamente expressa no curso da DP experimental, apresentando correlação positiva com a expressão de mediadores diretamente envolvidos na patogênese da doença, como TNF$\alpha$, IFN- $\gamma$, MMPs e RANKL (Garlet, Martins et al., 2003; Garlet, Martins et al., 2004; Garlet, Cardoso et al., 2007; Garlet, Cardoso et al., 2008). MIP-1 $\alpha$, quimiocina da família CC, exibe atividade quimiotática e de ativação celular através da ligação aos receptores CCR1: expresso em eosinófilos, monócitos e células dendríticas, e CCR5, expresso por monócitos, células dendríticas, células NK e linfócitos Th1. Tais tipos celulares são caracteristicamente encontrados durante a doença periodontal, e potencialmente envolvidos em sua patogênese (Kinane e Lappin, 2001; Graves e Cochran, 2003). Além disso, MIP-1 $\alpha$ e seu receptor CCR5 têm sido claramente associados às doenças inflamatórias como a $\mathrm{AR}$, encefalomielite autoimune experimental, doença de chagas, entre outras (Sato, Kuziel et al., 1999; Lindell, Standiford et al., 2001; Teixeira, Gazzinelli et al., 2002). Como anteriormente citado, a AR possui características comuns com as DPs, como a cronicidade da resposta inflamatória e a ocorrência de reabsorção óssea (Mercado, Marshall et al., 2001; Bartold, Marshall et al., 2005). A expressão de MIP-1 $\alpha$ e CCR5 se mostra aumentada no tecido sinovial inflamado, assim como o número de células CCR5+ nas lesões artríticas é extremamente elevado 
(Wedderburn, Robinson et al., 2000; Yuan, Masuko-Hongo et al., 2001; Wang e Liu, 2003). Além de seu papel na quimioatração de leucócitos, MIP-1 $\alpha$ tem sido descrita como indutora da expressão de MMPs e como fator quimiotático e de diferenciação de osteoclastos (Scheven, Milne et al., 1999; Robinson, Scott et al., 2002; Roodman e Choi, 2004; Oba, Lee et al., 2005). Os efeitos de MIP-1 $\alpha$ sobre os osteoclastos parecem ser mediados pelos receptores CCR5 e/ou CCR1 (Oba, Lee et al., 2005), reforçando a idéia que tais fatores podem estar diretamente relacionados à atividade de reabsorção óssea.

Estudos demonstram que a utilização de anticorpos neutralizantes anti-MIP1 $\alpha$, de animais geneticamente deficientes de MIP-1 $\alpha$, com deleção ou mutações no receptor CCR5, leva a atenuação da severidade da artrite experimental (e em diversos outros modelos experimentais, como a encefalomielite autoimune experimental), demonstrando claramente seu papel na patogênese da doença (Yuan, Masuko-Hongo et al., 2001; Yang, Mukai et al., 2002; Proudfoot, Power et al., 2003; Maurer e Von Stebut, 2004). Essas observações sugerem que o desenvolvimento de estratégias terapêuticas visando à inibição das funções de MIP1 $\alpha$ e CCR5 é extremamente promissor. De fato, o tratamento com antagonista de CCR5 MetRANTES (Proudfoot, Power et al., 1996) leva a atenuação do processo inflamatório em diversos modelos experimentais, incluindo a AR (Proudfoot, Power et al., 1996; Proudfoot, Power et al., 2003). Além disso, uma vez que CCR5 é um co-receptor para a invasão celular pelo vírus HIV, a pesquisa por inibidores de CCR5 tem sido intensa, já sendo utilizados em trials clínicos em humanos (Proudfoot, Power et al., 1996; Proudfoot, Power et al., 2003).

A diversidade de estudos relacionados à MIP-1 $\alpha$ acaba contribuindo para 0 levantamento de dúvidas e sugestões da contribuição desta quimiocina na imunopatogênese das DPs. Embora diversos estudos tenham demonstrado a presença de MIP-1 $\alpha$ nos tecidos periodontais em condições patológicas, até agora não se pode estabelecer uma relação de causa efeito entre sua presença e o processo de doença. Visando facilitar essa relação nas DPs, modelos animais têm sido utilizados com sucesso, uma vez que tais variáveis podem ser controladas ou minimizadas, possibilitando a análise individual de fatores da resposta do hospedeiro, assim como o papel de diferentes periodontopatógenos (Genco, Van Dyke et al., 1998). Modelos utilizando camundongos apresentam vantagens como a ocorrência natural da doença em determinadas espécies, com prevalência e características comparáveis à doença humana (Wiebe, Adkins et al., 2001), além da suscetibilidade à indução experimental de DP (Baker, Evans et al., 1994; Iwasaki, Hara et al., 1998). 
Além disso, camundongos apresentam custo relativamente baixo, são de fácil manejo e os processos inflamatórios e imunológicos são extensamente estudados e bem conhecidos. Seu background genético é conhecido e manipulável, permitindo que aspectos muito bem definidos possam ser avaliados de maneira precisa, através da geração de animais geneticamente modificados, ou da utilização de substâncias bloqueadoras ou antagonistas, que em sua grande maioria são desenvolvidas experimentalmente em camundongos (Genco, Van Dyke et al., 1998). O modelo experimental que temos empregado em nossos estudos foi baseado no originalmente desenvolvido por Baker e colaboradores (Baker, Evans et al., 1994), diferindo basicamente na utilização do Aggregatibacter actinomycetemcomitans, e reproduzido em alguns trabalhos do nosso grupo de pesquisa (Garlet, Avila-Campos et al., 2005; Garlet, Cardoso et al., 2006; Garlet, Cardoso et al., 2007; Garlet, Cardoso et al., 2008).

O A. actinomycetemcomitans é considerado um dos principais periodontopatógenos, sendo relacionado como fator etiológico de determinados casos de periodontite agressiva, e presente em um significativo número dos casos de periodontite crônica. A virulência de tal microrganismo é relacionada à sua marcante capacidade de invasão tecidual, produção de diversas proteases e de uma potente leucotoxina, especialmente por determinados clones extremamente virulentos, como o JP2 (Spitznagel, Kraig et al., 1991; Haubek, Ennibi et al., 2004). Acredita-se que tais fatores de virulência interfiram na resposta imune contra tal patógeno, resultando em maior dificuldade na obtenção de sucesso no tratamento de pacientes infectados com A. actinomycetemcomitans, assim como provavelmente potencializem os efeitos sistêmicos da infecção periodontal (Saito, Hosaka et al., 1993; Fives-Taylor, Meyer et al., 1995; Wilson, Rowan et al., 1995; Fives-Taylor, Meyer et al., 1999). Realmente, a infecção oral por A. actinomycetemcomitans em camundongos C57BL/6 desencadeiam uma reação imune/inflamatória local exacerbada, com um aumento na migração de leucócitos, reabsorção óssea alveolar e presença aumentada da expressão de diversas quimiocinas, com destaque para MIP-1 $\alpha$ (Garlet, Avila-Campos et al., 2005). Entretanto, o papel individual da quimiocina MIP-1 $\alpha$ nos mecanismos imunológicos envolvidos para o controle de periodontopatógenos, como o A. actinomycetemcomitans, é desconhecido.

Porém, sabe-se que o conhecimento do papel da quimiocina MIP-1 $\alpha$ e seus receptores, nos mecanismos em que estão envolvidos na imunopatogênese das doenças periodontais, certamente será útil, não apenas para o entendimento dos mecanismos que levam a resistência à doença ou ao dano tecidual decorrente da resposta, mas também poderá contribuir para o desenvolvimento de metodologias de diagnóstico mais precisas e de estratégias terapêuticas para tais patologias. 


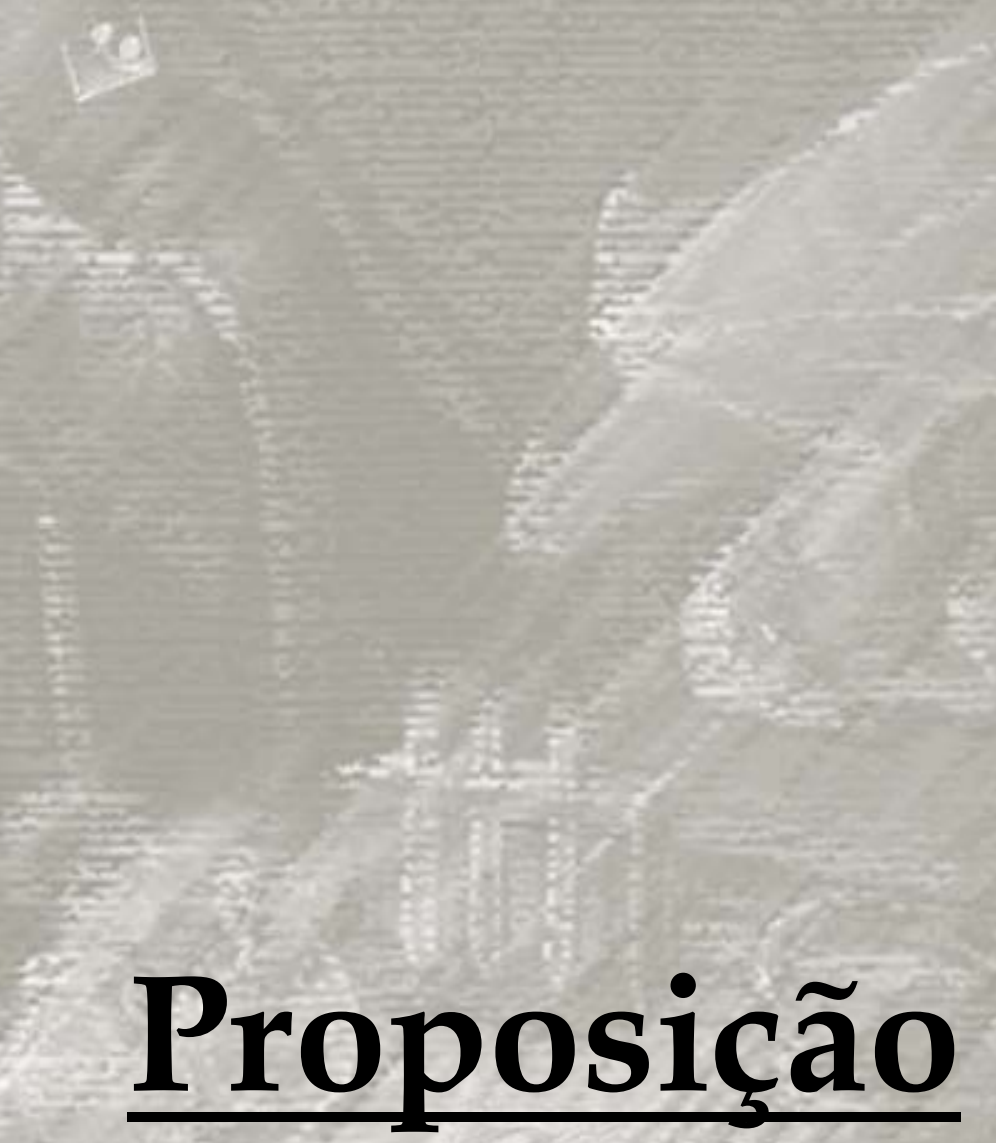





\section{Proposição}

O objetivo deste estudo foi avaliar o papel da quimiocina MIP-1 $\alpha$ na imunopatogênese da doença periodontal experimental em camundongos induzida por Aggregatibacter actinomycetemcomitans.

Mais especificamente, os objetivos deste estudo foram:

1- Analisar o papel da MIP-1 $\alpha$ na modulação da severidade da doença periodontal experimental, e os mecanismos envolvidos nesse processo.

2- Analisar o papel da quimiocina MIP-1 $\alpha$ na modulação do controle da infecção bacteriana na doença periodontal experimental. 


\section{Material e Métodos}





\section{Material e métodos}

3.1. Animais de experimentação - Foram utilizados camundongos C57B1/6 (WT) e MIP- $1 \alpha \mathrm{KO}$, machos, com idade aproximada de 8 semanas, os quais foram obtidos junto ao biotério da Área de Pós-Graduação em Imunologia Básica e Aplicada da Faculdade de Medicina de Ribeirão Preto-USP; e posteriormente mantidos no biotério da Faculdade de Odontologia de Bauru - FOB/USP. No decorrer do protocolo experimental os animais foram alimentados normalmente com ração, sendo que apenas nos dias das inoculações dos microrganismos a alimentação foi suprimida. Os grupos experimentais foram compostos de 21 a 30 animais, nos quais 3 camundongos foram utilizados em cada tempo para as diferentes análises. O presente projeto aprovado pela da Comissão de Ética em Pesquisa Animal da FOB/USP, processo/protocolo $\mathrm{n}^{\mathrm{o}} 15 / 2007$.

3.2. Protocolo de indução de doença periodontal - O protocolo de indução da doença periodontal foi realizado como previamente descrito (Garlet, Martins et al., 2004; Garlet, Cardoso et al., 2006; Garlet, Cardoso et al., 2007; Garlet, Cardoso et al., 2008). Resumidamente, A. actinomycetemcomitans JP2 foi utilizado nesse estudo, sendo cultivado em jarro de anaerobiose em meio agar suplementado (TSBV). Uma vez colhidos da placa, os microrganismos foram transferidos para um tubo eppendorf com $100 \mu \mathrm{l}$ de PBS, e comparando-se com uma escala padrão de densidade bacteriana em meio líquido, é determinada então a concentração, em CFU da solução. A solução foi diluída de modo a atingir a concentração de $10^{9} \mathrm{CFU}$ em $100 \mu \mathrm{l}$ de PBS. Os grupos de animais infectados foram submetidos ao protocolo que consiste da inoculação oral de $10^{9} \mathrm{CFU}$ em $100 \mu 1$ de PBS, acrescida de $2 \%$ de carboximetilcelulose, sendo esta solução aplicada diretamente na cavidade oral dos animais com o auxílio de um micropipetador automático. Após 48 horas e 96 horas, o procedimento de inoculação oral é repetido. Grupos controle (animais sham-infectados) foram criados a partir da inoculação oral de $100 \mu 1$ de uma solução de PBS a $2 \%$ de carboximetilcelulose, com metodologia semelhante a descrita para o grupo anterior. Animais não infectados, com a mesma idade dos demais grupos, foram utilizados como controles negativos.

3.3. Coleta de amostras - As amostras de tecido mole analisadas consistem do tecido gengival palatino. Para sua remoção, foi realizada uma incisão no palato, distal aos molares, perpendicular a linha media. A partir da incisão o tecido palatino foi descolado em toda a sua 
extensão com um descolador de Molt, até a mesial dos molares, sendo então realizada uma nova incisão de modo a remover o tecido. Em cada tempo, biopsias de cada grupo foram colocadas em Trizol (para as análises de expressão gênica) e congeladas em nitrogênio líquido e conservadas a temperatura de $-70^{\circ} \mathrm{C}$ (para possíveis análises posteriores). Conforme estudos prévios (Garlet, Martins et al., 2004; Garlet, Cardoso et al., 2007), as datas para sacrifício dos animais e coleta de amostras foram $0 \mathrm{~h}, 7,15,30$ e 60 dias após a inoculação inicial de A. actinomycetemcomitans.

3.4. Avaliação da reabsorção óssea alveolar - A análise da reabsorção óssea alveolar foi realizada como previamente descrito (Garlet, Cardoso et al., 2008). Para a avaliação do nível ósseo periodontal, o protocolo compreende: a peça cirúrgica, contendo os processos alveolares, dentes e palato ósseo, foi separada em duas hemi-arcadas pela ruptura da sutura palatina. As peças cirúrgicas foram então tratadas com solução de peróxido de hidrogênio 30 volumes a $50 \%$ por 24 horas para a remoção dos tecidos moles. O material foi então fotografado em lupa de dissecção, com aumento de 20 vezes (Zeiss), com a face oclusal dos molares posicionada perpendicularmente a base da lupa, e de modo a ser fotografada a face palatina. As imagens foram codificadas, de modo a que quando realizada a medição o examinador não saiba a que grupo ou tempo a amostra fazia parte. Com o auxílio do programa de análise de imagens ImageToll 2.0 (The University of Texas Health Science Center, San Antonio, USA), foi realizada então a medição da área compreendida entre a junção amelocementária e a crista óssea alveolar, em unidades arbitrárias de área (UAA), correspondentes aos pixels contidos na área selecionada. Para cada animal, a perda óssea alveolar foi definida como a média da área total entre a junção amelocementária e a crista óssea alveolar, avaliada na face palatina dos 6 dentes posteriores. Para as análises da reabsorção óssea alveolar, foram analisadas maxilas proveniente de 3 camundongos de cada grupo experimental, coletadas nos tempos de $0 \mathrm{~h}, 7$, 15,30 e 60 dias após a infecção, de três experimentos independentes.

3.5. Análise quantitativa do infiltrado inflamatório. A análise quantitativa e fenotípica de células extraídas dos tecidos periodontais foi realizada por citometria de fluxo, como previamente descrito (Garlet, Martins et al., 2003; Garlet, Cardoso et al., 2007). As amostras de tecido foram separadas e depositados em placas de 12 poços (Corning) contendo $1 \mathrm{ml}$ de meio incompleto (RPMI) e liberase (1:100) e então incubadas a $37^{\circ} \mathrm{C}$ durante 1 hora. 
Após a incubação, foram colocados em trituradores (medcons) juntamente com meio completo a $10 \%$ e DNAse $0,05 \%$ (Sigma DN-25) e triturados no Medmachine (BD bioscience PharMingen, San Diego, CA, USA) por 4 min. O líquido foi aspirado com uma seringa de $10 \mathrm{ml}$, filtrado (Filcons) em tubo Falcon de $15 \mathrm{ml}$ e adicionados aproximadamente $10 \mathrm{ml}$ de meio completo e DNAse. A suspensão celular foi centrifugada 12000 x g por 4 minutos. O pellet foi ressuspenso em $1 \mathrm{ml}$ de meio completo a $10 \%$ e células foram contadas em câmara de Newbauer, sendo que o número absoluto de leucócitos utilizado para a análise quantitativa das células inflamatórias. Para as análises quantitativa das células inflamatórias nos tecidos peridontais foi utilizado um pool contendo o tecido gengival palatino de 3 animais de cada grupo experimental, coletados nos tempos de $0 \mathrm{~h}, 7,15,30$ e 60 dias após a infecção; foram considerados dados provenientes de três experimentos independentes.

3.6. Extração de RNA e Transcrição Reversa - A extração do RNA total foi realizada com o reagente Trizol, seguindo-se o protocolo recomendado pelo fabricante (Gibco BRL, USA) como previamente descrito (Garlet, Cardoso et al., 2006). Brevemente, para cada amostra, em um tubo tipo "eppendorf”, foi adicionado o reagente Trizol $(1 \mathrm{ml}$ para $1 \mathrm{mg}$ de tecido), sendo agitado por 30 segundos e deixadas à temperatura ambiente por 5 minutos. Para cada $1 \mathrm{ml}$ da suspensão foi adicionado $0,2 \mathrm{ml}$ de clorofórmio (Sigma) e centrifugadas a 13000 rpm por 15 minutos a $4^{\circ} \mathrm{C}$. A fase aquosa foi transferida para um tubo novo, ao qual foi adicionado o mesmo volume de isopropanol, sofrendo agitação em vortex e incubado por no 20 minutos a $-20^{\circ} \mathrm{C}$ para precipitar o RNA da fase aquosa. Novamente os tubos foram centrifugados a $13000 \mathrm{rpm}$ por 15 minutos a $4^{\circ} \mathrm{C}$. O precipitado foi lavado em etanol $100 \%$, sendo então seco a temperatura ambiente, com o tubo invertido sobre um papel de filtro. As amostras de RNA foram suspensas em $50 \mu 1$ de água deionizada e livre de RNAse, sendo então as amostras armazenadas a -70 C. Uma alíquota de $5 \mu 1$ foi utilizada para a obtenção concentração de RNA/ $\mu 1$ nas amostras, determinada usando o aparelho GeneQuant (Pharmacia, USA). O DNA complementar (cDNA) foi sintetizado através de uma reação de transcrição reversa, com a utilização de uma transcriptase reversa (Superscript II, Gibco Life Tech.) utilizando $5 \mu \mathrm{g}$ de RNA, de acordo com as especificações do fabricante.

Uma amostra negativa (água) foi submetida à reação com cada par das seqüências dos primers utilizados.

3.7. Reações de Real Time PCR - A expressão quantitativa de mRNA codificado de citocinas e quimiocinas, assim como a quantificação da carga bacteriana no tecido 
periodontal, foi analisada através de reações de RealTimePCR, utilizando-se o sistema SYBRGreen em um aparelho MiniOpticon (BioRad - USA)(Garlet, Cardoso et al., 2006). Primers adequados para tais reações foram criados a partir do programa Primer Express, e tais reações já estavam devidamente padronizadas e utilizadas na rotina do laboratório. Esse sistema realiza as reações de amplificação e detecção e quantifica as amostras através de nucleases fluorogênicas utilizadas na reação, sendo tal expressão normalizada com base em controles endógenos. O DNA complementar sintetizado a partir do RNA mensageiro foi utilizado juntamente com reagentes SYBR Green, como determinado pelo fabricante. A reação compreende 2 minutos a $50^{\circ} \mathrm{C}, 10$ minutos a $95^{\circ} \mathrm{C}$, e quarenta ciclos de 15 segundos a $95^{\circ} \mathrm{C}$ e 1 minuto a $60^{\circ} \mathrm{C}$, além de um ciclo final de vinte minutos, com temperatura crescente de 60 a $95^{\circ} \mathrm{C}$ foi empregada para a obtenção de uma curva de dissociação dos produtos da reação, utilizada para a análise da especificidade de amplificação. Os resultados foram analisados com base no valor de CT (cicle threshold - ou ciclo limiar), sendo este o ponto correspondente ao número de ciclos aonde a amplificação atinge um dado limiar, que permite a análise quantitativa da expressão do fator avaliado. Uma amostra negativa (água) foi submetida à reação com cada par das seqüências dos primers utilizados.

3.8. Detecção e quantificação de A. actinomycetemcomitans. Para a quantificação de A. actinomycetemcomitans, foram utilizadas reações de RealTimePCR. A extração de DNA bacteriano foi realizada conforme método previamente descrito (Garlet, Martins et al., 2003). Após a coleta em água mili-Q estéril, as amostras foram homogenizadas através da utilização de um triturador de tecidos (UltraTurrax 8.0; IKA, Staufen, Alemanha), centrifugadas a $13000 \mathrm{~g}$ por 10 minutos, sendo o sedimento resuspendido em $500 \mu \mathrm{l}$ de água mili-Q estéril, e novamente centrifugadas e resuspendido em $500 \mu \mathrm{l}$ de água mili-Q estéril. As amostras foram então fervidas por 10 minutos, e novamente centrifugadas. Após a centrifugação, as amostras foram ressuspendidas em $10 \mu 1$ de água mili-Q estéril. Para a quantificação de $A$. actinomycetemcomitans foram utilizados $12,5 \mu 1$ do reagente SYBRGreen Master Mix (Invitrogen), $5 \mu 1$ da solução de DNA bacteriano, $4 \mu 1$ de água MiliQ tratada com DEPC, e $1 \mu 1$ da solução contendo cada primer. A reação compreende basicamente 2 minutos a $50^{\circ} \mathrm{C}, 10$ minutos a $95^{\circ} \mathrm{C}$, e quarenta ciclos de 15 segundos a $95^{\circ} \mathrm{C}$ e 1 minuto a $60^{\circ} \mathrm{C}$, além de um ciclo final de vinte minutos, com temperatura crescente de 60 a $95^{\circ} \mathrm{C}$, empregada para a obtenção de uma curva de dissociação dos produtos da reação, utilizada para a análise da especificidade de amplificação. Os resultados serão analisados com base no valor de Ct (cicle threshold - ou 
ciclo limiar), como previamente descrito. Para a normalização dos valores de expressão de DNA de A. actinomycetemcomitans, serão utilizados os valores do peso do fragmento de tecido periodontal utilizado para a extração. Nas reações de detecção e quantificação de $A$. actinomycetemcomitans, foram utilizadas independentemente amostras de DNA proveniente do tecido gengival palatino de 2 animais de cada grupo experimental, coletados nos tempos de 0 h, 7, 15, 30 e 60 dias após a infecção.

3.9. ELISA. A produção de citocinas nos tecidos periodontais também foi analisada por ELISA, como previamente descrito (Talvani, Santana et al., 2003). Para tanto, o tecido gengival palatino foi coletado (conforme previamente descrito), pesado, e homogenizado com o homogenizador de tecidos (Ultra Turrax - IKA, Alemanha) em solução de PBS 1X contendo inibidor enzimático (Protease Inhibitor - Boehringer Mannhein, Alemanha). O homogenizado foi centrifugado a $2500 \mathrm{~g}$ por 10 minutos a $4^{\circ} \mathrm{C}$, sendo então o sobrenadante coletado e armazenado a $-70^{\circ} \mathrm{C}$ até a realização dos ensaios de ELISA. Os fatores osteoclastogênicos RANKL e OPG, foram quantificadas utilizando kits Quantikine (R\&D Systems, EUA), de acordo com o protocolo recomendado pelo fabricante. A concentração das diferentes citocinas e quimiocinas nos sobrenadantes de tecido periodontal foi determinada a partir dos valores obtidos com as respectivas curvas-padrão. Para os ensaios de ELISA foi utilizado um pool de tecido gengival palatino, proveniente de 5 camundongos por grupo, sacrificados nos tempos de 30 dias após a infecção. Os resultados apresentados são expressos como valores da média \pm SD de picogramas de citocina por miligrama de tecido, e representam os valores de duplicatas de cada amostra, obtidos em dois experimentos independentes.

3.10. Dosagem de mieloperoxidase (MPO). A análise da atividade de MPO nos tecidos periodontais foi realizada como previamente descrito (Souza, Lemos et al., 2004). Para tanto, o tecido periodontal palatino foi homogeneizado em tampão contendo $\mathrm{NaCl}$ (1,0M), NaPO4 (0,02M), NaEDTA $(0,015 \mathrm{M})$, gelado e em $\mathrm{pH} 4.7$. O homogenato foi centrifugado a $3000 \mathrm{~g}$ por 15 minutos, sendo então submetido a choque hipotônico com $900 \mu \mathrm{l}$ de $\mathrm{NaCl} 0,2 \%$, seguido por 900 ul de $\mathrm{NaCl} 1,6 \%$ e glicose 5\%. Depois de novamente centrifugado, o pellet foi ressuspenso em tampão NaPO4 (pH 5,4) contendo 0,5\% de brometo de tetrametilbenzidine $(1, \mathrm{mM})$ e $\mathrm{H} 2 \mathrm{O} 2(0,5 \mathrm{mM})$. Em seguida, o homogenato foi submetido a congelamento e descongelamento por 3 vezes, e centrifugado por $10000 \mathrm{~g}$ por 15 minutos a 
$4^{\circ} \mathrm{C}$. A determinação da atividade de MPO foi realizada por meio da análise da densidade óptica (DO) a 450nm, utilizando-se tetrametilbenzidine $(1,6 \mathrm{mM})$ e $\mathrm{H} 2 \mathrm{O} 2(0,5 \mathrm{mM})$. Para a dosagem de MPO, foi utilizado um pool de tecido gengival palatino, proveniente de 5 camundongos por grupo, sacrificados nos tempos de 30 dias após a infecção. Os resultados representam os valores de duplicatas de cada amostra, obtidos em dois experimentos independentes.

3.11. Tratamento dos animais com MetRANTES. O tratamento com MetRANTES (gentilmente cedido pela $\operatorname{Dr}^{\mathrm{a}}$ Amanda Proudfoot, do Serono Pharmaceutical Research Institute, Suíça) foi realizado conforme protocolos previamente descritos (Matsui, Weaver et al., 2002), consistindo na injeção intraperitoneal de $0,5 \mu \mathrm{g} / \mathrm{kg} /$ dia de Met-RANTES, diluído em PBS, em dias alternados. Em um grupo de camundongos C57BL/6 o tratamento com MetRANTES foi realizado a partir de 8 semanas de idade, iniciado simultaneamente ao protocolo de indução da DP. Como controles, foram analisados animais não infectados, tratados ou não com MetRANTES; e animais infectados, tratados ou não com veículo (PBS). Nestes experimentos, foram utilizadas independentemente amostras provenientes 3 animais de cada grupo experimental, coletadas nos tempos de 0h, 15, 30 e 60 dias após a infecção; serão analisados os dados de 3 experimentos independentes.

3.12. Análise estatística - Análises entre três ou mais grupos experimentais, como os dados relativos ao número de células inflamatórias, níveis de reabsorção óssea, níveis de expressão de mRNA, dos grupos de animais C57Bl/6(WT) e MIP-1 $\alpha \mathrm{KO}$, infectados, animais sham infectados ou não infectados, foram submetidos ao teste estatístico one-way ANOVA, seguido pelo teste de Bonferroni. Nas análises entre apenas dois grupos ou amostras foi utilizado o teste " $\mathrm{t}$ ". Correlações foram analisadas através de regressão linear. Para todas as análises, valores de $\mathrm{P}<0.05$ foram considerados estatisticamente significantes. Todos os testes estatísticos foram aplicados através dos programas GraphPad InStat e Prism5 (GraphPad, San Diego, CA). 
$\underline{\text { Resultados }}$ 



\section{Resultados}

\subsection{Cinética de expressão da quimiocina MIP-1a nos tecidos periodontais de camundongos infectados com $A$. actinomycetemcomitans}

Conhecendo as características e a função de MIP-1 $\alpha$ em doenças inflamatórias, nosso primeiro passo foi caracterizar a cinética de expressão d MIP-1 $\alpha$ durante o curso da doença periodontal. Amostras de tecidos periodontais de camundongos C57BL/6 (WT) submetidos ao protocolo de indução de DP com A. actinomycetemcomitans foram analisados com relação à expressão de mRNA para tal quimiocina (Fig. 1).

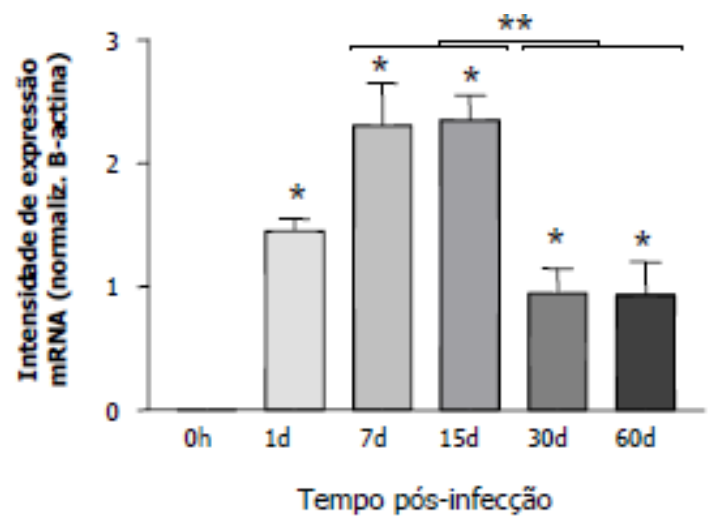

Figura 1 - Cinética de expressão da quimiocina MIP-1a nos tecidos periodontais de camundongos infectados com A. actinomycetemcomitans. Amostras de tecido periodontal de camundongos C57BL/6 submetidos ao protocolo de indução de doença periodontal com A. actinomycetemcomitans (AA), foram coletadas, o RNA total extraído e o nível de expressão de MIP-1 $\alpha$ (CCL3) foi analisados por RealTimePCR. O resultado apresentado representa o valor da média $\pm \mathrm{SD}$, da intensidade de expressão de mRNA para o gene alvo, normalizado pela expressão da beta-actina. ${ }^{*} \mathrm{p}<0.05$ vs $0 \mathrm{~h},{ }^{*} \mathrm{p} p<0.05$ vs tempo indicado.

A expressão de MIP-1 $\alpha$ apresentou um aumento significativo no primeiro dia após a infecção ( $p<0.05$ vs 0h) e um intenso aumento nos dias $7(p<0.05)$ e $15(p<0.05)$. Logo após, a expressão de MIP-1 $\alpha$ sofreu uma redução significativa nos dias 30 ( $<<0.05$ vs $7 \mathrm{~d}$ e $15 \mathrm{~d})$ e $60(\mathrm{p}<0.05$ vs $7 \mathrm{~d}$ e $15 \mathrm{~d})$, porém continuando aumentadas se comparadas ao tempo de 0 hora $(\mathrm{p}<0.05 \mathrm{vs} 0 \mathrm{~h})$.

4.2 Cinética de migração de células CCR5+ e CCR1+ para os tecidos periodontais de camundongos infectados com $A$. actinomycetemcomitans 
Após demonstrar a cinética expressão de MIP-1 $\alpha$ nos tecidos periodontais dos camundongos WT infectados e devido ao fato da quimiocina MIP-1 $\alpha$ exercer quimioatração sobre células que possuam os receptores CCR5 e CCR1, analisamos a migração de células CCR5+ e CCR1+ para os tecidos periodontais de camundongos C57BL/6 (WT) infectados com A. actinomycetemcomitans.
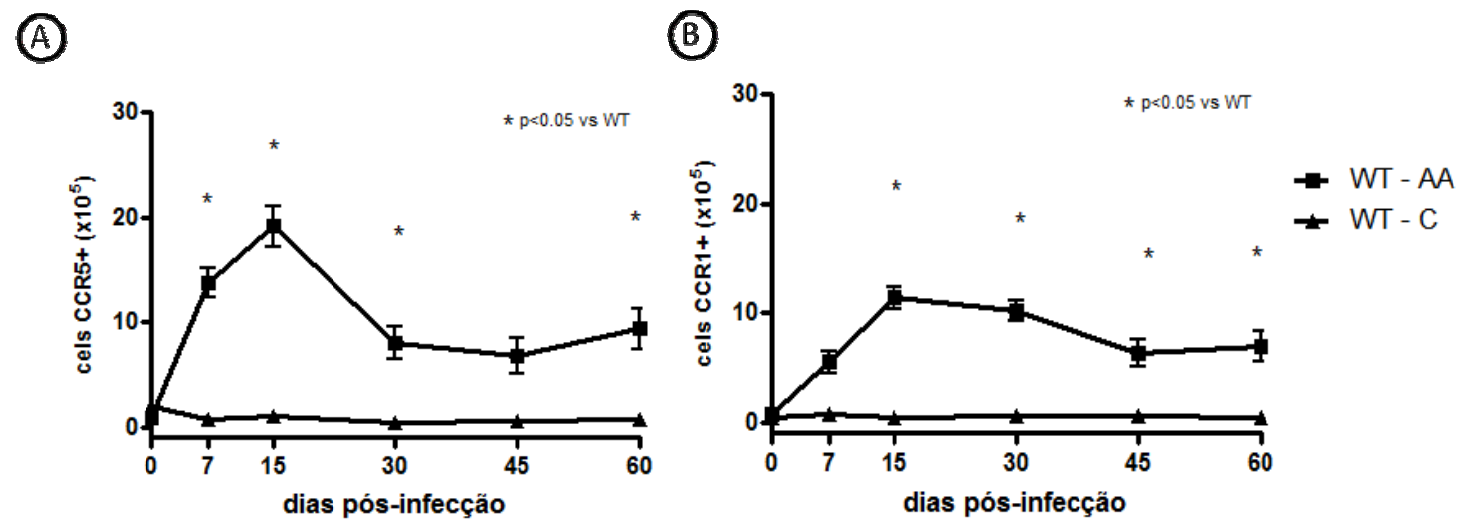

Figura 2 - Cinética de migração de células CCR5+ e CCR1+ para os tecidos periodontais de camundongos infectados com A. actinomycetemcomitans. Camundongos C57BL/6 (WT) submetidos ao protocolo de indução de doença periodontal com A. actinomycetemcomitans (AA) e grupos de animais não infectados foram analisados quanto à cinética de migração de células CCR5+ e CCR1+ para os tecidos periodontais através de citometria de fluxo. ${ }^{*} \mathrm{p}<0.05$ vs $\mathrm{C}$.

Observamos uma intensa migração de células CCR5+, nos camundongos WT infectados, a partir do tempo 7 dias pós infecção ( $<<0.001$ vs $0 \mathrm{~h}$ ), mantendo-se significativo nos demais tempos, 15 ( $\mathrm{p}<0.001$ vs $0 \mathrm{~h}$ ), 30 ( $\mathrm{p}<0.05$ vs $0 \mathrm{~h})$ e 60 ( $\mathrm{p}<0.05$ vs $0 \mathrm{~h}$ ) dias, com exceção do tempo de 45 ( $>0.05$ vs 0 h) dias pós infecção (Fig 2a). Já dentre as células CCR1+, houve um aumento significativo a partir do tempo de 15 dias ( $p<0.001$ vs 0h), continuando significativos nos tempo de 30 ( $\mathrm{p}<0.001$ vs $0 \mathrm{~h}$ ), 45 ( $<<0.05$ vs $0 \mathrm{~h}$ ) e 60 ( $<<0.01$ vs $0 \mathrm{~h}$ ), só não obtendo significância no primeiro tempo analisado, 7 dias ( $>0.05$ vs $0 \mathrm{~h}$ ) apesar da tendência ao aumento (Fig. 2b).

\subsection{Análise fenotípica das células CCR5+ e CCR1+ extraídas dos tecidos periodontais de camundongos infectados com A. actinomycetemcomitans}

Visto a cinética de migração de células CCR5+ e CCR1+ para os tecidos periodontais dos camundongos WT infectados com A. actinomycetemcomitans, nosso próximo objetivo foi analisar o fenótipo destas células. Para tal, os animais submetidos ao protocolo de indução de DP foram sacrificados ao tempo de 30 dias e foram coletadas amostras de tecidos periodontal 
palatino. Estas amostras foram submetidas à digestão enzimáticas e as células CCR5+ (Fig. 3a) e CCR1+ (Fig. 3b) foram analisadas quanto ao seu fenótipo por citometria de fluxo.

(A)

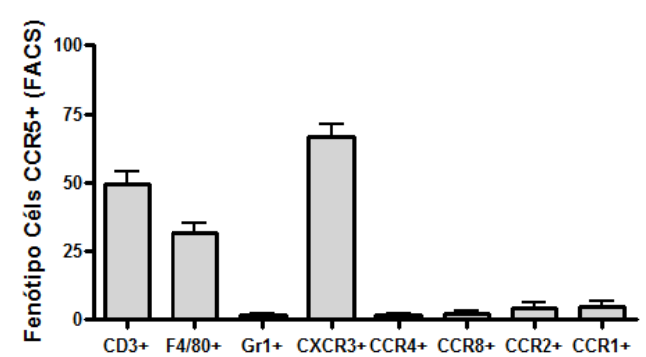

(B)

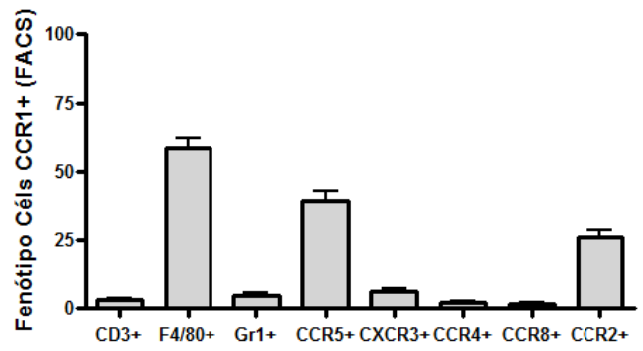

Figura 3 - Análise fenotípica dos leucócitos extraídos dos tecidos periodontais de camundongos infectados com A. actinomycetemcomitans. Amostras de tecido periodontal palatino de camundongos C57BL/6 (WT) submetidos ao protocolo de indução de doença periodontal com A. actinomycetemcomitans (AA) foram coletadas, ao tempo de 30 dias, submetidas à digestão enzimática, e a contagem de células realizada em câmara de Neubauer. Para as análises de citometria de fluxo, $1 \times 10^{6} \mathrm{cel} / \mathrm{ml}$ células foram incubadas com anticorpos conjugados a fluorocromos específicos para os seguintes marcadores: CD3, F4/80, Gr1, CXCR3, CCR4, CCR8, CCR2, CCR1 e CCR5, e a análise realizada em FACScan utilizando-se parâmetros de tamanho (FSC), granularidade (SSC), e fluorescência (FL1 e FL2). A porcentagem de células CCR5+ e CCR1+ que coexpressavam os marcardores $\mathrm{CD} 3+, \mathrm{F} 4 / 80+, \mathrm{Gr} 1+, \mathrm{CXC} 3+, \mathrm{CCR} 4+$, CCR8+, CCR2+, CCR1+/CCR5+, foram calculados proporcionalmente em relação ao número de células CCR5+ ou CCR1+ totais. Os resultados representam os valores da média $\pm \mathrm{SD}$ da porcentagem de células, provenientes de dois experimentos independentes.

Observamos dentre as células CCR5+ uma maior quantidade de células positivas para o receptor de quimiocina $\mathrm{CXCR} 3$, assim como um grande número de células $\mathrm{CD} 3+$, o que nos sugere uma maior população de células Th1. Outro marcador frequentemente expresso pelas células CCR5+ é F4/80, sugerindo que uma importante parcela das células CCR5+ provavelmente corresponde a macrófagos. Ao contrário, a expressão dos marcadores Gr1 (marcador fenotípico de neutrófilos), CCR4 e CCR8 (caracteristicamente expressos por células Th2), e CCR1 (expresso em eosinófilos, monócitos e células dendríticas) e CCR2 (caracteristicamente expresso em monócitos, células dendríticas, células natural killer (NK) e células T) se mostrou não significante entre as células CCR5+. Já dentre as células CCR1+, os resultados mostram maior quantidade de macrófagos (células $\mathrm{F} 4 / 80+$ ), seguidas por células CCR5+ e CCR2+. Dentre os demais marcadores analisados, CD3+, Gr1+, CXCR3+, CCR4+ e CCR8+ se mostraram pouco expressos na subpopulação de células CCR1+.

\subsection{Papel de MIP-1a na modulação da reação inflamatória e perda óssea alveolar induzida por A. actinomycetemcomitans}

Buscando investigar o papel de MIP-1 $\alpha$ (CCL3) na determinação da severidade da doença periodontal, nosso primeiro passo foi à análise da cinética de desenvolvimento da 
resposta inflamatória e a reabsorção óssea alveolar em resposta a inoculação oral de $A$. actinomycetemcomitans em camundongos C57BL/6 (WT) e MIP-1 $\alpha$ KO. Para tanto, os animais submetidos à inoculação das bactérias foram analisados quanto ao desenvolvimento de reação inflamatória nos tecidos periodontais e perda óssea alveolar em diferentes tempos de pós infecção (Fig. 4).

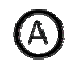

(B)
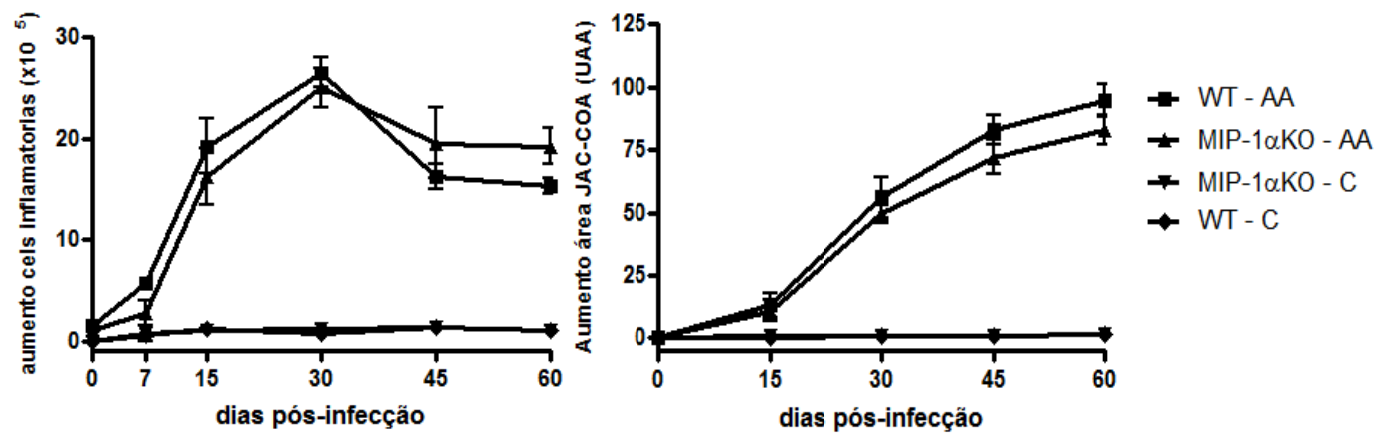

Figura 4 - Reação inflamatória e perda óssea alveolar induzida por A. actinomycetemcomitans em

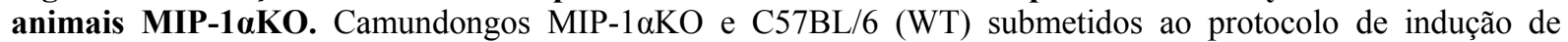
doença periodontal com A. actinomycetemcomitans (AA), os grupos de animais foram analisados quanto à cinética de desenvolvimento de reação inflamatória nos tecidos periodontais e perda óssea alveolar. A) Número de leucócitos extraídos através de digestão enzimática do tecido periodontal, corados com azul de tripam e contados em câmara de Neubauer. B) Aumento da área JAC-COA na face palatina dos molares, em relação aos animais controle, medida em unidades arbitrárias de área (UAA) com o programa ImageToll 2.0. Os resultados representam os valores da média $\pm \mathrm{SD}$, da área JAC-COA ou número de células por animal.

Nossos resultados demonstram que os animais infectados (WT-AA e MIP-1 $\alpha$ KO-AA) apresentaram uma tendência ao aumento do número de células inflamatórias extraídas do tecido periodontal no tempo de 7 dias $(p>0.05)$ e um aumento significativo aos 15 ( $<<0.001$ vs 0 h), 30 ( $\mathrm{p}<0.001$ vs $0 \mathrm{~h}$ ), 45 ( $\mathrm{p}<0.001$ vs $0 \mathrm{~h}$ ) e 60 ( $\mathrm{p}<0.001$ vs $0 \mathrm{~h})$ dias após a inoculação inicial dos microrganismos (Fig. 4a). Também constatamos, um aumento gradual da reabsorção óssea alveolar, determinada pelo crescente aumento na área compreendida entre a junção amelo-cementária (JAC) e a crista óssea alveolar (COA) nos camundongos submetidos

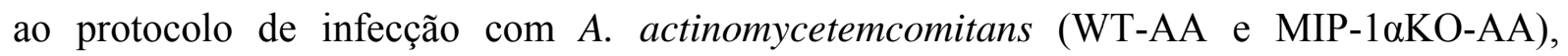
apresentando uma tendência ao aumento no tempo de 15 dias ( $>0.05$ vs 0 h) e um aumento significativo nos tempos de 30 ( $\mathrm{p}<0.001$ vs $0 \mathrm{~h}$ ), 45 ( $\mathrm{p}<0.001$ vs $0 \mathrm{~h})$ e 60 ( $<<0.001$ vs $0 \mathrm{~h}$ ) dias pós infecção, quando comparados aos grupos controle (WT-C e MIP-1 $\alpha$ KO-C) (Fig. 4b).

Quando comparados os animais infectados (WT-AA e MIP-1 $\alpha \mathrm{KO}-\mathrm{AA}$ ), não encontramos nenhuma diferença significativa em nenhum dos diferentes tempos analisados ( $>0.05)$, tanto na análise de células inflamatórias quanto no tamanho da área JAC-COA. Os 
animais controle, não infectados (MIP-1 $1 \alpha \mathrm{KO}-\mathrm{C}$ e WT-C) também não obtiveram diferenças significativas em ambos os experimentos $(p>0.05)$

\subsection{Papel de MIP-1a na migração de células CCR5+ e CCR1+ extraídas dos tecidos periodontais de camundongos infectados $\operatorname{com}$ A. actinomycetemcomitans}

Sabe-se que a quimiocina MIP-1 $\alpha$ é um ligante dos receptores de quimiocina CCR5 e CCR1, sendo desta forma responsável pela quimiotaxia de células CCR5+ e CCR1+. Sendo assim, examinamos a quantidade de células que apresentavam os receptores de quimiocinas CCR5 e CCR1 presentes nos tecidos periodontais dos camundongos C57BL/6 (WT) e MIP$1 \alpha \mathrm{KO}$ (Fig. 5).

(A)

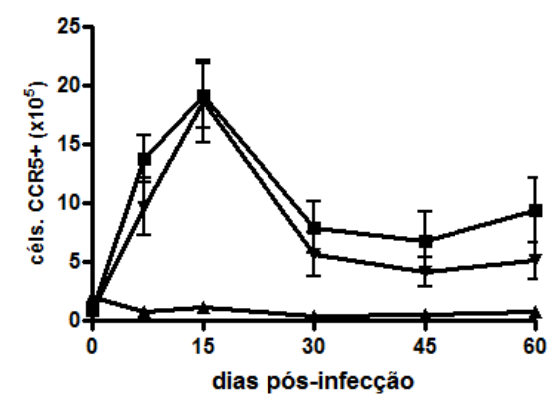

(B)

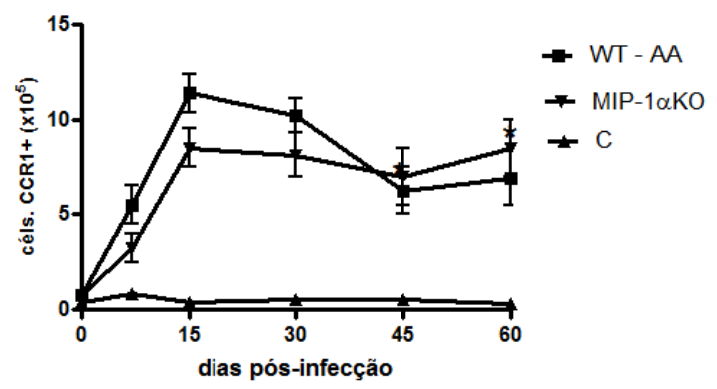

Figura 5 - Papel de MIP-1 $\alpha$ na modulação da migração de células CCR5+ e CCR1+ para os tecidos periodontais de camundongos infectados com A. actinomycetemcomitans. Camundongos MIP- $1 \alpha \mathrm{KO}$ e C57BL/6 (WT) submetidos ao protocolo de indução de doença periodontal com A. actinomycetemcomitans (AA), grupos de animais não infectados foram analisados quanto a cinética de migração de células CCR5+e CCR1+ para os tecidos periodontais através de citometria de fluxo.

Nossos resultados demonstram que nos animais infectados, WT-AA e MIP-1 $\alpha$ KO-AA, houve uma intensa quantidade de células CCR5+ presente nos tecidos periodontais, nos dias 7 ( $<<0.01$ vs 0 h) e 15 ( $<<0.001$ vs $0 h$ ). Com o decorrer da infecção observamos um decréscimo na quantidade de células CCR5+, mesmo assim os animais WT-AA apresentaram uma diferença significativa na quantidade destas células aos 30 ( $\mathrm{p}<0.05$ vs $0 \mathrm{~h}$ ) dias pós infecção, o que não foi observado aos 45 dias ( $>0.05$ vs 0 h). Por fim, aos 60 dias foi constatado um leve aumento na quantidade de células CCR5+, voltando a ter uma quantidade significativa $(\mathrm{p}<0.05)$. Já nos animais MIP-1 $\alpha \mathrm{KO}-\mathrm{AA}$, não foram observadas diferenças significativas na quantidade de células CCR5+ aos tempos de 30 (p>0.05 vs 0h), 45 (p>0.05 vs 0h) e 60 dias ( $\mathrm{p}>0.05$ vs $0 \mathrm{~h}$ ), quando comparados aos camundongos controle (Fig 5a).

Ao analisarmos a quantidade de células CCR1+ nos tecidos periodontais dos animais infectados (WT-AA e MIP-1 $\alpha$ KO-AA), observamos uma tendência ao aumento destas células 
ao tempo de 7 dias ( $p>0.05$ vs 0 h) e um aumento significativo ao tempo de 15 dias $(\mathrm{p}<0.001$ vs 0 h) e 30 dias ( $<<0.01$ vs 0 h), o que não foi observados nos demais tempos analisados, 45 dias ( $p>0.05$ vs 0 h) e 60 dias ( $p>0.05$ vs 0 ; Fig. $5 b$ ).

Quando comparamos os camundongos infectados WT-AA e MIP-1 $\alpha$ KO-AA, não obtivemos diferenças significativas na quantidade de células CCR5+ presentes no tecido periodontal ( $>0.05$; Fig. 5a). Semelhantemente, não foram encontradas diferenças significativas na quantidade de células CCR1+ quando comparamos os animais infectados WT-AA e MIP-1 $\alpha$ KO-AA. Apesar da ausência de significância, nos 30 primeiros dias pós infecção as células CCR1+ apresentaram uma quantidade maior nos animais WT-AA ( $>0.05$; Fig. 5b).

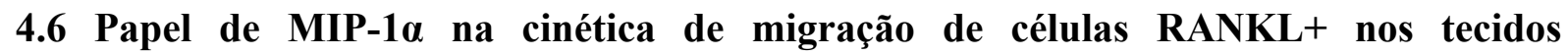 periodontais de camundongos infectados com $A$. actinomycetemcomitans}

Sabe-se que células RANKL+ são capazes de promover a osteoclastogênese e o aumento da produção de MIP-1 $\alpha$ em células tronco-hematopoiética, e que a quimiocina MIP$1 \alpha$ tem um potencial de quimiotaxia de células RANKL+ para o tecido infectado (TSUBAKI et al., 2007). Com base em tais informações, analisamos o papel desta quimiocina na cinética de células RANKL+ extraídas dos tecidos periodontais infectados com $A$. actinomycetemcomitans (Fig. 6).

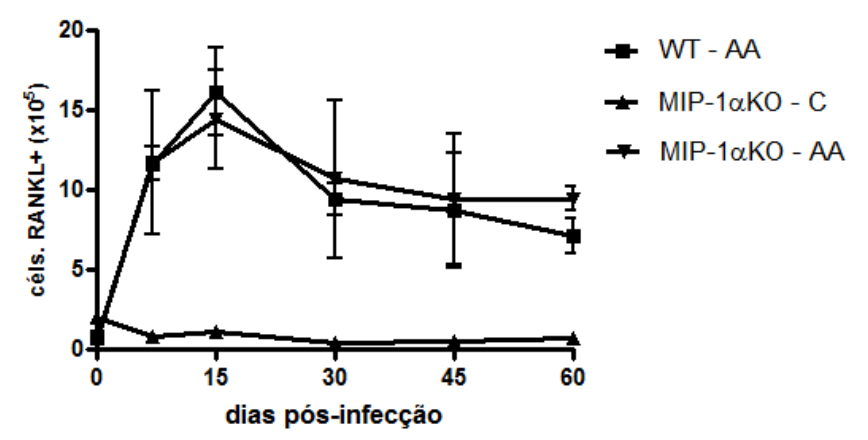

Figura 6 - Migração de células RANKL+ extraídas dos tecidos periodontais de camundongos infectados com A. actinomycetemcomitans. Camundongos MIP-1 $\alpha \mathrm{KO}$ e C57BL/6 (WT) submetidos ao protocolo de indução de doença periodontal com A. actinomycetemcomitans (AA), grupos de animais não infectados foram analisados quanto a cinética de migração de células RANKL+ para os tecidos periodontais através de citometria de fluxo

Os resultados encontrados demonstram um aumento significativo na presença de células RANKL+ aos tempos de 7 ( $<<0.05$ vs $0 \mathrm{~h})$ e 15 ( $\mathrm{p}<0.001$ vs $0 \mathrm{~h}$ ) dias pós a infecção 
dos microrganismos nos camundongos WT- AA; e nos tempos de 7 ( $p<0.05$ vs 0h), 15

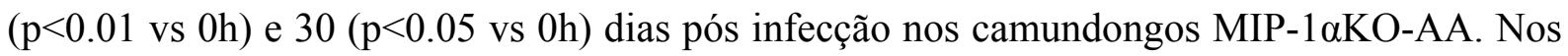
animais não infectados (MIP-1 $\alpha \mathrm{KO}-\mathrm{C})$ a cinética de expressão de células RANKL+ não apresentou diferenças significativas em nenhum dos tempos por nós analisados $(p<0.05$ vs $0 \mathrm{~h})$.

Ao compararmos os animais (WT-AA e MIP-1 $\alpha$ KO-AA) infectados, não observamos diferenças estatísticas significativas em nenhum dos tempos analisados $(\mathrm{p}>0.05)$.

\subsection{Papel de MIP-1a na modulação da expressão de RANKL e OPG nos tecidos periodontais de camundongos infectados com $A$. actinomycetemcomitans}

Uma vez que a reabsorção óssea alveolar é um dos eventos principais na patogênese das DPs, nosso próximo objetivo foi comparar o papel de MIP-1 $\alpha$ na modulação da cinética de expressão de fatores envolvidos na diferenciação e ativação de osteoclastos (fig. 7).
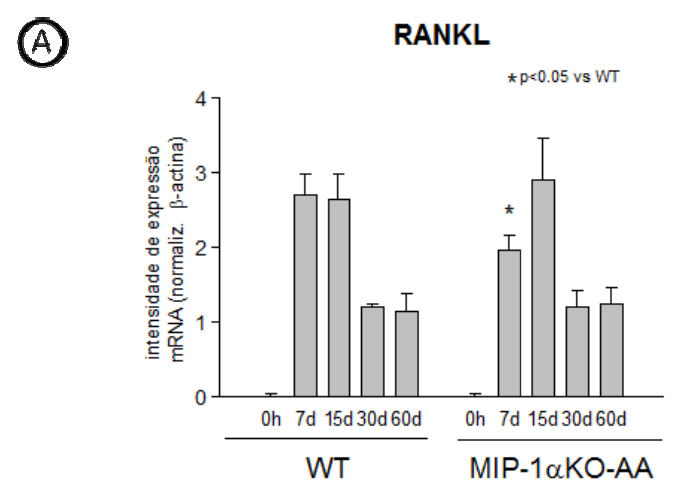

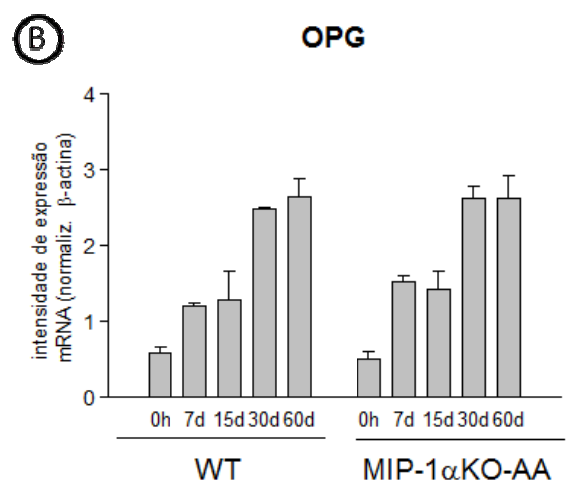

Figura 7 - Cinética de expressão de RANKL e OPG nos tecidos periodontais de camundongos MIP-1aKO infectados com A. actinomycetemcomitans. Amostras de tecido periodontal de camundongos MIP-1 $\alpha$ KO e C57BL/6 (WT) submetidos ao protocolo de indução de doença periodontal com A. actinomycetemcomitans (AA) foram coletadas, o RNA total extraído e os níveis de expressão de RANKL e OPG foram analisados por RealTimePCR. Os resultados apresentados representam os valores da média \pm SD da intensidade de expressão de mRNA para o gene alvo, normalizado pela expressão da beta-actina. Um experimento representativo de três experimentos independentes. ${ }^{*} \mathrm{p}<0.05$ vs WT.

Os resultados demonstram que a expressão de RANKL (Fig. 7a) nos camundongos WT infectados, tanto aos 7 dias quanto aos 15 dias após a infecção dos microrganismos, estão significativamente aumentadas quando comparadas aos 30 dias ( $<<0.05$ vs $7 d$ e 15d) e 60 dias $(\mathrm{p}<0.05$ vs $7 \mathrm{~d}$ e $15 \mathrm{~d})$, não sendo expressa no tempo de $0 \mathrm{~h}$. Resultados semelhantes foram encontrados nos camundongos MIP-1 $\alpha$ KO-AA infectados, onde nos tempos de 7 dias e 15 dias também verificamos uma maior expressão de RANKL, que apresentava um decréscimo 
parcial aos tempos de $30(p<0.05$ vs $7 d$ e $15 d)$ e 60 ( $p<0.05$ vs $7 d$ e $15 d)$ dias. Contudo, ao compararmos a cinética de expressão de RANKL dos camundongos WT-AA com as do MIP$1 \alpha \mathrm{KO}-\mathrm{AA}$ constatamos que a expressão de RANKL no $7^{\circ}$ dia dos camundongos WT-AA apresentava-se significativamente maior a expressão de RANKL do camundongos MIP$1 \alpha \mathrm{KO}-\mathrm{AA}(\mathrm{p}<0.05)$. Ao contrário, a expressão do OPG foi detectada em baixos níveis no tempo de 0h (Fig. 7b), tanto no camundongo WT-AA quanto no MIP-1 $\alpha \mathrm{KO}-\mathrm{AA}$, assim sendo constitutivamente expressa nos animais não infectados. Também constatamos, nos camundongos WT-AA e MIP-1 $\alpha$ KO-AA, um aumento significativo na expressão de OPG no período de 7 dias $(\mathrm{p}<0.001$ vs $0 \mathrm{~h})$ e entre 15 e 30 dias $(\mathrm{p}<0.05)$ onde obtivemos o maior valor da expressão de OPG. Ao compararmos as expressões de OPG dos camundongos MIP-1 $\alpha$-AA com a expressão do WT-AA não foram encontrados diferenças significativas ( $p>0.05)$.

\subsection{Papel de MIP-1a na modulação da produção de RANKL e OPG nos tecidos periodontais de camundongos infectados $\operatorname{com} A$. actinomycetemcomitans}

Para confirmar se as expressões dos fatores osteoclastogênicos (RANKL e OPG) estavam sendo produzidos, utilizamos o ensaio imunoenzimático (ELISA) ao tempo de 30 dias pós infecção (Fig. 8).

(A)

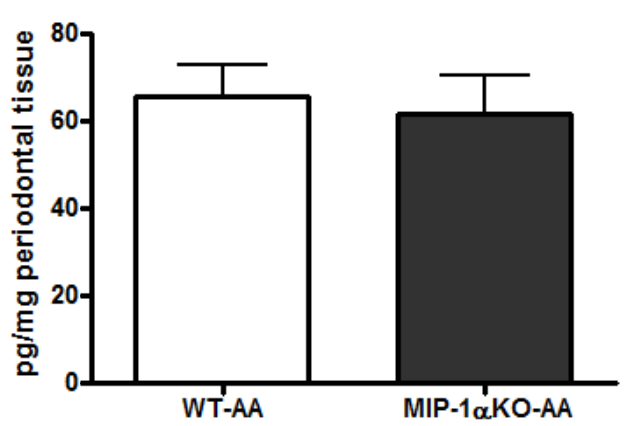

(B)

RANKL ELISA

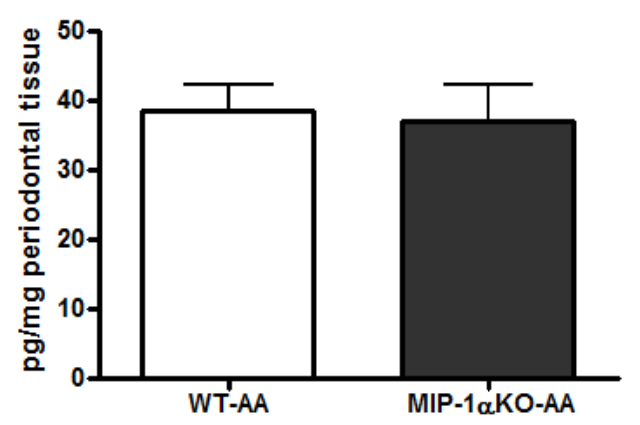

Figura 8 - Níveis de RANKL e OPG nos tecidos periodontais de camundongos MIP1 $\alpha$-KO infectados com A. actinomycetemcomitans. Amostras de tecido periodontal palatino de camundongos MIP1 $\alpha-\mathrm{KO}$ e C57BL/6 submetidos ao protocolo de indução de doença periodontal foram coletadas, pesadas e homogenizadas, ao tempo de 30 dias pós infecção, sendo o sobrenadante analisado quanto aos níveis de RANKL e OPG por ELISA. Os resultados são expressos com pg de RANKL e OPG por mg de tecido por animal, e representam os valores (média + desvio padrão), provenientes de 2 animais por grupo em cada tempo, representativos de 3 experimentos independentes.

Semelhantemente ao resultado encontrado na expressão dos fatores osteoclastogênicos analisados, não obtivemos nenhuma diferença significativa na produção de RANKL (Fig. 8a) 
e OPG (Fig. 8b) quando comparamos os camundongos WT-AA com os animais MIP-1 $\alpha \mathrm{KO}-$ AA, ambos infectados pelo A. actinomycetemcomitans.

\subsection{Papel de MIP-1a na modulação da expressão de citocinas nos tecidos periodontais de} camundongos infectados com $A$. actinomycetemcomitans

Uma vez que diversas citocinas têm sido implicadas na patogênese das DPs, nosso próximo passo foi caracterizar a cinética e o padrão de expressão de tais fatores durante o curso da doença experimental. Para tanto, camundongos WT e MIP- $1 \alpha \mathrm{KO}$ submetidos ao protocolo de indução de doença periodontal com A. actinomycetemcomitans foram sacrificados em diferentes tempos após a infecção, amostras de tecidos periodontais foram coletadas, o RNA total isolado e a expressão de citocinas analisadas por RealTimePCR (Fig. 9).

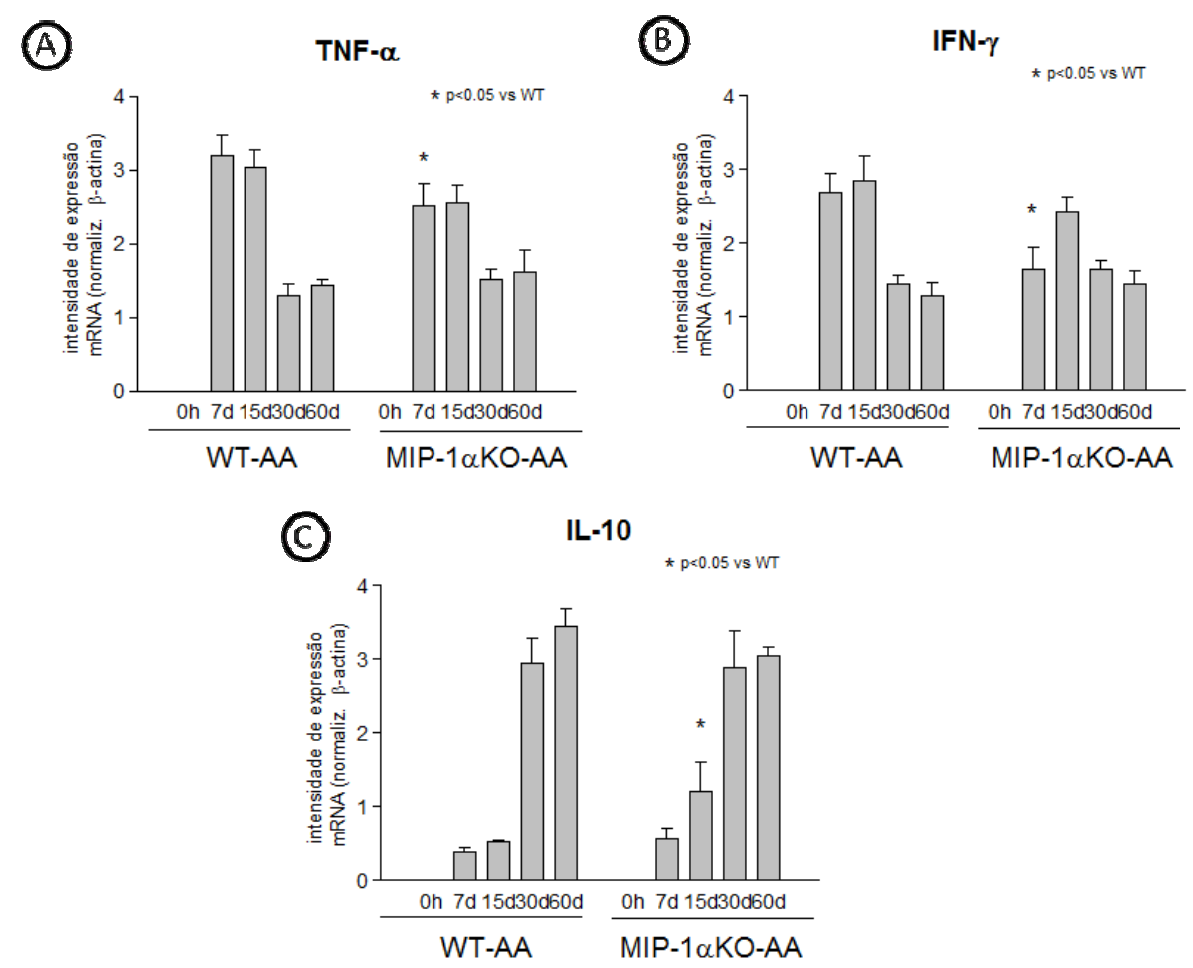

Figura 9 - Cinética de expressão de citocinas nos tecidos periodontais de camundongos MIP-1aKO infectados com A. actinomycetemcomitans. Amostras de tecido periodontal de camundongos MIP-1 $\alpha \mathrm{KO}$ e C57BL/6 (WT) submetidos ao protocolo de indução de doença periodontal com A. actinomycetemcomitans (AA) foram coletadas, o RNA total extraído e os níveis de expressão de TNF- $\alpha$, IFN- $\gamma$ e IL-10 foram analisados por RealTimePCR. Os resultados apresentados representam os valores da média \pm SD da intensidade de expressão de mRNA para o gene alvo, normalizado pela expressão da beta-actina,. Um experimento representativo de três experimentos independentes. ${ }^{*} \mathrm{p}<0.05$ vs WT. 
Os resultados mostraram que, nos camundongos infectados (WT-AA e MIP-1 $\alpha$ KOAA) a expressão das citocinas pró-inflamatórias TNF- $\alpha$ (Fig. 9a) e IFN- $\gamma$ (Fig. 9b) apresentou um aumento significativo ao $7^{\circ}$ ( $\mathrm{p}<0.05$ vs $0 \mathrm{~h}$ ) dia a qual se manteve no dia 14 ( $\mathrm{p}<0.05$ vs $0 \mathrm{~h}$ ) pós infecção, decaindo nos tempos de 30 (p<0.05 vs 0h) e 60 ( $\mathrm{p}<0.05$ vs $0 \mathrm{~h})$ dias. Ao compararmos as expressões, nos diferentes tempos, entre os camundongos WT-AA e MIP$1 \alpha$ KO-AA observamos que ao tempo de 7 dias a expressão de TNF- $\alpha$ no camundongo MIP$1 \alpha \mathrm{KO}-\mathrm{AA}$ é significantemente menor a expressão do animal WT-AA $(\mathrm{p}<0.01)$, igualmente a expressão de IFN- $\gamma$ onde no mesmo tempo de 7 dias a expressão nos animais MIP-1 $\alpha \mathrm{KO}-\mathrm{AA}$ é significantemente menor as dos camundongos WT $(\mathrm{p}<0.001)$.

Resultados opostos foram encontrados com relação à citocina antinflamatória IL-10 (Fig. 9c), a qual nos camundongos WT apresentou uma discreta expressão nos tempos de 7 ( $>0.05$ vs $0 \mathrm{~h}$ ) e 15 ( $>0.05$ vs $0 \mathrm{~h}$ ) dias, e um intenso aumento ao tempo de 30 ( $<<0.001$ vs 0h) dias, permanecendo intenso aos 60 ( $\mathrm{p}<0.001$ vs 0h) dias.. Já nos camundongos MIP$1 \alpha \mathrm{KO}-\mathrm{AA}$, nossos resultados demonstram uma tendência a um aumento na expressão de IL10 aos 7 dias ( $p>0.05$ vs 0 h), um aumento significativo ao tempo de 15 dias ( $<<0.001$ vs $0 \mathrm{~h}$ ) e, igualmente aos camundongos WT, um intenso aumento na expressão nos dias 30 ( $<<0.001$ vs 0h) e 60 ( $<<0.001$ vs $0 \mathrm{~h})$ pós infecção. Quando comparamos as duas linhagens de camundongos observamos que ao tempo de 15 dias a expressão de IL-10 nos camundongos MIP-1 $\alpha$ KO-AA é significantemente maior se comparado a expressão de IL-10 dos camundongos WT $(\mathrm{p}<0.05)$. Nos tempos 0h não foram detectadas a expressão de mRNA para nenhuma das citocinas investigadas nos tecidos periodontais dos animais analisados. A expressão do gene constitutivo beta-actina foi verificada em todos os tempos analisados (dados não mostrados), sendo utilizada como controle positivo de reação e para a normalização dos níveis de expressão de mRNA.

\subsection{Papel de MIP-1 $\alpha$ na modulação da expressão de metaloproteinases (MMPs) e seus inibidores (TIMPs) nos tecidos periodontais de camundongos infectados com $A$. actinomycetemcomitans}

O balanço entre a expressão MMPs e TIMPs está diretamente envolvido na degradação da matrix extracelular, podendo estar relacionada com a patogênese das DPs. Sendo assim, sua cinética de expressão pode ter relevância para a progressão da doença. Neste sentido, investigamos a expressão de tais fatores nos tecidos periodontais de camundongos WT e MIP$1 \alpha \mathrm{KO}$ (Fig. 10). 

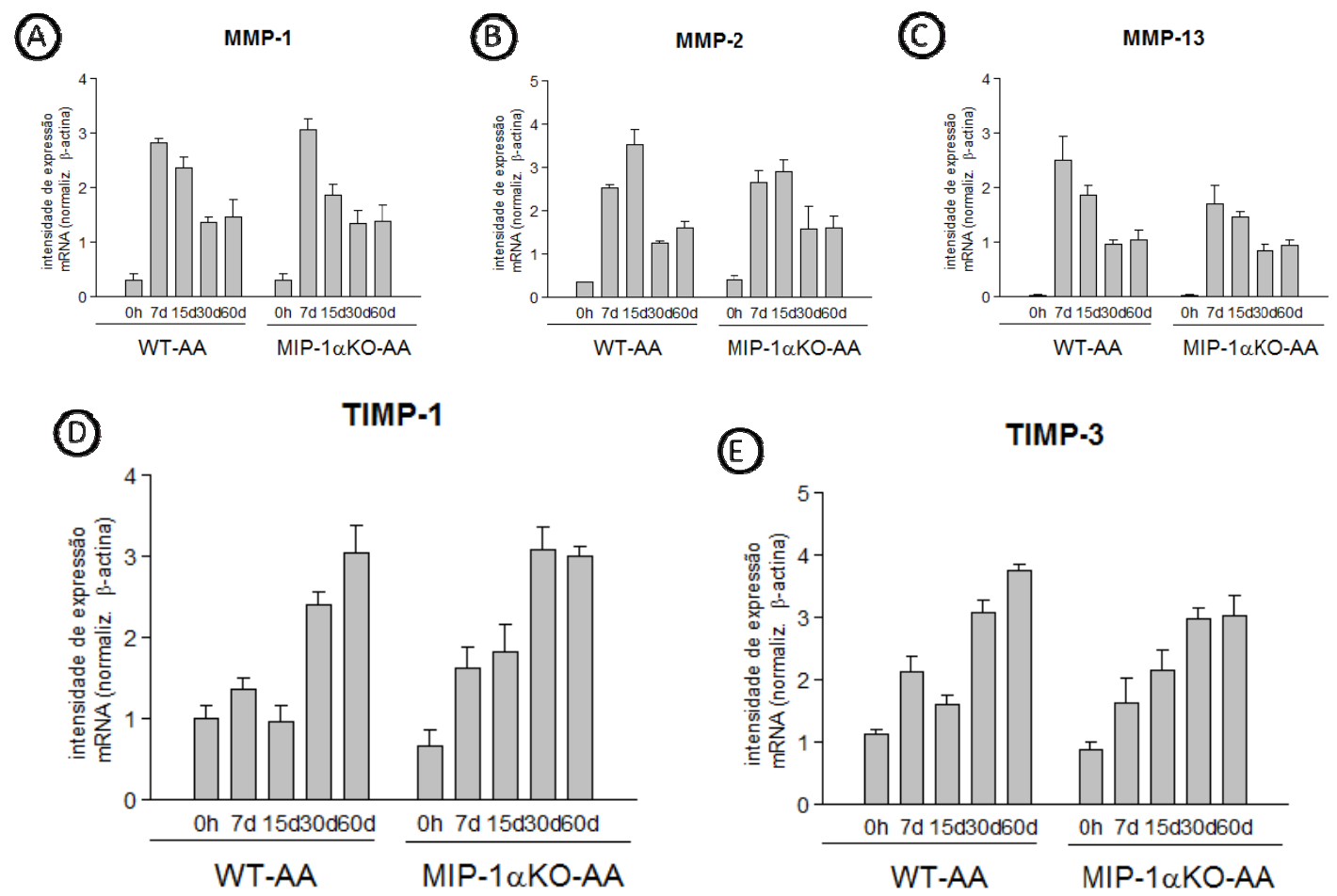

Figura 10 - Cinética de expressão de metaloprotease (MMPs) e inibidores teciduais de MMPs (TIMPs) nos

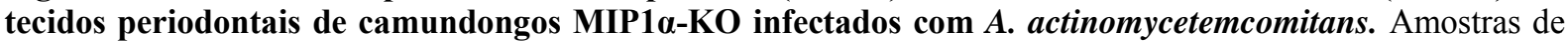
tecido periodontal de camundongos MIP1 $\alpha-\mathrm{KO}$ e C57BL/6 (WT) submetidos ao protocolo de indução de doença periodontal com A. actinomycetemcomitans (AA) forma coletadas, o RNA total extraído e os níveis de expressão de MMP-1, MMP-13, MMP-2, TIMP-1 e TIMP-3 foram analisados por RealTimePCR. Os resultados apresentados representam os valores da média \pm SD da intensidade de expressão de mRNA para o gene alvo, normalizado pela expressão da beta-actina, obtidos de 2 animais em cada Tempo. Um experimento representativo de três experimentos independentes.

A expressão das MMPs analisadas (MMP-1, MMP-2 e MMP-13) foram detectadas em baixos níveis nos tecidos normais (0h) dos camundongos WT e MIP-1 $\alpha$ KO. Durante o curso da doença, detectamos uma intensa expressão de MMP-1 (Fig. 10a), MMP-2 (Fig. 10b) e MMP-13 (Fig. 10c) nos tempos de 7 ( $<<0.001$ vs $0 \mathrm{~h})$ e 15 ( $<<0.001$ vs $0 \mathrm{~h}$ ) dias, que ao avançar do tempo sofreu uma diminuição nos tempos de 30 ( $p<0.001$ vs 0 h) e 60 ( $<<0.001$ vs 0h) dias, em ambos grupos de camundongos (WT-AA e MIP-1 $\alpha$ KO-AA). Além do mais, ao compararmos a expressão de MMPs no tempo de 7 dias, observamos uma menor expressão significativa de MMP-1 e MMP-13 dos camundongos MIP-1 $\alpha$ KO-AA quando comparados ao WT-AA $(\mathrm{p}<0.001)$. Também constatamos uma menor expressão de MMP-2 nos camundongos MIP-1 $\alpha \mathrm{KO}-\mathrm{AA}$ se comparados aos WT-AA no tempo de 15 dias $(\mathrm{p}<0.001)$. Por outro lado, a expressão de TIMPs, TIMP-1 (Fig. 10d) e TIMP-3 (Fig. 10e), nos camundongos WT-AA e MIP-1 $\alpha \mathrm{KO}-\mathrm{AA}$ apresentou um intenso aumento após 15 dias, nos tempos de 30 ( $p<0.001$ vs 0 h) e 60 ( $p<0.001$ vs 0 h) dias, apresentando expressão relativamente 
baixa no tempo de $0 \mathrm{~h}$. Quando comparamos a expressão de TIMPs entre os camundongos WT-AA e MIP-1 $1 \alpha \mathrm{KO}$ observamos ao tempo de $60(\mathrm{p}<0.01)$ dias uma menor expressão de TIMP-3 nos camundongos MIP-1 $\alpha$ KO-AA, o mesmo acontece nos tempos de 15 ( $<<0.001)$ e $30(\mathrm{p}<0.01)$ dias na expressão de TIMP-1.

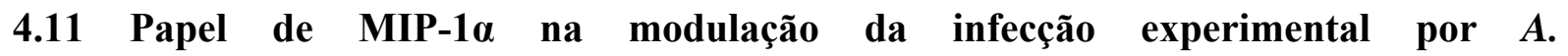 actinomycetemcomitans}

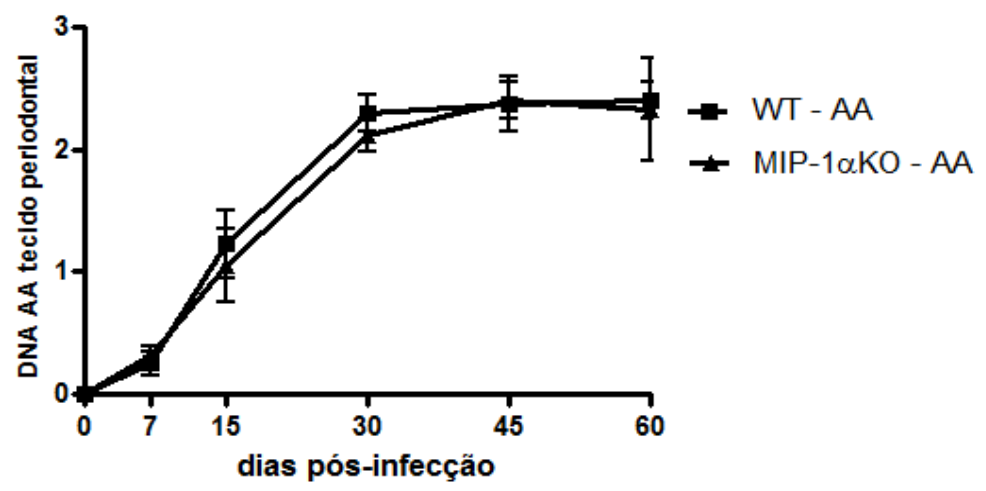

Figura 11 - Quantificação da carga bacteriana nos tecidos periodontais em resposta à infecção de

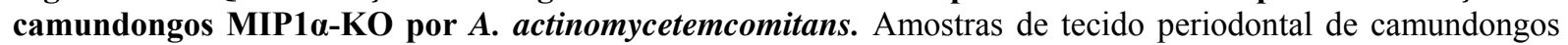
MIP-1 $\alpha$ KO-AA e C57BL/6 (WT-AA) submetidos ao protocolo de indução de doença periodontal com $A$. actinomycetemcomitans foram analisadas quanto à carga bacteriana nos tecidos periodontais (média $\pm \mathrm{SD}$ níveis de expressão de DNA de A. actinomycetemcomitans (AA), por RealTimePCR). Resultado representativo de 3 experimentos independentes.

Nosso próximo experimento foi a análise da resistência da infecção experimental por A. actinomycetemcomitans (Fig. 11). Nossos dados demonstram que a detecção de DNA de $A$. actinomycetemcomitans obteve uma tendência a aumentar no tempo de 7 dias pós infecção ( $p>0.05$ ) e um aumento intenso ao tempo de 15 dias ( $<<0.05$ vs $0 \mathrm{~d}$ ), continuando significativo nos tempos de 30 ( $\mathrm{p}<0.001$ vs $0 \mathrm{~h}$ ), 45 ( $\mathrm{p}<0.001$ vs $0 \mathrm{~h})$ e 60 ( $<<0.001$ vs $0 \mathrm{~h}$ ) dias após a infecção do microrganismo. Semelhantemente aos resultados encontrados nos outros experimentos, não obtivemos diferenças significativas entre as expressões de DNA de $A$. actinomycetemcomitans nos tecidos periodontais dos camundongos WT-AA quando comparados com os camundongos MIP- $1 \alpha \mathrm{KO}-\mathrm{AA}$ em todos os tempos analisados ( $\mathrm{p}>0.05$ ).

4.12 Papel de MIP-1 $\alpha$ nos níveis de expressão de óxido nítrico sintetase induzível (iNOS) nos tecidos periodontais de camundongos infectados com A. actinomycetemcomitans 


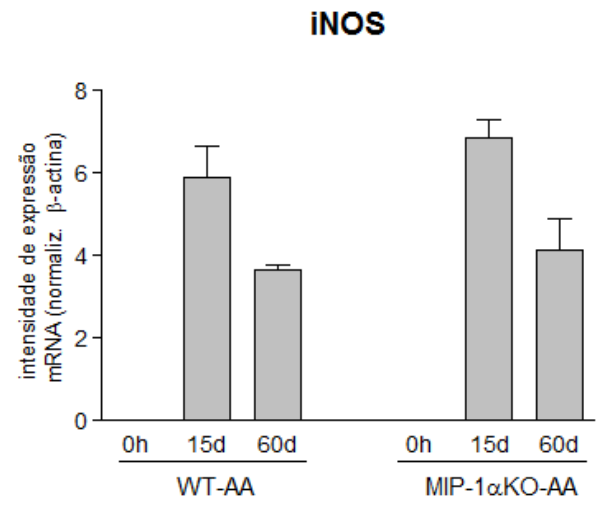

Figura 12 - Produção do mediador antimicrobiano óxido nítrico sintase induzível (iNOS) durante o curso da doença periodontal experimental induzida por $A$. actinomycetemcomitans em camundongos MIP-

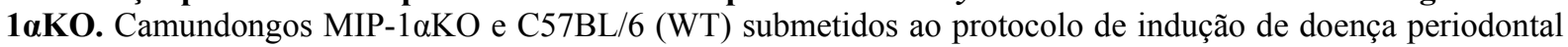
com A. actinomycetemcomitans (AA) foram analisados quanto a expressão de mRNA para iNOS (média $\pm \mathrm{SD}$, da intensidade de expressão de mRNA, normalizado pela beta-actina, obtidos de 2 animais em cada tempo). Resultados representativos de 3 experimentos independentes.

Estudos demonstram que a produção de óxido nítrico (NO) mediada pela enzima iNOS pode matar certos periodontopatógenos, estando este mediador potencialmente envolvido no controle da infecção periodontal. Neste sentido, camundongos WT-AA e MIP$1 \alpha \mathrm{KO}-\mathrm{AA}$ infectados com A. actinomycetemcomitans foram analisados quanto aos níveis de expressão de iNOS nos tecidos periodontais, aos tempos de 0h, 15d e 60d (Fig. 12). Nossos resultados demonstram que a expressão de iNOS foi exacerbadamente detectada no tecido periodontal no $15^{\circ}$ dia ( $<<0.05$ vs $0 \mathrm{~h}$ ) e diminui significantemente no tempo de $60 \mathrm{~d}$ ( $\mathrm{p}<0.05$ vs $0 \mathrm{~h}$ ), tanto para os camundongos WT-AA quanto para os MIP-1 $\alpha \mathrm{KO}-\mathrm{AA}$, não havendo diferenças significativas entre eles. 
4.13 Papel de MIP-1 $\alpha$ na modulação dos níveis de mieloperoxidase (MPO) nos tecidos periodontais de camundongos infectados com A. actinomycetemcomitans

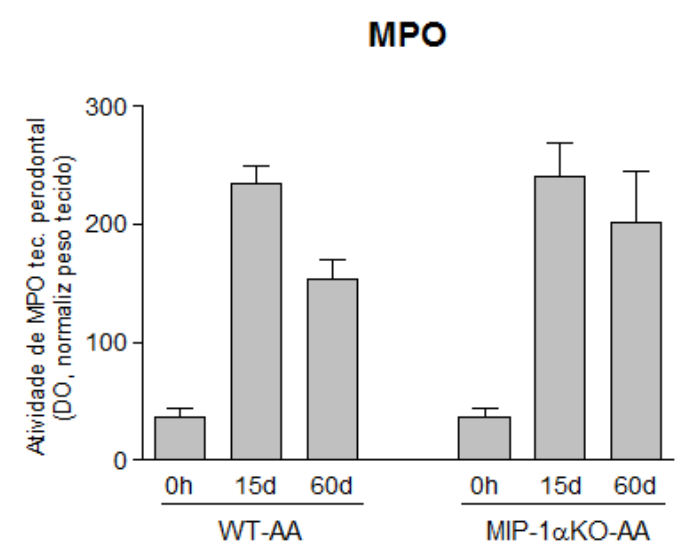

Figura 13 - Produção do mediador antimicrobiano mieloperoxidase (MPO) durante o curso da doença

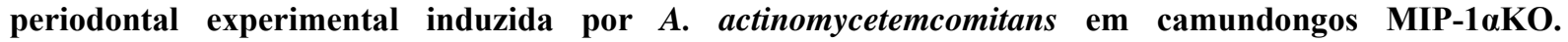
Camundongos MIP-1 $\alpha \mathrm{KO}$ e C57BL/6 (WT) submetidos ao protocolo de indução de doença periodontal com $A$. actinomycetemcomitans (AA) foram analisados quanto ao nível de MPO nos tecidos periodontais (média \pm SD da DO referente a atividade de MPO nos tecidos periodontais por animal, normatizados pelo peso do tecido, pool de 5 animais em cada tempo). Resultados representativos de 3 experimentos independentes.

Pouco se sabe a respeito dos mecanismos envolvidos no controle da infecção periodontal, mas acredita-se que mediadores antimicrobianos, produzidos por neutrófilos, participem desse processo. Neste sentido, analisamos os níveis de MPO nos tecidos

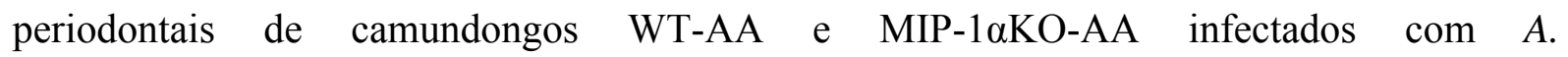
actinomycetemcomitans nos tempos de 0h, 15d e 60d (Fig. 13). Nossos resultados demonstram que uma intensa expressão de MPO foi detectada nos tecidos periodontais 15 ( $\mathrm{p}<0.05$ vs $0 \mathrm{~h})$ e 60 ( $<<0.05$ vs $0 \mathrm{~h}$ ) dias após a infecção, tanto para os camundongos WT-AA quanto para os MIP-1 $\alpha \mathrm{KO}-\mathrm{AA}$, não havendo diferenças significativas entre eles.

\subsection{Cinética de expressão das quimiocinas MIP-1ß e RANTES nos tecidos periodontais de camundongos infectados com A. actinomycetemcomitans}

Com relação às DPs, diversas quimiocinas, como MIP-1 $\beta$ (CCL4) e RANTES (CCL5), têm sido identificados nos tecidos periodontais inflamados, enquanto sua expressão em condições de saúde periodontal é mínima ou inexistente. Por meio disto e pelo compartilhamento de receptores entre MIP-1 $\alpha$, MIP-1 $\beta$ e RANTES, analisamos a expressão 
das quimiocinas MIP-1 $\beta$ (Fig. 14a) e RANTES (Fig. 14b) nos tecidos periodontais dos camundongos infectados com A. actinomycetemcomitans.
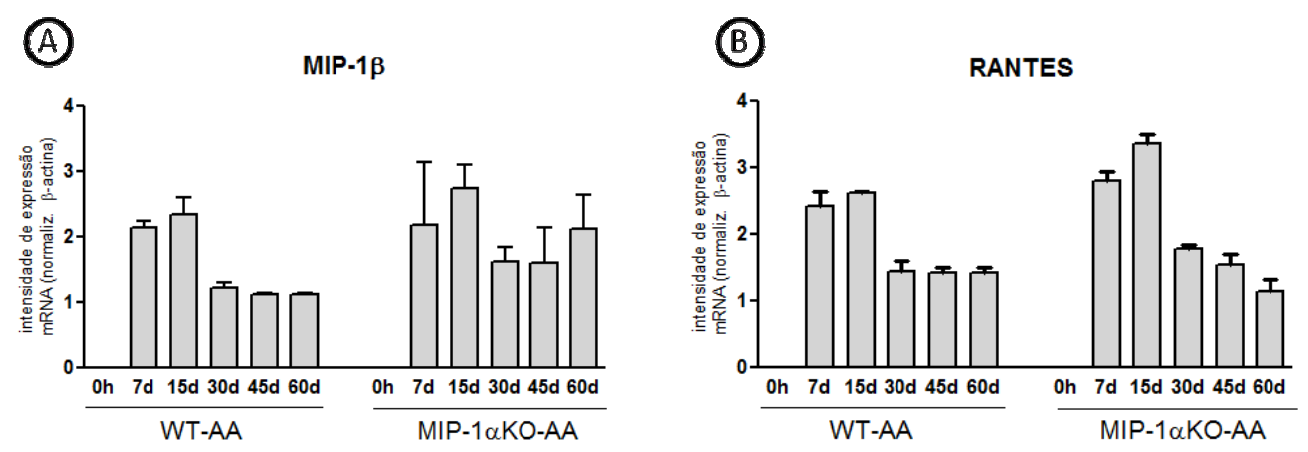

Figura 14 - Cinética de expressão de quimiocinas nos tecidos periodontais de camundongos MIP-1aKO infectados com A. actinomycetemcomitans. Amostras de tecido periodontal de camundongos MIP-1 $\alpha \mathrm{KO}$ e C57BL/6 (WT) submetidos ao protocolo de indução de doença periodontal com A. actinomycetemcomitans (AA) foram coletadas, o RNA total extraído e os níveis de expressão de MIP-1 $\beta$, e RANTES foram analisados por RealTimePCR. Os resultados apresentados representam os valores da média \pm SD da intensidade de expressão de mRNA para o gene alvo, normalizado pela expressão da beta-actina. Um experimento representativo de três experimentos independentes. ${ }^{*} \mathrm{p}<0.05$ vs WT.

Em nossos resultados observamos aumentos significativos na expressão de MIP-1 $\beta$ nos tempos $7 \quad(\mathrm{p}<0.01$ vs $0 \mathrm{~h})$ e $15 \quad(\mathrm{p}<0.01$ vs0h $)$ dias pós infecção por $A$. actinomycetemcomitans nos camundongos WT-AA; e aumentos nos tempos 7 ( $<<0.01$ vs $0 \mathrm{~h}$ ), 15 ( $<<0.001$ vs 0 h) e 60 ( $p<0.05$ vs 0 h) dias nos camundongos MIP-1 $\alpha$ KO-AA. Não havendo diferenças significativas entre os dois grupos de camundongos infectados (MIP-1 $\alpha \mathrm{KO}-\mathrm{AA}$ e WT-AA) nos diferentes tempos analisados. De acordo com os resultados encontrados com a expressão de MIP-1 $\beta$, a expressão de RANTES aumentou significativamente entre os tempos de 0 h e 7 ( $\mathrm{p}<0.001$ vs 0 h) dias pós infecção com AA, porém, diferentemente da cinética de expressão de MIP-1 $\beta$, este aumento continuou significativo nos demais tempos analisados, 15 ( $\mathrm{p}<0.001$ vs $0 \mathrm{~h}), 30(\mathrm{p}<0.001$ vs $0 \mathrm{~h})$ e 60 ( $\mathrm{p}<0.001$ vs $0 \mathrm{~h}$ ) dias, tanto para os camundongos WT-AA quanto para os MIP-1 $\alpha \mathrm{KO}-\mathrm{AA}$. Além do mais, observamos uma maior expressão significativa de RANTES nos camundongos MIP-1 $\alpha \mathrm{KO}-\mathrm{AA}$ quando comparados aos WT-AA no tempo de 15 dias $(\mathrm{p}<0.01)$, não sendo observada essa mesma diferença nos demais tempos analisados ( $>0.05$ ). Os animais não infectados MIP-1 $\alpha$ KO-C não apresentaram expressões significativas de MIP-1 $\beta$ e RANTES em nenhum dos tempos analisado ( $p>0.05$ ). 


\subsection{Efeito de MetRANTES na migração de células inflamatórias e perda óssea alveolar} induzida por A. actinomycetemcomitans
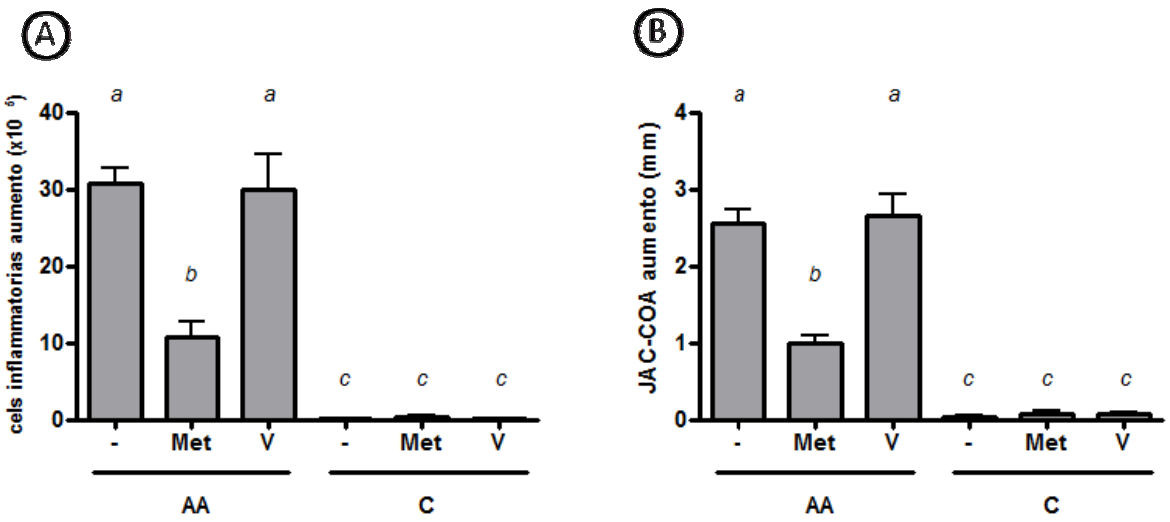

Figura 15 - Efeito de MetRANTES na reação inflamatória e perda óssea alveolar induzida por $A$. actinomytemcomitans em camundongos C57BL/6 (WT). Camundongos WT submetidos ao protocolo de indução de doença periodontal com A. actinomytemcomitans (AA), grupos controle de animais não infectados (-) e tratados ou não com MetRANTES (Met) ou com veículo PBS (V). Foram analisados a migração de células inflamatórias nos tecidos periodontais e perda óssea alveolar no tempo de 30 dias. A) Número de leucócitos extraídos através de digestão enzimática do tecido periodontal, corados com azul de tripam e contados em câmara de Neubauer. B) Aumento da área JAC-COA na face palatina dos molares, em relação aos animais controle, medida em unidades arbitrárias de área (UAA) com o programa ImageToll 2.0. Os resultados representam os valores da média $\pm \mathrm{SD}$, da área JAC-COA ou número de células por animal, representativos de três experimentos independentes. Letras diferentes representam diferenças estatísticas significativas entre os grupos.

Nossos resultados demonstram que os camundongos WT infectados por A. actinomycetemcomitans tratados com MetRANTES (Met) apresentam uma redução significativa tanto na quantidade de células inflamatórias quanto na perda óssea alveolar quando comparados com os camundongos infectados por A. actinomycetemcomitans não tratados (-) ou tratados com PBS (V) $(\mathrm{p}<0.05)$. Os camundongos não infectados não apresentaram uma quantidade significativa na quantidade de células inflamatória e na perda óssea, sendo que todos os grupos de animais infectados por A. actinomycetemcomitans apresentaram uma quantidade significativamente maior de células inflamatória e perda óssea alveolar quando comparado com os grupos de animais não infectados $(\mathrm{p}<0.05)$. 
90

$\underline{\text { Discussão }}$ 



\section{Discussão}

A interação entre as bactérias e as células do tecido periodontal do hospedeiro é um processo complexo onde, até certo ponto, existe um estado de equilíbrio, que permite a manutenção da saúde periodontal mesmo na presença de determinados microrganismos. Entretanto, a presença de bactérias periodontopatogênicas no biofilme associado ao tecido periodontal resulta em alterações crônicas inflamatórias as quais chamamos de doença periodontal (DP) (Loesche, 1993). Apesar de microrganismos serem fundamentais para o início do desenvolvimento da doença, a amplificação desse processo e a destruição dos tecidos periodontais estão diretamente relacionadas à resposta imune do hospedeiro (Kinane e Lappin, 2001; Yamazaki, Yoshie et al., 2003; Kinane e Attstrom, 2005). Entretanto, acreditase também que tal resposta desempenhe um papel de proteção do hospedeiro frente às bactérias invasoras, porém não é bem definido o nível de proteção oferecida, já que diversos estudos demonstram que a excessiva liberação de mediadores inflamatórios predispõe a ocorrência ou o agravamento de diversos estados patológicos (Kinane e Lappin, 2001; Teng, 2003; Kinane e Attstrom, 2005). Mediadores inflamatórios como citocinas e quimiocinas têm sido identificados em grande quantidade em lesões periodontais (Garlet, Martins et al., 2003), porém os papéis de alguns destes mediadores na patogênese das DPs não são bem conhecidos.

Uma vez que a resposta inflamatória e imunológica, montada pelo hospedeiro em resposta ao periodontopatógeno, parece ser determinante quanto à proteção ou desenvolvimento de alterações patológicas, fatores envolvidos no recrutamento seletivo de diferentes tipos celulares para o sítio inflamatório estão potencialmente envolvidos na imunopatologia das doenças periodontais. Quimiocinas são consideradas um fator inflamatório que parece desencadear um papel crucial na atração e manutenção de leucócitos no local em que desenvolve um processo inflamatório. Dentre as quimiocinas, MIP-1 $\alpha$ é considerada por alguns autores a quimiocina mais abundante no tecido periodontal inflamado (Kabashima, Yoneda et al., 2002). Nossos resultados demonstram que nos camundongos WT infectados por A. actinomycetemcomitans a expressão de MIP-1 $\alpha$ nos tecidos periodontais apresentou-se intensa (Fig. 1), sugerindo que tal quimiocina possa exercer um papel importante na patogênese da DP. Essa quimiocina colabora de forma importante com as respostas imune e inflamatória induzindo a migração celular de leucócitos e células possuidoras dos receptores de quimiocinas CCR1 e CCR5 (Mantovani, 1999; Luther e Cyster, 2001). De fato, quando analisamos a cinética de expressão de MIP-1 $\alpha$, e a migração de células 
positivas para CCR5+ e CCR1+ observamos uma intensa migração destas células para o tecido gengival a partir do sétimo dia após a infecção por A. actinomycetemcomitans (Fig. 2). De acordo com tais resultados, uma expressão elevada de CCR5 pode ser verificada em lesões periodontais humanas (Gamonal, Acevedo et al., 2001; Kabashima, Yoneda et al., 2002; Folwaczny, Glas et al., 2003; Kim, Park et al., 2006). Além do mais, outras doenças orais de caráter inflamatório, como é o caso das lesões periapicais, caracterizadas pela persistente migração de leucócitos apresentam uma intensa expressão de CCR5+ e CCR1+ (Kabashima, Yoneda et al., 2001; Silva, Garlet et al., 2005; Menezes, Garlet et al., 2008). Recentemente foi demonstrado por reações de imunohistoquímica que células $T$, macrófagos e células dendríticas no tecido gengival inflamado expressam CCR5 (Jotwani, Muthukuru et al., 2004), porém, o exato fenótipo de tais células não está bem caracterizado. Visto isto, ao tempo de 30 dias, fenotipamos as células CCR1+ e CCR5+ presentes nos tecidos periodontais dos camundongos WT infectados. Como em outras doenças crônicas inflamatórias (Choi, Cruz et al., 2000; Bartold, Marshall et al., 2005), observamos que a maioria das células CCR5+ também co-expressavam CXCR3, caracterizando um fenótipo de células Th1 (Fig. 3a), caracterizando uma resposta imune com tendências a um padrão Th1 (Luther e Cyster, 2001; Teng, 2003; Wang e Liu, 2003). Além disso, também identificamos uma quantidade significativa de macrófagos (células F4/80+) dentre as células CCR1+ (Fig. 3b). Os resultados apresentados sugerem que não necessariamente a mesma célula faz parte de diversas sub populações dentre CCR5+ e CCR1+, levando em consideração que a co expressão de ambos os receptores é baixa.

Tal padrão de resposta (Th1) pode ser determinado pela expressão seletiva de diferentes quimioatraentes nos tecidos periodontais, como exemplo a quimiocina MIP-1 $\alpha$. O processo de migração celular ocorre através de complexas interações de moléculas de adesão e quimioatraentes e seus respectivos receptores, envolvendo inicialmente o endotélio vascular e as células circulantes, e posteriormente, a interação dessas com a matriz extracelular conjuntiva e fatores quimiotáticos nela gerados (Mantovani, 1999). Então, sabendo que, na DP experimental realizada em nosso estudo, a migração de células CCR5+ e CCR1+ é abundante e se mostra correlacionada com a cinética de expressão de MIP-1 $\alpha$ (Fig.1), e que o fenótipo destas células caracteriza uma resposta de padrão Th1 (Fig. 3), torna-se evidente o potencial papel exercido pela quimiocina MIP-1 $\alpha$ no desenvolvimento das DPs. Com o intuito de estudar o papel da quimiocina MIP-1 $\alpha$ no desenvolvimento da DP infectamos camundongos geneticamente modificados, que não expressam MIP-1 $\alpha$ (MIP-1 $1 \alpha \mathrm{KO})$, com $A$. 
actinomycetemcomitans, e comparamos o estabelecimento e progressão da doença nesta linhagem com camundongos C57BL/6 (WT).

Como previamente demonstrado em camundongos WT, a infecção com $A$. actinomycetemcomitans leva ao desenvolvimento de um infiltrado inflamatório nos tecidos periodontais (Fig. 4a) (Garlet, Cardoso et al., 2006; Garlet, Cardoso et al., 2007; Garlet, Cardoso et al., 2008). Os animais MIP-1 $\alpha \mathrm{KO}$ apresentaram um desenvolvimento do infiltrado inflamatório muito semelhante aos dos camundongos WT, apesar da quantidade de total de células inflamatórias estar reduzida nos primeiros 30 dias de infecção ( $>>0.05)$. Apesar da importância do papel de MIP-1 $\alpha$ na quimiotaxia de células inflamatórias, a exclusividade desse papel não é garantida somente a essa quimiocina. Quimiocinas como, MIP1- $\beta$ (CCL4), RANTES (CCL5) e MCP-2 (CCL8), que também estão presentes em abundância nos sítios de inflamação periodontal (Gamonal, Bascones et al., 2000; Gamonal, Acevedo et al., 2001; Gemmell, Carter et al., 2001; Kabashima, Yoneda et al., 2002; Garlet, Martins et al., 2003), são ligantes do receptor CCR5(Graves e Jiang, 1995), e as quimiocinas MCP-3 (CCL7), eotaxina (CCL11) e leucotaxina (CCL15), ligantes do receptor CCR1 (Graves e Jiang, 1995), podem desempenhar papel semelhante de quimioatração que MIP-1 $\alpha$ no desenvolvimento da resposta inflamatória nos camundongos MIP-1 $\alpha$ KO(Mantovani, 1999).

Além de seu papel na quimioatração de leucócitos, MIP-1 $\alpha$ tem sido descrita como fator quimiotático e de diferenciação de osteoclastos (Scheven, Milne et al., 1999; Roodman e Choi, 2004). Estudos demonstram um papel da quimiocina MIP-1 $\alpha$ na indução da formação de osteoclastos, sendo responsável por parte da reabsorção óssea em diversas condições patológicas, como mieloma múltiplo, artrite reumatóide, doença periodontal entre outras (Mercado, Marshall et al., 2001; Bartold, Marshall et al., 2005; Oba, Lee et al., 2005). Em nossos resultados (Fig. 4b) e como já estabelecido (Garlet, Cardoso et al., 2006; Garlet, Cardoso et al., 2007), os camundongos WT com doença periodontal experimental, infectados com A. actinomycetemcomitans (WT-AA), apresentaram um aumento crescente da área compreendida entre a junção amelo-cementária (JAC) e a crista óssea alveolar (COA), representativa de reabsorção óssea. Porém, apesar de apresentarem uma quantidade de reabsorção óssea discretamente menor, não encontramos diferenças significativas entre tal parâmetro ao compararmos os nos camundongos da linhagem MIP-1 $1 \alpha \mathrm{KO}$ e WT. Relatos demonstram que os efeitos de MIP-1 $\alpha$ sobre os osteoclastos são mediados pelos receptores CCR5 e/ou CCR1, pois quando utilizado anticorpos contra os receptores CCR1 ou CCR5 o efeito estimulatório de MIP-1 $\alpha$ na formação de osteoclastos humanos é inibido (Oba, Lee et al., 2005). Dessa forma, é possível que outras quimiocinas ligantes de CCR1 e/ou CCR5 
possam suprir a falta de MIP-1 $\alpha$ nos camundongos MIP-1 $1 \alpha \mathrm{KO}$. Ao contrário da possível redundância com outras quimiocinas no desenvolvimento da resposta inflamatória, o efeito de MIP-1 $\alpha$ sobre os precursores de osteoclastos parece ser altamente específico (Han, Choi et al., 2001). Assim, apesar de algumas controvérsias, MIP-1 $\alpha$, através principalmente do receptor CCR5, parece participar da diferenciação e a sobrevida dos osteoclastos via a ativação do

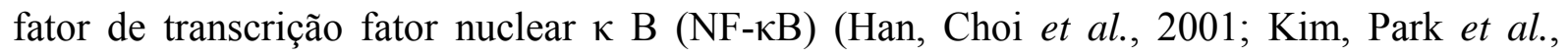
2006). Porém a ativação deste fator de transcrição em células pré-osteoclasticas é um evento complexo, onde diversas moléculas presentes nas DPs podem participar concomitantemente. Citocinas pró-inflamatórias como TNF- $\alpha$ e IL-1 $\beta$ podem promover a ativação de NF- $\kappa \mathrm{B}$, participando da osteoclastogênese (Assuma, Oates et al., 1998; Theoleyre, Wittrant et al., 2004; Takayanagi, Sato et al., 2005; Takayanagi, 2007). Além do mais, descobertas recentes indicam a presença de moléculas co-estimulatórias de osteoclastos, as quais aumentam a quantidade de cálcio intracelular das células formadoras de osteoclastos, fato indispensável para a ativação de NF-кB (Takayanagi, Sato et al., 2005; Takayanagi, 2007; Nakashima e Takayanagi, 2008). Assim, outros fatores que participam da osteoclastogênese presentes na doença periodontal parecem suprir a ausência de MIP-1 $\alpha$ na reabsorção óssea, o que parece não acontecer com tanta ênfase em modelos experimentais de outras patologias semelhantes (Bessis e Boissier, 2001). Apesar de estudos demonstrarem um papel importante para MIP-1 $\alpha$ em modelos de mieloma múltiplo e artrite reumatóide, devemos considerar que apesar de certas similaridades com a reabsorção óssea inflamatória verificada na periodontite, tais patologias apresentam diferenças importantes, tais como os mecanismos envolvidos em seu estabelecimento, presença ou ausência de microrganismos, entre outros, que poderiam justificar as diferenças entre o possível papel de MIP-1 $\alpha$ nos diferentes modelos (Loesche, 1993; Fives-Taylor, Meyer et al., 1999; Bartold, Marshall et al., 2005). De fato, a presença dos periodontopatógeno e seus subprodutos, mais especificadamente o LPS (lipopolissacarídeo), desencadeia vias de sinalizações celulares, como as vias ativadas pelos receptores TLR (Toll like receptor), que não participam patologias não infecciosas (Albiger, Dahlberg et al., 2007; Carpenter e O'neill, 2007; Kikkert, Laine et al., 2007; Mitchell, PaulClark et al., 2007; Yoshioka, Yoshimura et al., 2008), podendo assim, alterar a forma ou a intensidade da resposta imune do hospedeiro infectado.

Como podemos ver a ligação da quimiocina com seus determinados receptores de quimiocinas não possuem uma exclusividade, apesar de possuírem certa especificidade. A família das quimiocinas do tipo CC é formada pelos grupos de quimiocinas como as proteínas inflamatórias de macrófagos (MIP-1 $\alpha$ e MIP-1 $\beta$ ), as proteínas quimioatrativas de monócitos 
(MCP-1, MCP-2 e MCP-3) e uma quimiocina designada como RANTES. Como o nome sugere essas proteínas atuam predominantemente em células mononucleares (Graves e Jiang, 1995; Sozzani, Locati et al., 1996; Yuan, Masuko-Hongo et al., 2001). Está bem estabelecido que estas quimiocinas desempenham papéis fisiológicos e patológicos através da ligação aos seus receptores correspondentes presentes nas superfícies das células, que no caso das quimiocinas CC são os receptores CCR (Graves e Jiang, 1995; Murphy, 2002). Então, células que expressam os receptores de quimiocinas CCR5 e CCR1 sofrem uma quimioatração não só pela quimiocina MIP-1 $\alpha$, mas também por uma gama de quimiocinas do grupo CC (Lukacs, Hogaboam et al., 1999; Mantovani, 1999). Isto pode ser constatado quando analisamos a cinética de migração das células CCR5+ (Fig. 5a) e CCR1+ (Fig. 5b) extraídas dos tecidos periodontais dos camundongos infectados MIP-1 $1 \alpha \mathrm{KO}$ quando comparados ao WT. Apesar de uma quantidade discretamente menor de células CCR5+ e CCR1+, a falta da quimiocina MIP$1 \alpha$ nos camundongos MIP-1 $1 \alpha \mathrm{KO}$ durante a infecção com $A$. actinomycetemcomitans, não se apresentou significativa. Resultado muito semelhante ao encontrado na cinética de migração de células RANKL+, essenciais na osteoclastogênese, onde observamos uma migração intensa nos camundongos infectados, como já estabelecido pela literatura (Garlet, Cardoso et al., 2007), porém não encontramos diferenças significativas entre os camundongos WT e MIP-1 $\alpha$ KO (Fig. 6).

Apesar de bem estabelecida à participação de MIP-1 $\alpha$ na osteoclastogênese (Choi, Cruz et al., 2000; Han, Choi et al., 2001), há uma divergência de opiniões em relação à participação de MIP-1 $\alpha$ na expressão de RANKL. Alguns autores relatam que MIP-1 $\alpha$ não é capaz de induzir a expressão de RANKL em células da medula óssea humana (Horton, Dorey et al., 1993), sugerindo que a participação de MIP-1 $\alpha$ é exclusivamente através dos receptores CCR5, e principalmente CCR1, na quimioatração de células RANKL+. Por outro lado, trabalhos sugerem que MIP-1 $\alpha$ afeta não apenas precursores de osteoclastos, mas também osteoclastos maduros, já diferenciados. Sendo assim, MIP-1 $\alpha$ é capaz de induzir não só a

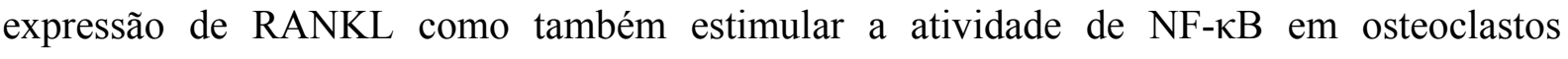
maduros (Lee, Shin et al., 2007). Portanto analisamos a expressão de fatores osteoclastogênicos como RANKL e OPG, um receptor decoy de RANK, em camundongos MIP-1 $1 \alpha \mathrm{KO}$ e WT infectados com AA (Fig. 7). No primeiro tempo analisado (7 dias), onde observamos um intenso aumento da expressão de RANKL nos camundongos infectados, percebemos que, apesar de intenso, a expressão de RANKL nos camundongos MIP-1 1 KO apresentava-se significativamente menor quando comparada aos WT infectado (Fig. 7a). Entretanto, esta mesma diferença não foi encontrada nos demais tempos ou quando 
comparamos a expressão de OPG entre os animais do grupo experimental (Fig. 7b), parecendo que a falta de MIP-1 $\alpha$ resulta em um retardo e diminuição inicial na produção local de RANKL, mas que não inibe significativamente a expressão de fatores osteoclastogênicos, como RANKL e OPG, em camundongos infectados com A. actinomycetemcomitans. Mais uma vez, é possível que podendo haver outras quimiocinas com papel redundante. Resultado este, confirmado pelos ensaios imunoenzimáticos (ELISA) para RANKL e OPG, onde observamos a produção da proteína de RANKL e OPG, onde ambas não sofreram diferenças significativas entre os grupos infectados, WT e MIP-1 $\alpha \mathrm{KO}$ (Fig. 8). De fato, quimiocinas como RANTES e MCP-1 podem influenciar na expressão e produção de RANKL estimulando a formação de osteoclastos (Kim, Day et al., 2005). Além do mais, também devemos considerar que não só MIP-1 $\alpha$ tem papel de quimiotaxia de células RANKL+, outras quimiocinas e citocinas fazem este papel de forma redundante (Kwak, Ha et al., 2008).

Outro fator que pode influenciar e ser influenciado por MIP-1 $\alpha$ é a expressão de algumas citocinas. TNF- $\alpha$ e IFN- $\gamma$, citocinas pró-inflamatórias clássicas, têm sido identificado em altos níveis em lesões periodontais e no fluido gengival de pacientes com DP (Engebretson, Lamster et al., 1999; Gorska, Gregorek et al., 2003; Graves e Cochran, 2003). A citocina TNF- $\alpha$ participa ativamente da manutenção e/ou amplificação da resposta inflamatória local, agindo no recrutamento de leucócitos, induzindo o aumento da expressão de moléculas de adesão em células endoteliais e em leucócitos e estimulando a produção local de quimiocinas (Graves, Chen et al., 2000; Graves e Cochran, 2003). TNF- $\alpha$ também aumenta os mecanismos de migração de neutrófilos através de MIP-1 $\alpha$ (Montecucco, Steffens et al., 2008). Por sua vez, IFN- $\gamma$ pode levar a um aumento da responsividade de células, como os fibroblastos gengivais, à ação do LPS, levando a uma maior produção de citocinas inflamatórias (Moriyama, Ukai et al., 2002). Em contra partida, citocinas antiinflamatórias, como é o caso da IL-10, parecem amenizar a severidade da doença periodontal. Estudos demonstram que os níveis de IL-10 parecem aumentar após tratamento periodontal (Gamonal, Bascones et al., 2000) e que sua ausência leva a uma maior reabsorção óssea alveolar (Sasaki, Hou et al., 2000; Al-Rasheed, Scheerens et al., 2004; Sasaki, Okamatsu et al., 2004). Além do mais, IL-10 parece ser responsável por uma rápida diminuição dos níveis de expressão de citocinas pró-inflamatórias (TNF- $\alpha$, IL-6, MIP-1 $\alpha$ e GRO- $\beta$ ) (Chiu, Stolberg et al., 2007). Quando analisamos a ausência de MIP-1 $\alpha$ na modulação da expressão de citocinas em camundongos infectados com A. actinomycetemcomitans., observamos que aos 7 dias as citocinas pró-inflamatórias, TNF- $\alpha$ e IFN- $\gamma$, estão significativamente reduzidas e que a citocina antiinflamatória, IL-10, aos 15 dias está aumentada nos camundongos MIP-1 $\alpha$ KO, 
quando comparado aos WT infectados (Fig. 9), mas tal diferença não se mostra duradoura ao longo do desenvolvimento da doença, sugerindo que MIP-1 $\alpha$ apresenta um papel importante no desenvolvimento da resposta inflamatória inicial, mas que outros ligantes de CCR5 e CCR1 podem compensar sua ausência.

Diversos estudos com modelos experimentais diferentes vêm tentando caracterizar a influencia de MIP-1 $\alpha$ e de seus receptores na expressão de citocinas (Lindell, Standiford et al., 2001; Matsui, Weaver et al., 2002; Hsieh, Frink et al., 2008; Machado, Souto et al., 2008; Medeiros, Silverio et al., 2008). Semelhantemente aos resultados encontrados. modelos experimentais utilizando camundongos com ausência ou bloqueio de receptores CCR5 não apresentam diferenças significativas na expressão de citocinas como IFN- $\gamma$, TNF- $\alpha$ e IL-10, apesar de haver relatos de uma tendência à diminuição (Medeiros, Silverio et al., 2008). Realmente, no modelo experimental de DP utilizado, não encontramos uma participação efetiva de MIP-1 $\alpha$ na modulação da expressão das citocinas analisadas, indo de acordo com o padrão de resultados encontrados ao longo do trabalho.

Uma prova disso é o resultado encontrado quando analisamos a expressão de MMPs e TIMPs (Fig. 10). Assim como os resultados relativos à expressão de citocinas, não encontramos diferenças significativas entre as expressões de MMPs e TIMPs em nenhum dos tempos analisados quando comparamos os dois grupos de camundongos infectados, sugerindo que MIP-1 $\alpha$ não interfere diretamente na expressão de tais fatores. Mediadores inflamatórios, como as citocinas pró inflamatórias IFN- $\gamma$ e TNF- $\alpha$, têm sido descritas como reguladores positivos da expressão de MMPs, enquanto citocinas antiinflamatórias (IL-10) são descritas como reguladores negativos da expressão de MMPs (Harris et al. 2002, Katagiri \& Takahashi 2002). Em relação à DP, trabalhos anteriores realizados por nosso grupo, mostram que a expressão da citocina IFN- $\gamma$ está em correlação positiva à expressão de MMP-1 e negativa à expressão do seu inibidor TIMP-1, diferentemente da expressão de IL-10 que se apresenta em correlação positiva com a expressão de TIMP-1 (Garlet, Cardoso et al., 2006). Uma vez que a expressão de MMPs e de TIMPs parece estar mais relacionada à presença de citocinas. De fato, no mesmo modelo de DP experimental utilizado em nosso trabalho, a expressão de MMP-1, MMP-2 e MMP-9 apresentam-se reduzidas e as expressões de TIMP-1, TIMP-2 e TIMP-3 aumentadas em camundongos geneticamente modificados para não expressar TNF- $\alpha$, quando comparados com camundongos C57BL/6 (Garlet, Cardoso et al., 2007).

Assim, apesar do papel desempenhado por MIP-1 $\alpha$ demonstrado em diversos estudos, a falta desta não interfere em fatores que possam desencadear um aumento da severidade de aspectos clínicos e biológicos relacionados à DP. Porém, ainda permanece nebuloso o papel 
que MIP-1 $\alpha$ poderia desempenhar no controle da infecção por A. actinomycetemcomitans (Sosroseno, Bird et al., 2009). Para isto, analisamos dois mecanismos de defesa em que MIP$1 \alpha$ pode interferir, através das enzimas iNOS e MPO, e a carga bacteriana local do periodontopatógeno utilizado.

A produção do radical livre óxido nítrico (NO) é um mecanismo de controle bacteriano apresentado por macrófagos através de uma isoenzima chamada de óxido nítrico sintetase induzível (iNOS). Níveis elevados de NO contribuem com danos teciduais, assim como outros mecanismos de defesa (Sosroseno, Bird et al., 2009). Interessantemente, camundongos geneticamente modificados para não apresentarem iNOS, apresentam uma redução significativa na resposta inflamatória quando desafiados por endotoxina (Fakhrzadeh, Laskin et al., 2002; Shanley, Zhao et al., 2002). Além do mais, estudos descrevem a habilidade de NO em modular a produção de quimiocinas, incluindo MIP-1 $\alpha$ (Calkins, Bensard et al., 2001; Giustizieri, Albanesi et al., 2002; Machado, Souto et al., 2008). Porém, o contrário não nos pareceu recíproco, pois quando comparamos a expressão de iNOS entre os animais MIP- $1 \alpha \mathrm{KO}$ e os WT, ambos infectados por A. actinomycetemcomitans, não encontramos diferenças significativas (Fig. 12), o que pode ser explicado pela semelhança na expressão das citocinas e da quantidade de leucócitos de ambos os grupos de camundongos infectados (MIP-1 $\alpha \mathrm{KO}$ e WT). Esta semelhança de expressão nas citocinas e na quantidade de células inflamatórias podem também justificar a falta de diferença na quantidade de mieloperoxidase (MPO) entre os grupos analisados (Fig. 13), sugerindo que a falta de MIP-1 $\alpha$ não interfere significativamente nos dois mecanismos de defesa analisados. Apesar de MIP-1 $\alpha$ fazer parte da resposta imunológica, e consequentemente no controle bacteriano, diversas citocinas e quimiocinas semelhantes que se apresentam em abundância nos tecidos periodontais inflamados, podem fazer papel redundante, não ocasionando grandes perdas na intensidade desta resposta. Isso vai de acordo com os resultados obtidos na análise da carga de A. actinomycetemcomitans nos tecidos periodontais dos camundongos, onde a ausência de MIP-1 $\alpha$ não apresentou diferenças (Fig. 11).

Assim, visto a capacidade de modulação de MIP-1 $\alpha$ e dos demais mediadores inflamatórios na resposta imunológica e a participação de quimiocinas semelhantes à MIP-1 $\alpha$ suprindo a ausência desta quimiocina na DP experimental, analisamos a cinética de expressão de quimiocinas da família CC, MIP-1 $\beta$ e RANTES, que potencialmente poderiam suprir a ausência de MIP-1 $\alpha$ De fato, ao analisarmos a expressão da quimiocina MIP-1 $\beta$ nos camundongos MIP-1 $\alpha \mathrm{KO}$ infectados verificamos uma intensa expressão e não observamos diferenças significativas entre os camundongos WT e MIP-1 $\alpha$ KO (Fig. 14a). 
Semelhantemente, a expressão de RANTES nos animais MIP-1 $\alpha$ KO apresentou-se levemente menor, porém só significativamente menor no tempo de 15 dias pós infecção, quando comparados aos WT (Fig. 14b). Assim, mostra-nos que apesar da ausência de MIP-1 $\alpha$, a expressão de quimiocinas semelhantes continua presente de forma significativa e abundante, o que sugere que estas possam desempenhar o papel de MIP-1 $\alpha$ sem déficits aparentes.

Uma estratégia válida para podermos comprovar se o efeito redundante das quimiocinas homólogas a MIP-1 $\alpha$ realmente pode suprir a ausência desta quimiocina seria a utilização de camundongos geneticamente modificados para os receptores CCR5 e/ou CCR1 ou ainda a utilização de algum bloqueador de tais receptores. Um bloqueador muito utilizado em outros modelos experimentais, como o de AR e infecção por T. cruzi, é o N-terminalmethionylated RANTES (Met-RANTES) (Proudfoot, Power et al., 1996; Plater-Zyberk, Hoogewerf et al., 1997; Proudfoot, Power et al., 2003; Medeiros, Silverio et al., 2008). O Met-RANTES tem se mostrado um bloqueador de CCR5 e CCR1 eficaz, evitando a ligação de quimiocinas como MIP-1 $\alpha$, MIP-1 $\beta$ e RANTES a seus receptores. De fato, em modelos experimentais em camundongos C57B1/6 de AR tratados com Met-RANTES a severidade da doença é significantemente menor se comparado aos camundongos não tratados (PlaterZyberk, Hoogewerf et al., 1997; Shahrara, Proudfoot et al., 2008), semelhantemente a outros modelos de estudos com patologias infecciosas (Marino, Da Silva et al., 2004; Longden, Cooke et al., 2008; Medeiros, Silverio et al., 2008). Resultados similares foram obtidos em nossos experimentos; ao tratarmos os camundongos infectados por A. actinomycetemcomitans observamos uma redução significativa na quantidade de células inflamatórias e na perda óssea alveolar (Fig. 15). Sugerindo que o bloqueio dos receptores CCR5 e CCR1 resulta em uma participação mais ampla no desenvolvimento da doença periodontal se comparados a ausência da quimiocina MIP-1 $\alpha$, já que resultados semelhantes na quantidade de células inflamatórias no tecido periodontal e na redução da perda óssea alveolar não foram encontrados nos camundongos MIP-1 $1 \alpha \mathrm{KO}$ infectados (Fig. 4). Além do mais, em experimentos preliminares de nosso laboratório com a utilização de camundongos geneticamente modificados para não expressar o receptor de quimiocina CCR5 (CCR5KO), observou-se uma diminuição na severidade da doença periodontal, apresentando não só uma diminuição da reação inflamatória local e uma redução na perda óssea alveolar, como também a diminuição da expressão de algumas citocinas e MMPs (dados não mostrados). Resultado esse, que pode ser explicado devido ao fato das quimiocinas se apresentarem em um número muito maior quando comparado ao número de receptores (Graves e Jiang, 1995; Mantovani, 1999; Murphy, 2002). Ao inibir um receptor de quimiocina qualquer, automaticamente desarmamos 
a função de uma ou mais quimiocina que se utilize de tal receptor. Assim, ao inibir ou bloquear os receptores CCR5 e CCR1, fazemos com que não só a quimiocina MIP-1 $\alpha$, mas também as quimiocinas MIP-1 $\beta$, RANTES e outras que utilizam os mesmos receptores, não desempenhem suas funções.

Obviamente, não podemos concluir que MIP-1 $\alpha$ ou sua ausência não desempenhe papel nenhum ou não tenha papel importante na defesa do organismo ou no curso das DPs em humanos. Devemos ter em vista que, apesar de tentarmos imitar a DP humana em nosso modelo de trabalho, muitas variáveis estão presentes. E que, apesar de camundongos serem considerados uma ferramenta importante e essencial para a pesquisa atual, seu organismo não tem a capacidade de resposta exatamente igual a dos seres humanos. Entretanto, apesar de considerados "resultados negativos", tendo em vista os resultados similares verificados para o desenvolvimento da DP experimental nas linhagens WT e MIP-1 $1 \alpha \mathrm{KO}$, nossos resultados demonstram que quimiocinas ligantes de um mesmo receptor podem apresentar papéis redundantes. Também é importante considerar que a exposição crônica a microrganismos no biofilme periodontal, assim como a microrganismos invasivos, como o $A$. actinomycetemcomitans, resulta em uma intensa e persistente resposta do hospedeiro, que envolve praticamente todos os subtipos de leucócitos (embora em diferentes fases da resposta) e diversas citocinas. Nesse ambiente, rico em estímulos microbianos e inflamatórios, a ocorrência de possíveis ações redundantes de mediadores da resposta imune e inflamatória é potencializada. Considerando em conjunto os resultados aqui apresentados, podemos ainda sugerir que interferir terapeuticamente no sistema quimiocinas-receptores de quimiocinas pode ser uma estratégia interessante no controle das DPs, mas que tal estratégia deveria ser focada na inibição de receptores específicos, e não de quimiocinas, resultando assim em um efeito potencialmente mais amplo. 
9.)

Conclusões 



\section{Conclusões}

1. A expressão da quimiocina MIP-1 $\alpha$, assim como a quantidade de células positivas para seus receptores (CCR5 e CCR1) estão aumentadas em camundongos submetidos ao protocolo de indução de doença periodontal pela inoculção oral de $A$. actinomycetemcomitans.

2. A coexpressão de CXCR3 pelas células CCR5+ encontradas no tecido periodontal dos camundongos infectados nos sugere uma população de células Th1. Com relação às células CCR1+, a alta expressão de F4/80 sugere que tais células sejam predominantemente macrófagos.

3. A ausência da quimiocina MIP-1 $\alpha$ não resultou em diferenças significativas no fenótipo da doença periodontal, como demonstrado pelos parâmetros quantidade de células inflamatórias nos tecidos periodontais e níveis de reabsorção óssea alveolar, migração de células CCR5+, CCR1+ e RANKL+, e modulação da expressão de citocinas, MMPs/TIMPs e RANKL/OPG, e níveis de infecção periodontal.

4. A expressão de quimiocinas homólogas à MIP-1 $\alpha$ (MIP-1 $\beta$ e RANTES), as quais utilizam os mesmos receptores (CCR5 e CCR1), apresentam uma cinética de expressão nos tecidos periodontais similar à expressão de MIP-1 $\alpha$, e não sofrem alterações significativas na ausência de MIP-1 $\alpha$; sugerindo que RANTES e MIP1 $\beta$ possam suprir a falta de MIP-1 $\alpha$ no curso da DP experimental em camundongos.

5. O tratamento de camundongos infectados por A. actinomycetemcomitans com MetRANTES, bloquedor dos receptores de MIP-1 $\alpha$ (CCR5 e CCR1), resulta em uma diminuição significativa na quantidade de células inflamatórias e na perda óssea alveolar, caracterizando o importante papel das células CCR5+ e CCR1+ no desenvolvimento da DP experimental. 


\section{Referências}

Bibliográficas 



\section{Referências}

Al-Rasheed, A., H. Scheerens, et al. Accelerated alveolar bone loss in mice lacking interleukin-10: late onset. J Periodontal Res, v.39, n.3, Jun, p.194-8. 2004.

Albiger, B., S. Dahlberg, et al. Role of the innate immune system in host defence against bacterial infections: focus on the Toll-like receptors. J Intern Med, v.261, n.6, Jun, p.511-28. 2007.

Aliberti, J. C., F. S. Machado, et al. beta-Chemokines enhance parasite uptake and promote nitric oxide-dependent microbiostatic activity in murine inflammatory macrophages infected with Trypanosoma cruzi. Infect Immun, v.67, n.9, Sep, p.4819-26. 1999.

Alpagot, T., C. Bell, et al. Longitudinal evaluation of GCF MMP-3 and TIMP-1 levels as prognostic factors for progression of periodontitis. J Clin Periodontol, v.28, n.4, Apr, p.353-9. 2001.

Assuma, R., T. Oates, et al. IL-1 and TNF antagonists inhibit the inflammatory response and bone loss in experimental periodontitis. J Immunol, v.160, n.1, Jan 1, p.403-9. 1998.

Baker, A. H., D. R. Edwards, et al. Metalloproteinase inhibitors: biological actions and therapeutic opportunities. J Cell Sci, v.115, n.Pt 19, Oct 1, p.3719-27. 2002.

Baker, P. J. The role of immune responses in bone loss during periodontal disease. Microbes Infect, v.2, n.10, Aug, p.1181-92. 2000.

Baker, P. J., M. Dixon, et al. CD4(+) T cells and the proinflammatory cytokines gamma interferon and interleukin-6 contribute to alveolar bone loss in mice. Infect Immun, v.67, n.6, Jun, p.2804-9. 1999.

Baker, P. J., R. T. Evans, et al. Oral infection with Porphyromonas gingivalis and induced alveolar bone loss in immunocompetent and severe combined immunodeficient mice. Arch Oral Biol, v.39, n.12, Dec, p.1035-40. 1994.

Bartold, P. M., R. I. Marshall, et al. Periodontitis and rheumatoid arthritis: a review. $\underline{J}$ Periodontol, v.76, n.11 Suppl, Nov, p.2066-74. 2005.

Bartova, J., Z. Kratka-Opatrna, et al. Th1 and Th2 cytokine profile in patients with early onset periodontitis and their healthy siblings. Mediators Inflamm, v.9, n.2, p.115-20. 2000.

Belkaid, Y., C. A. Piccirillo, et al. CD4+CD25+ regulatory T cells control Leishmania major persistence and immunity. Nature, v.420, n.6915, Dec 5, p.502-7. 2002.

Berglundh, T., B. Liljenberg, et al. Some cytokine profiles of T-helper cells in lesions of advanced periodontitis. J Clin Periodontol, v.29, n.8, Aug, p.705-9. 2002.

Bessis, N. e M. C. Boissier. Novel pro-inflammatory interleukins: potential therapeutic targets in rheumatoid arthritis. Joint Bone Spine, v.68, n.6, Dec, p.477-81. 2001. 
Blix, I. J. e K. Helgeland. LPS from Actinobacillus actinomycetemcomitans and production of nitric oxide in murine macrophages J774. Eur J Oral Sci, v.106, n.1, Feb, p.576-81. 1998.

Bokoch, G. M. Chemoattractant signaling and leukocyte activation. Blood, v.86, n.5, Sep 1, p.1649-60. 1995.

Calkins, C. M., D. D. Bensard, et al. L-arginine attenuates lipopolysaccharide-induced lung chemokine production. Am J Physiol Lung Cell Mol Physiol, v.280, n.3, Mar, p.L400-8. 2001.

Carpenter, S. e L. A. O'neill. How important are Toll-like receptors for antimicrobial responses? Cell Microbiol, v.9, n.8, Aug, p.1891-901. 2007.

Chakraborti, S., M. Mandal, et al. Regulation of matrix metalloproteinases: an overview. Mol Cell Biochem, v.253, n.1-2, Nov, p.269-85. 2003.

Chapple, C. C., M. Srivastava, et al. Failure of macrophage activation in destructive periodontal disease. J Pathol, v.186, n.3, Nov, p.281-6. 1998.

Cheng, X., M. Kinosaki, et al. The TNF receptor superfamily: role in immune inflammation and bone formation. Immunol Res, v.27, n.2-3, p.287-94. 2003.

Chiu, B. C., V. R. Stolberg, et al. Mononuclear phagocyte-derived interleukin-10 suppresses the innate pulmonary granuloma cytokine response in aged mice. Am J Pathol, v.171, n.3, Sep, p.829-37. 2007.

Choi, S. J., J. C. Cruz, et al. Macrophage inflammatory protein 1-alpha is a potential osteoclast stimulatory factor in multiple myeloma. Blood, v.96, n.2, Jul 15, p.671-5. 2000.

Craig, R. G., J. K. Yip, et al. Relationship of destructive periodontal disease to the acutephase response. J Periodontol, v.74, n.7, Jul, p.1007-16. 2003.

Crotti, T., M. D. Smith, et al. Receptor activator NF kappaB ligand (RANKL) and osteoprotegerin (OPG) protein expression in periodontitis. J Periodontal Res, v.38, n.4, Aug, p.380-7. 2003.

Cutler, C. W., T. W. Stanford, et al. Clinical benefits of oral irrigation for periodontitis are related to reduction of pro-inflammatory cytokine levels and plaque. J Clin Periodontol, v.27, n.2, Feb, p.134-43. 2000.

Dean, D. D., J. Martel-Pelletier, et al. Evidence for metalloproteinase and metalloproteinase inhibitor imbalance in human osteoarthritic cartilage. J Clin Invest, v.84, n.2, Aug, p.678-85. 1989.

Delima, A. J., T. Oates, et al. Soluble antagonists to interleukin-1 (IL-1) and tumor necrosis factor (TNF) inhibits loss of tissue attachment in experimental periodontitis. $\underline{\mathrm{J} \text { Clin }}$ Periodontol, v.28, n.3, Mar, p.233-40. 2001.

Dinarello, C. A. The pathophysiology of the pro-inflammatory cytokines. Biotherapy, v.2, n.3, p.189-91. 1990. 
Proinflammatory cytokines. Chest, v.118, n.2, Aug, p.503-8. 2000.

Eastcott, J. W., K. Yamashita, et al. Adoptive transfer of cloned T helper cells ameliorates periodontal disease in nude rats. Oral Microbiol Immunol, v.9, n.5, Oct, p.284-9. 1994.

Ebersole, J. L. e M. A. Taubman. The protective nature of host responses in periodontal diseases. Periodontol 2000, v.5, Jun, p.112-41. 1994.

Ejeil, A. L., S. Igondjo-Tchen, et al. Expression of matrix metalloproteinases (MMPs) and tissue inhibitors of metalloproteinases (TIMPs) in healthy and diseased human gingiva. $\underline{\mathrm{J}}$ Periodontol, v.74, n.2, Feb, p.188-95. 2003.

Emingil, G., G. Atilla, et al. The effect of adjunctive low-dose doxycycline therapy on clinical parameters and gingival crevicular fluid matrix metalloproteinase-8 levels in chronic periodontitis. J Periodontol, v.75, n.1, Jan, p.106-15. 2004.

Engebretson, S. P., I. B. Lamster, et al. The influence of interleukin gene polymorphism on expression of interleukin-1beta and tumor necrosis factor-alpha in periodontal tissue and gingival crevicular fluid. J Periodontol, v.70, n.6, Jun, p.567-73. 1999.

Fakhrzadeh, L., J. D. Laskin, et al. Deficiency in inducible nitric oxide synthase protects mice from ozone-induced lung inflammation and tissue injury. Am J Respir Cell Mol Biol, v.26, n.4, Apr, p.413-9. 2002.

Fassmann, A., L. I. Holla, et al. Polymorphisms in the +252(A/G) lymphotoxin-alpha and the -308(A/G) tumor necrosis factor-alpha genes and susceptibility to chronic periodontitis in a Czech population. J Periodontal Res, v.38, n.4, Aug, p.394-9. 2003.

Ferrante, A. Activation of neutrophils by interleukins-1 and -2 and tumor necrosis factors. Immunol Ser, v.57, p.417-36. 1992.

Fives-Taylor, P., D. Meyer, et al. Characteristics of Actinobacillus actinomycetemcomitans invasion of and adhesion to cultured epithelial cells. Adv Dent Res, v.9, n.1, Feb, p.55-62. 1995.

Fives-Taylor, P. M., D. H. Meyer, et al. Virulence factors of Actinobacillus actinomycetemcomitans. Periodontol 2000, v.20, Jun, p.136-67. 1999.

Folwaczny, M., J. Glas, et al. Prevalence of the chemokine receptor CCR5-Delta32 gene mutation in periodontal disease. Clin Immunol, v.109, n.3, Dec, p.325-9. 2003.

Fukada, S. Y., T. A. Silva, et al. iNOS-derived nitric oxide modulates infection-stimulated bone loss. J Dent Res, v.87, n.12, Dec, p.1155-9. 2008.

Gale, L. M. e S. R. Mccoll. Chemokines: extracellular messengers for all occasions?

Bioessays, v.21, n.1, Jan, p.17-28. 1999. 
Gamonal, J., A. Acevedo, et al. Characterization of cellular infiltrate, detection of chemokine receptor CCR5 and interleukin-8 and RANTES chemokines in adult periodontitis. $\underline{J}$ Periodontal Res, v.36, n.3, Jun, p.194-203. 2001.

Gamonal, J., A. Bascones, et al. Chemokine RANTES in gingival crevicular fluid of adult patients with periodontitis. J Clin Periodontol, v.27, n.9, Sep, p.675-81. 2000.

Garlet, G. P., M. J. Avila-Campos, et al. Actinobacillus actinomycetemcomitans-induced periodontal disease in mice: patterns of cytokine, chemokine, and chemokine receptor expression and leukocyte migration. Microbes Infect, v.7, n.4, Apr, p.738-47. 2005.

Garlet, G. P., C. R. Cardoso, et al. The dual role of p55 tumour necrosis factor-alpha receptor in Actinobacillus actinomycetemcomitans-induced experimental periodontitis: host protection and tissue destruction. Clin Exp Immunol, v.147, n.1, Jan, p.128-38. 2007.

. The essential role of IFN-gamma in the control of lethal Aggregatibacter actinomycetemcomitans infection in mice. Microbes Infect, v.10, n.5, Apr, p.489-96. 2008.

. Cytokine pattern determines the progression of experimental periodontal disease induced by Actinobacillus actinomycetemcomitans through the modulation of MMPs, RANKL, and their physiological inhibitors. Oral Microbiol Immunol, v.21, n.1, Feb, p.12-20. 2006.

Garlet, G. P., W. Martins, Jr., et al. Patterns of chemokines and chemokine receptors expression in different forms of human periodontal disease. J Periodontal Res, v.38, n.2, Apr, p.210-7. 2003.

. Matrix metalloproteinases, their physiological inhibitors and osteoclast factors are differentially regulated by the cytokine profile in human periodontal disease. $\mathrm{J}$ Clin Periodontol, v.31, n.8, Aug, p.671-9. 2004.

Gemmell, E., C. L. Carter, et al. Chemokines in human periodontal disease tissues. Clin Exp Immunol, v.125, n.1, Jul, p.134-41. 2001.

Gemmell, E., R. I. Marshall, et al. Cytokines and prostaglandins in immune homeostasis and tissue destruction in periodontal disease. Periodontol 2000, v.14, Jun, p.112-43. 1997.

Gemmell, E. e G. J. Seymour. Cytokine profiles of cells extracted from humans with periodontal diseases. J Dent Res, v.77, n.1, Jan, p.16-26. 1998.

Immunoregulatory control of Th1/Th2 cytokine profiles in periodontal disease.

Periodontol 2000, v.35, p.21-41. 2004.

Genco, C. A., T. Van Dyke, et al. Animal models for Porphyromonas gingivalis-mediated periodontal disease. Trends Microbiol, v.6, n.11, Nov, p.444-9. 1998.

Giustizieri, M. L., C. Albanesi, et al. Nitric oxide donors suppress chemokine production by keratinocytes in vitro and in vivo. Am J Pathol, v.161, n.4, Oct, p.1409-18. 2002. 
Goldring, M. B. Osteoarthritis and cartilage: the role of cytokines. Curr Rheumatol Rep, v.2, n.6, Dec, p.459-65. 2000.

Golub, L. M., T. F. Mcnamara, et al. Adjunctive treatment with subantimicrobial doses of doxycycline: effects on gingival fluid collagenase activity and attachment loss in adult periodontitis. J Clin Periodontol, v.28, n.2, Feb, p.146-56. 2001.

Gorska, R., H. Gregorek, et al. Relationship between clinical parameters and cytokine profiles in inflamed gingival tissue and serum samples from patients with chronic periodontitis. $\underline{J}$ Clin Periodontol, v.30, n.12, Dec, p.1046-52. 2003.

Goutoudi, P., E. Diza, et al. Effect of periodontal therapy on crevicular fluid interleukin-1beta and interleukin-10 levels in chronic periodontitis. J Dent, v.32, n.7, Sep, p.511-20. 2004.

Graves, D. T., C. P. Chen, et al. Interleukin-1 receptor signaling rather than that of tumor necrosis factor is critical in protecting the host from the severe consequences of a polymicrobe anaerobic infection. Infect Immun, v.68, n.8, Aug, p.4746-51. 2000.

Graves, D. T. e D. Cochran. The contribution of interleukin-1 and tumor necrosis factor to periodontal tissue destruction. J Periodontol, v.74, n.3, Mar, p.391-401. 2003.

Graves, D. T., A. J. Delima, et al. Interleukin-1 and tumor necrosis factor antagonists inhibit the progression of inflammatory cell infiltration toward alveolar bone in experimental periodontitis. J Periodontol, v.69, n.12, Dec, p.1419-25. 1998.

Graves, D. T. e Y. Jiang. Chemokines, a family of chemotactic cytokines. $\underline{\text { Crit Rev Oral Biol }}$ Med, v.6, n.2, p.109-18. 1995.

Hamilton, T. A., Y. Ohmori, et al. Regulation of macrophage gene expression by pro- and anti-inflammatory cytokines. Pathobiology, v.67, n.5-6, p.241-4. 1999.

Han, J. H., S. J. Choi, et al. Macrophage inflammatory protein-1alpha is an osteoclastogenic factor in myeloma that is independent of receptor activator of nuclear factor kappaB ligand. Blood, v.97, n.11, Jun 1, p.3349-53. 2001.

Haubek, D., O. K. Ennibi, et al. The highly leukotoxic JP2 clone of Actinobacillus actinomycetemcomitans and progression of periodontal attachment loss. J Dent Res, v.83, n.10, Oct, p.767-70. 2004.

Henderson, B. e S. P. Nair. Hard labour: bacterial infection of the skeleton. Trends Microbiol, v.11, n.12, Dec, p.570-7. 2003.

Henderson, B., M. Wilson, et al. Actinobacillus actinomycetemcomitans. J Med Microbiol, v.51, n.12, Dec, p.1013-20. 2002.

Horton, M. A., E. L. Dorey, et al. Modulation of vitronectin receptor-mediated osteoclast adhesion by Arg-Gly-Asp peptide analogs: a structure-function analysis. $\underline{\mathrm{J} \text { Bone Miner Res, }}$ v.8, n.2, Feb, p.239-47. 1993. 
Hsieh, C. H., M. Frink, et al. The role of MIP-1 alpha in the development of systemic inflammatory response and organ injury following trauma hemorrhage. J Immunol, v.181, n.4, Aug 15, p.2806-12. 2008.

Iredale, J. P. Tissue inhibitors of metalloproteinases in liver fibrosis. Int J Biochem Cell Biol, v.29, n.1, Jan, p.43-54. 1997.

Iwasaki, Y., Y. Hara, et al. Differential expression of IFN-gamma, IL-4, IL-10, and IL-1beta mRNAs in decalcified tissue sections of mouse lipopolysaccharide-induced periodontitis mandibles assessed by in situ hybridization. Histochem Cell Biol, v.109, n.4, Apr, p.339-47. 1998.

Jiang, Y., L. Magli, et al. Bacterium-dependent induction of cytokines in mononuclear cells and their pathologic consequences in vivo. Infect Immun, v.67, n.5, May, p.2125-30. 1999.

Jotwani, R., M. Muthukuru, et al. Increase in HIV receptors/co-receptors/alpha-defensins in inflamed human gingiva. J Dent Res, v.83, n.5, May, p.371-7. 2004.

Kabashima, H., M. Yoneda, et al. The presence of chemokine receptor (CCR5, CXCR3, CCR3)-positive cells and chemokine (MCP1, MIP-1alpha, MIP-1beta, IP-10)-positive cells in human periapical granulomas. Cytokine, v.16, n.2, Oct 21, p.62-6. 2001.

. The presence of chemokine (MCP-1, MIP-1alpha, MIP-1beta, IP-10, RANTES)positive cells and chemokine receptor (CCR5, CXCR3)-positive cells in inflamed human gingival tissues. Cytokine, v.20, n.2, Oct 21, p.70-7. 2002.

Karpus, W. J. e K. J. Kennedy. MIP-1alpha and MCP-1 differentially regulate acute and relapsing autoimmune encephalomyelitis as well as Th1/Th2 lymphocyte differentiation. $\underline{J}$ Leukoc Biol, v.62, n.5, Nov, p.681-7. 1997.

Karpus, W. J., N. W. Lukacs, et al. Differential CC chemokine-induced enhancement of T helper cell cytokine production. J Immunol, v.158, n.9, May 1, p.4129-36. 1997.

Katagiri, T. e N. Takahashi. Regulatory mechanisms of osteoblast and osteoclast differentiation. Oral Dis, v.8, n.3, May, p.147-59. 2002.

Kawai, T., R. Eisen-Lev, et al. Requirement of B7 costimulation for Th1-mediated inflammatory bone resorption in experimental periodontal disease. J Immunol, v.164, n.4, Feb 15, p.2102-9. 2000.

Kiili, M., S. W. Cox, et al. Collagenase-2 (MMP-8) and collagenase-3 (MMP-13) in adult periodontitis: molecular forms and levels in gingival crevicular fluid and immunolocalisation in gingival tissue. J Clin Periodontol, v.29, n.3, Mar, p.224-32. 2002.

Kikkert, R., M. L. Laine, et al. Activation of toll-like receptors 2 and 4 by gram-negative periodontal bacteria. Oral Microbiol Immunol, v.22, n.3, Jun, p.145-51. 2007.

Kim, H. K., H. R. Park, et al. Induction of RANTES and CCR5 through NF-kappaB activation via MAPK pathway in aged rat gingival tissues. Biotechnol Lett, v.28, n.1, Jan, p.17-23. 2006. 
Kim, M. S., C. J. Day, et al. MCP-1 is induced by receptor activator of nuclear factor\{kappa\}B ligand, promotes human osteoclast fusion, and rescues granulocyte macrophage colony-stimulating factor suppression of osteoclast formation. J Biol Chem, v.280, n.16, Apr 22, p.16163-9. 2005.

Kinane, D. F. e R. Attstrom. Advances in the pathogenesis of periodontitis. Group B consensus report of the fifth European Workshop in Periodontology. J Clin Periodontol, v.32 Suppl 6, p.130-1. 2005.

Kinane, D. F., D. R. Demuth, et al. Human variability in innate immunity. Periodontol 2000, v.45, p.14-34. 2007.

Kinane, D. F. e D. F. Lappin. Clinical, pathological and immunological aspects of periodontal disease. Acta Odontol Scand, v.59, n.3, Jun, p.154-60. 2001.

Kobayashi, H., T. Nagasawa, et al. Individual diversities in interferon gamma production by human peripheral blood mononuclear cells stimulated with periodontopathic bacteria. $\underline{J}$ Periodontal Res, v.35, n.6, Dec, p.319-28. 2000.

Kubota, T., T. Nomura, et al. Expression of mRNA for matrix metalloproteinases and tissue inhibitors of metalloproteinases in periodontitis-affected human gingival tissue. Arch Oral Biol, v.41, n.3, Mar, p.253-62. 1996.

Kut-Lasserre, C., C. C. Miller, et al. Effect of avocado and soybean unsaponifiables on gelatinase A (MMP-2), stromelysin 1 (MMP-3), and tissue inhibitors of matrix metalloproteinase (TIMP- 1 and TIMP-2) secretion by human fibroblasts in culture. $\underline{\mathrm{J}}$ Periodontol, v.72, n.12, Dec, p.1685-94. 2001.

Kwak, H. B., H. Ha, et al. Reciprocal cross-talk between RANKL and interferon-gammainducible protein 10 is responsible for bone-erosive experimental arthritis. Arthritis Rheum, v.58, n.5, May, p.1332-42. 2008.

Lappin, D. F., M. Kjeldsen, et al. Inducible nitric oxide synthase expression in periodontitis. $\underline{\mathrm{J}}$ Periodontal Res, v.35, n.6, Dec, p.369-73. 2000.

Lappin, D. F., C. P. Macleod, et al. Anti-inflammatory cytokine IL-10 and T cell cytokine profile in periodontitis granulation tissue. Clin Exp Immunol, v.123, n.2, Feb, p.294-300. 2001.

Lee, J. E., H. H. Shin, et al. Stimulation of osteoclastogenesis by enhanced levels of MIP1alpha in BALB/c mice in vitro. Exp Hematol, v.35, n.7, Jul, p.1100-8. 2007.

Li, Y. Y., C. F. Mctiernan, et al. Interplay of matrix metalloproteinases, tissue inhibitors of metalloproteinases and their regulators in cardiac matrix remodeling. Cardiovasc Res, v.46, n.2, May, p.214-24. 2000.

Lindell, D. M., T. J. Standiford, et al. Macrophage inflammatory protein 1alpha/CCL3 is required for clearance of an acute Klebsiella pneumoniae pulmonary infection. Infect Immun, v.69, n.10, Oct, p.6364-9. 2001. 
Liu, D., J. K. Xu, et al. Expression of RANKL and OPG mRNA in periodontal disease: possible involvement in bone destruction. Int J Mol Med, v.11, n.1, Jan, p.17-21. 2003.

Loesche, W. J. Bacterial mediators in periodontal disease. Clin Infect Dis, v.16 Suppl 4, Jun, p.S203-10. 1993.

Longden, J., E. L. Cooke, et al. Effect of CCR5 receptor antagonists on endocytosis of the human CCR5 receptor in CHO-K1 cells. Br J Pharmacol, v.153, n.7, Apr, p.1513-27. 2008.

Lukacs, N. W., C. Hogaboam, et al. Chemokines: function, regulation and alteration of inflammatory responses. Chem Immunol, v.72, p.102-20. 1999.

Luther, S. A. e J. G. Cyster. Chemokines as regulators of T cell differentiation. Nat Immunol, v.2, n.2, Feb, p.102-7. 2001.

Machado, F. S., J. T. Souto, et al. Nitric oxide synthase-2 modulates chemokine production by Trypanosoma cruzi-infected cardiac myocytes. Microbes Infect, v.10, n.14-15, Nov-Dec, p.1558-66. 2008.

Mantovani, A. The chemokine system: redundancy for robust outputs. Immunol Today, v.20, n.6, Jun, p.254-7. 1999.

Marino, A. P., A. Da Silva, et al. Regulated on activation, normal T cell expressed and secreted (RANTES) antagonist (Met-RANTES) controls the early phase of Trypanosoma cruzi-elicited myocarditis. Circulation, v.110, n.11, Sep 14, p.1443-9. 2004.

Martelli-Junior, H., P. Cotrim, et al. Effect of transforming growth factor-beta1, interleukin-6, and interferon-gamma on the expression of type I collagen, heat shock protein 47, matrix metalloproteinase (MMP)-1 and MMP-2 by fibroblasts from normal gingiva and hereditary gingival fibromatosis. J Periodontol, v.74, n.3, Mar, p.296-306. 2003.

Matsui, M., J. Weaver, et al. Treatment of experimental autoimmune encephalomyelitis with the chemokine receptor antagonist Met-RANTES. J Neuroimmunol, v.128, n.1-2, Jul, p.1622. 2002.

Matsuki, Y., T. Yamamoto, et al. Detection of inflammatory cytokine messenger RNA (mRNA)-expressing cells in human inflamed gingiva by combined in situ hybridization and immunohistochemistry. Immunology, v.76, n.1, May, p.42-7. 1992.

Maurer, M. e E. Von Stebut. Macrophage inflammatory protein-1. Int J Biochem Cell Biol, v.36, n.10, Oct, p.1882-6. 2004.

Medeiros, G. A., J. C. Silverio, et al. Treatment of chronically Trypanosoma cruzi-infected mice with a CCR1/CCR5 antagonist (Met-RANTES) results in amelioration of cardiac tissue damage. Microbes Infect, Dec 7. 2008.

Menezes, R., T. P. Garlet, et al. The potential role of suppressors of cytokine signaling in the attenuation of inflammatory reaction and alveolar bone loss associated with apical periodontitis. J Endod, v.34, n.12, Dec, p.1480-4. 2008. 
Mercado, F. B., R. I. Marshall, et al. Inter-relationships between rheumatoid arthritis and periodontal disease. A review. J Clin Periodontol, v.30, n.9, Sep, p.761-72. 2003.

. Relationship between rheumatoid arthritis and periodontitis. J Periodontol, v.72, n.6, Jun, p.779-87. 2001.

Mertz, P. M., D. L. Dewitt, et al. Interleukin 10 suppression of monocyte prostaglandin H synthase-2. Mechanism of inhibition of prostaglandin-dependent matrix metalloproteinase production. J Biol Chem, v.269, n.33, Aug 19, p.21322-9. 1994.

Miranda, L. A., R. G. Fischer, et al. Periodontal conditions in patients with juvenile idiopathic arthritis. J Clin Periodontol, v.30, n.11, Nov, p.969-74. 2003.

Mitchell, J. A., M. J. Paul-Clark, et al. Critical role of toll-like receptors and nucleotide oligomerisation domain in the regulation of health and disease. J Endocrinol, v.193, n.3, Jun, p.323-30. 2007.

Mittrucker, H. W. e S. H. Kaufmann. Mini-review: regulatory T cells and infection: suppression revisited. Eur J Immunol, v.34, n.2, Feb, p.306-12. 2004.

Mochizuki, S., M. Kobayashi, et al. Gamma-interferon enhances expression of CD14/MyD88 and subsequent responsiveness to lipopolysaccharide from Actinobacillus actinomycetemcomitans in human gingival fibroblasts. J Periodontal Res, v.39, n.5, Oct, p.333-43. 2004.

Mogi, M., J. Otogoto, et al. Differential expression of RANKL and osteoprotegerin in gingival crevicular fluid of patients with periodontitis. J Dent Res, v.83, n.2, Feb, p.166-9. 2004.

Mombelli, A., F. Casagni, et al. Can presence or absence of periodontal pathogens distinguish between subjects with chronic and aggressive periodontitis? A systematic review. J Clin Periodontol, v.29 Suppl 3, p.10-21; discussion 37-8. 2002.

Montecucco, F., S. Steffens, et al. Tumor necrosis factor-alpha (TNF-alpha) induces integrin CD11b/CD18 (Mac-1) up-regulation and migration to the CC chemokine CCL3 (MIP-1alpha) on human neutrophils through defined signalling pathways. Cell Signal, v.20, n.3, Mar, p.55768. 2008.

Moore, K. W., A. O'garra, et al. Interleukin-10. Annu Rev Immunol, v.11, p.165-90. 1993.

Moriyama, H., T. Ukai, et al. Interferon-gamma production changes in parallel with bacterial lipopolysaccharide induced bone resorption in mice: an immunohistometrical study. Calcif Tissue Int, v.71, n.1, Jul, p.53-8. 2002.

Murdoch, C. e A. Finn. Chemokine receptors and their role in inflammation and infectious diseases. Blood, v.95, n.10, May 15, p.3032-43. 2000.

Murphy, G., A. J. Docherty, et al. Metalloproteinases and tissue damage. Br J Rheumatol, v.30 Suppl 1, p.25-31. 1991. 
Murphy, P. M. International Union of Pharmacology. XXX. Update on chemokine receptor nomenclature. Pharmacol Rev, v.54, n.2, Jun, p.227-9. 2002.

Nakashima, T. e H. Takayanagi. The dynamic interplay between osteoclasts and the immune system. Arch Biochem Biophys, v.473, n.2, May 15, p.166-71. 2008.

Nawrocki, B., M. Polette, et al. Expression of matrix metalloproteinases and their inhibitors in human bronchopulmonary carcinomas: quantificative and morphological analyses. Int $\mathrm{J}$ Cancer, v.72, n.4, Aug 7, p.556-64. 1997.

O'garra, A., L. M. Mcevoy, et al. T-cell subsets: chemokine receptors guide the way. Curr Biol, v.8, n.18, Sep 10, p.R646-9. 1998.

Oba, Y., J. W. Lee, et al. MIP-1alpha utilizes both CCR1 and CCR5 to induce osteoclast formation and increase adhesion of myeloma cells to marrow stromal cells. Exp Hematol, v.33, n.3, Mar, p.272-8. 2005.

Offenbacher, S., B. M. Odle, et al. Changes in cyclooxygenase metabolites in experimental periodontitis in Macaca mulatta. J Periodontal Res, v.24, n.1, Jan, p.63-74. 1989.

Parsons, C. J., B. U. Bradford, et al. Antifibrotic effects of a tissue inhibitor of metalloproteinase-1 antibody on established liver fibrosis in rats. Hepatology, v.40, n.5, Nov, p.1106-15. 2004.

Pestka, S., C. D. Krause, et al. Interleukin-10 and related cytokines and receptors. Annu Rev Immunol, v.22, p.929-79. 2004.

Petit, M. D., E. Hovenkamp, et al. Phenotypical and functional analysis of T cells in periodontitis. J Periodontal Res, v.36, n.4, Aug, p.214-20. 2001.

Pfizenmaier, K., H. Wajant, et al. Tumor necrosis factors in 1996. Cytokine Growth Factor Rev, v.7, n.3, Oct, p.271-7. 1996.

Plater-Zyberk, C., A. J. Hoogewerf, et al. Effect of a CC chemokine receptor antagonist on collagen induced arthritis in DBA/1 mice. Immunol Lett, v.57, n.1-3, Jun 1, p.117-20. 1997.

Proudfoot, A. E., C. A. Power, et al. Extension of recombinant human RANTES by the retention of the initiating methionine produces a potent antagonist. J Biol Chem, v.271, n.5, Feb 2, p.2599-603. 1996.

. Strategies for chemokine antagonists as therapeutics. Semin Immunol, v.15, n.1, Feb, p.57-65. 2003.

Ramamurthy, N. S., J. W. Xu, et al. Inhibition of alveolar bone loss by matrix metalloproteinase inhibitors in experimental periodontal disease. J Periodontal Res, v.37, n.1, Feb, p.1-7. 2002. 
Reddy, M. S., N. C. Geurs, et al. Periodontal host modulation with antiproteinase, antiinflammatory, and bone-sparing agents. A systematic review. Ann Periodontol, v.8, n.1, Dec, p.12-37. 2003.

Reynolds, J. J. Collagenases and tissue inhibitors of metalloproteinases: a functional balance in tissue degradation. Oral Dis, v.2, n.1, Mar, p.70-6. 1996.

Ridderstad, A., M. Abedi-Valugerdi, et al. Cytokines in rheumatoid arthritis. Ann Med, v.23, n.3, Aug, p.219-23. 1991.

Roberts, F. A., K. A. Mccaffery, et al. Profile of cytokine mRNA expression in chronic adult periodontitis. J Dent Res, v.76, n.12, Dec, p.1833-9. 1997.

Robinson, S. C., K. A. Scott, et al. Chemokine stimulation of monocyte matrix metalloproteinase-9 requires endogenous TNF-alpha. Eur J Immunol, v.32, n.2, Feb, p.40412. 2002.

Rodan, G. A. e T. J. Martin. Therapeutic approaches to bone diseases. Science, v.289, n.5484, Sep 1, p.1508-14. 2000.

Rollins, B. J. Chemokines. Blood, v.90, n.3, Aug 1, p.909-28. 1997.

Romas, E., M. T. Gillespie, et al. Involvement of receptor activator of NFkappaB ligand and tumor necrosis factor-alpha in bone destruction in rheumatoid arthritis. Bone, v.30, n.2, Feb, p.340-6. 2002.

Roodman, G. D. e S. J. Choi. MIP-1 alpha and myeloma bone disease. Cancer Treat Res, v.118, p.83-100. 2004.

Rossi, D. e A. Zlotnik. The biology of chemokines and their receptors. Annu Rev Immunol, v.18, p.217-42. 2000.

Rossomando, E. F., J. E. Kennedy, et al. Tumour necrosis factor alpha in gingival crevicular fluid as a possible indicator of periodontal disease in humans. Arch Oral Biol, v.35, n.6, p.431-4. 1990.

Rousset, F., E. Garcia, et al. Interleukin 10 is a potent growth and differentiation factor for activated human B lymphocytes. Proc Natl Acad Sci U S A, v.89, n.5, Mar 1, p.1890-3. 1992.

Ryu, O. H., S. J. Choi, et al. Gingival epithelial cell expression of macrophage inflammatory protein-1alpha induced by interleukin-1beta and lipopolysaccharide. J Periodontol, v.78, n.8, Aug, p.1627-34. 2007.

Saidenberg-Kermanac'h, N., M. Cohen-Solal, et al. Role for osteoprotegerin in rheumatoid inflammation. Joint Bone Spine, v.71, n.1, Jan, p.9-13. 2004.

Saito, A., Y. Hosaka, et al. Significance of serum antibody against surface antigens of Actinobacillus actinomycetemcomitans in patients with adult periodontitis. Oral Microbiol Immunol, v.8, n.3, Jun, p.146-53. 1993. 
Sakaguchi, S. Naturally arising CD4+ regulatory t cells for immunologic self-tolerance and negative control of immune responses. Annu Rev Immunol, v.22, p.531-62. 2004.

Salvi, G. E., C. E. Brown, et al. Inflammatory mediators of the terminal dentition in adult and early onset periodontitis. J Periodontal Res, v.33, n.4, May, p.212-25. 1998.

Sasaki, H., L. Hou, et al. IL-10, but not IL-4, suppresses infection-stimulated bone resorption in vivo. $\mathrm{J}$ Immunol, v.165, n.7, Oct 1, p.3626-30. 2000.

Sasaki, H., Y. Okamatsu, et al. The interleukin-10 knockout mouse is highly susceptible to Porphyromonas gingivalis-induced alveolar bone loss. J Periodontal Res, v.39, n.6, Dec, p.432-41. 2004.

Sato, N., W. A. Kuziel, et al. Defects in the generation of IFN-gamma are overcome to control infection with Leishmania donovani in CC chemokine receptor (CCR) 5-, macrophage inflammatory protein-1 alpha-, or CCR2-deficient mice. J Immunol, v.163, n.10, Nov 15, p.5519-25. 1999.

Saunders, J. e C. M. Tarby. Opportunities for novel therapeutic agents acting at chemokine receptors. Drug Discov Today, v.4, n.2, Feb, p.80-92. 1999.

Scheven, B. A., J. S. Milne, et al. Macrophage-inflammatory protein-1alpha regulates preosteoclast differentiation in vitro. Biochem Biophys Res Commun, v.254, n.3, Jan 27, p.773-8. 1999.

Seguier, S., B. Gogly, et al. Is collagen breakdown during periodontitis linked to inflammatory cells and expression of matrix metalloproteinases and tissue inhibitors of metalloproteinases in human gingival tissue? J Periodontol, v.72, n.10, Oct, p.1398-406. 2001.

Sezer, O., U. Heider, et al. RANK ligand and osteoprotegerin in myeloma bone disease. Blood, v.101, n.6, Mar 15, p.2094-8. 2003.

Shahrara, S., A. E. Proudfoot, et al. Inhibition of monocyte chemoattractant protein-1 ameliorates rat adjuvant-induced arthritis. J Immunol, v.180, n.5, Mar 1, p.3447-56. 2008.

Shanley, T. P., B. Zhao, et al. Role of nitric oxide in acute lung inflammation: lessons learned from the inducible nitric oxide synthase knockout mouse. Crit Care Med, v.30, n.9, Sep, p.1960-8. 2002.

Sigusch, B., G. Klinger, et al. Early-onset and adult periodontitis associated with abnormal cytokine production by activated T lymphocytes. J Periodontol, v.69, n.10, Oct, p.1098-104. 1998.

Silva, T. A., G. P. Garlet, et al. Differential expression of chemokines and chemokine receptors in inflammatory periapical diseases. Oral Microbiol Immunol, v.20, n.5, Oct, p.3106. 2005. 
Soga, Y., F. Nishimura, et al. Tumor necrosis factor-alpha gene (TNF-alpha) -1031/-863, 857 single-nucleotide polymorphisms (SNPs) are associated with severe adult periodontitis in Japanese. J Clin Periodontol, v.30, n.6, Jun, p.524-31. 2003.

Sosroseno, W., P. S. Bird, et al. Nitric oxide production by a human osteoblast cell line stimulated with Aggregatibacter actinomycetemcomitans lipopolysaccharide. Oral Microbiol Immunol, v.24, n.1, Feb, p.50-5. 2009.

Souza, M. H., H. P. Lemos, et al. Gastric damage and granulocyte infiltration induced by indomethacin in tumour necrosis factor receptor 1 (TNF-R1) or inducible nitric oxide synthase (iNOS) deficient mice. Gut, v.53, n.6, Jun, p.791-6. 2004.

Sozzani, S., M. Locati, et al. Chemokines: a superfamily of chemotactic cytokines. Int J Clin Lab Res, v.26, n.2, p.69-82. 1996.

Spitznagel, J., Jr., E. Kraig, et al. Regulation of leukotoxin in leukotoxic and nonleukotoxic strains of Actinobacillus actinomycetemcomitans. Infect Immun, v.59, n.4, Apr, p.1394-401. 1991.

Stashenko, P., F. E. Dewhirst, et al. Synergistic interactions between interleukin 1, tumor necrosis factor, and lymphotoxin in bone resorption. J Immunol, v.138, n.5, Mar 1, p.1464-8. 1987.

Stashenko, P., J. J. Jandinski, et al. Tissue levels of bone resorptive cytokines in periodontal disease. J Periodontol, v.62, n.8, Aug, p.504-9. 1991.

Suematsu, A. e H. Takayanagi. [Interplay between the immune and skeletal cells in the regulation of inflammatory bone destruction]. Nihon Rinsho Meneki Gakkai Kaishi, v.30, n.1, Feb, p.22-8. 2007.

Tak, P. P., P. C. Taylor, et al. Decrease in cellularity and expression of adhesion molecules by anti-tumor necrosis factor alpha monoclonal antibody treatment in patients with rheumatoid arthritis. Arthritis Rheum, v.39, n.7, Jul, p.1077-81. 1996.

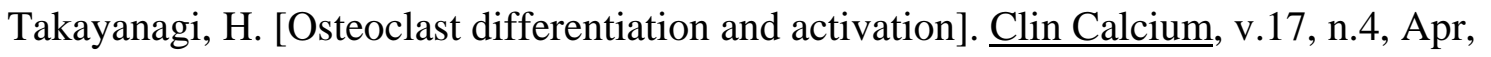
p.484-92. 2007.

Takayanagi, H., K. Sato, et al. Interplay between interferon and other cytokine systems in bone metabolism. Immunol Rev, v.208, Dec, p.181-93. 2005.

Takeichi, O., J. Haber, et al. Cytokine profiles of T-lymphocytes from gingival tissues with pathological pocketing. J Dent Res, v.79, n.8, Aug, p.1548-55. 2000.

Talvani, A., G. Santana, et al. Experimental Trypanosoma cruzi infection in plateletactivating factor receptor-deficient mice. Microbes Infect, v.5, n.9, Jul, p.789-96. 2003.

Tamai, R., T. Sakuta, et al. Human gingival CD14(+) fibroblasts primed with gamma interferon increase production of interleukin-8 in response to lipopolysaccharide through upregulation of membrane CD14 and MyD88 mRNA expression. Infect Immun, v.70, n.3, Mar, p.1272-8. 2002. 
Teitelbaum, S. L. Bone resorption by osteoclasts. Science, v.289, n.5484, Sep 1, p.1504-8. 2000.

Teixeira, M. M., R. T. Gazzinelli, et al. Chemokines, inflammation and Trypanosoma cruzi infection. Trends Parasitol, v.18, n.6, Jun, p.262-5. 2002.

Teng, Y. T. The role of acquired immunity and periodontal disease progression. Crit Rev Oral Biol Med, v.14, n.4, p.237-52. 2003.

Teng, Y. T., H. Nguyen, et al. Functional human T-cell immunity and osteoprotegerin ligand control alveolar bone destruction in periodontal infection. J Clin Invest, v.106, n.6, Sep, p.R59-67. 2000.

Tervahartiala, T., E. Pirila, et al. The in vivo expression of the collagenolytic matrix metalloproteinases (MMP-2, -8, -13, and -14) and matrilysin (MMP-7) in adult and localized juvenile periodontitis. J Dent Res, v.79, n.12, Dec, p.1969-77. 2000.

Theoleyre, S., Y. Wittrant, et al. The molecular triad OPG/RANK/RANKL: involvement in the orchestration of pathophysiological bone remodeling. Cytokine Growth Factor Rev, v.15, n.6, Dec, p.457-75. 2004.

Tonetti, M. S., M. A. Imboden, et al. Localized expression of mRNA for phagocyte-specific chemotactic cytokines in human periodontal infections. Infect Immun, v.62, n.9, Sep, p.400514. 1994.

Trombone, A. P., C. R. Cardoso, et al. Tumor necrosis factor-alpha -308G/A single nucleotide polymorphism and red-complex periodontopathogens are independently associated with increased levels of tumor necrosis factor-alpha in diseased periodontal tissues. $\underline{\mathrm{J}}$ Periodontal Res, Dec 11. 2008.

Tsubaki, M., C. Kato, et al. Macrophage inflammatory protein-1alpha (MIP-1alpha) enhances a receptor activator of nuclear factor kappaB ligand (RANKL) expression in mouse bone marrow stromal cells and osteoblasts through MAPK and PI3K/Akt pathways. Mol Cell Biochem, v.304, n.1-2, Oct, p.53-60. 2007.

Tuter, G., B. Kurtis, et al. Effects of phase I periodontal treatment on gingival crevicular fluid levels of matrix metalloproteinase- 1 and tissue inhibitor of metalloproteinase-1. J Periodontol, v.73, n.5, May, p.487-93. 2002.

Ukai, T., Y. Mori, et al. Immunohistological study of interferon-gamma- and interleukin-4bearing cells in human periodontitis gingiva. Arch Oral Biol, v.46, n.10, Oct, p.901-8. 2001.

Ulfgren, A. K., U. Andersson, et al. Systemic anti-tumor necrosis factor alpha therapy in rheumatoid arthritis down-regulates synovial tumor necrosis factor alpha synthesis. Arthritis Rheum, v.43, n.11, Nov, p.2391-6. 2000.

Van Der Zee, E., V. Everts, et al. Cytokines modulate routes of collagen breakdown. Review with special emphasis on mechanisms of collagen degradation in the periodontium and the 
burst hypothesis of periodontal disease progression. J Clin Periodontol, v.24, n.5, May, p.297305. 1997.

Wang, C. R. e M. F. Liu. Regulation of CCR5 expression and MIP-1alpha production in CD4+ T cells from patients with rheumatoid arthritis. Clin Exp Immunol, v.132, n.2, May, p.371-8. 2003.

Wang, P. L., K. Ohura, et al. DNA microarray analysis of human gingival fibroblasts from healthy and inflammatory gingival tissues. Biochem Biophys Res Commun, v.305, n.4, Jun 13, p.970-3. 2003.

Wedderburn, L. R., N. Robinson, et al. Selective recruitment of polarized T cells expressing CCR5 and CXCR3 to the inflamed joints of children with juvenile idiopathic arthritis.

Arthritis Rheum, v.43, n.4, Apr, p.765-74. 2000.

Wiebe, C. B., C. A. Adkins, et al. Naturally occurring periodontal bone loss in the wild deer mouse, genus Peromyscus. J Periodontol, v.72, n.5, May, p.620-5. 2001.

Wilson, R., M. S. Rowan, et al. Core and comprehensive health care services: 1 . Introduction to the Canadian Medical Association's decision-making framework. Cmaj, v.152, n.7, Apr 1, p.1063-6. 1995.

Yamamoto, M., K. Fujihashi, et al. Molecular and cellular mechanisms for periodontal diseases: role of Th1 and Th2 type cytokines in induction of mucosal inflammation. $\underline{\mathrm{J}}$ Periodontal Res, v.32, n.1 Pt 2, Jan, p.115-9. 1997.

Yamazaki, K., T. Nakajima, et al. Immunohistological analysis of T cell functional subsets in chronic inflammatory periodontal disease. Clin Exp Immunol, v.99, n.3, Mar, p.384-91. 1995.

Cytokine messenger RNA expression in chronic inflammatory periodontal disease. Oral Microbiol Immunol, v.12, n.5, Oct, p.281-7. 1997.

Yamazaki, K., H. Yoshie, et al. T cell regulation of the immune response to infection in periodontal diseases. Histol Histopathol, v.18, n.3, Jul, p.889-96. 2003.

Yang, Y. F., T. Mukai, et al. A non-peptide CCR5 antagonist inhibits collagen-induced arthritis by modulating $\mathrm{T}$ cell migration without affecting anti-collagen $\mathrm{T}$ cell responses. Eur $\mathrm{J}$ Immunol, v.32, n.8, Aug, p.2124-32. 2002.

Yoshioka, H., A. Yoshimura, et al. Analysis of the activity to induce toll-like receptor (TLR)2- and TLR4-mediated stimulation of supragingival plaque. J Periodontol, v.79, n.5, May, p.920-8. 2008.

Yuan, G. H., K. Masuko-Hongo, et al. The role of C-C chemokines and their receptors in osteoarthritis. Arthritis Rheum, v.44, n.5, May, p.1056-70. 2001. 


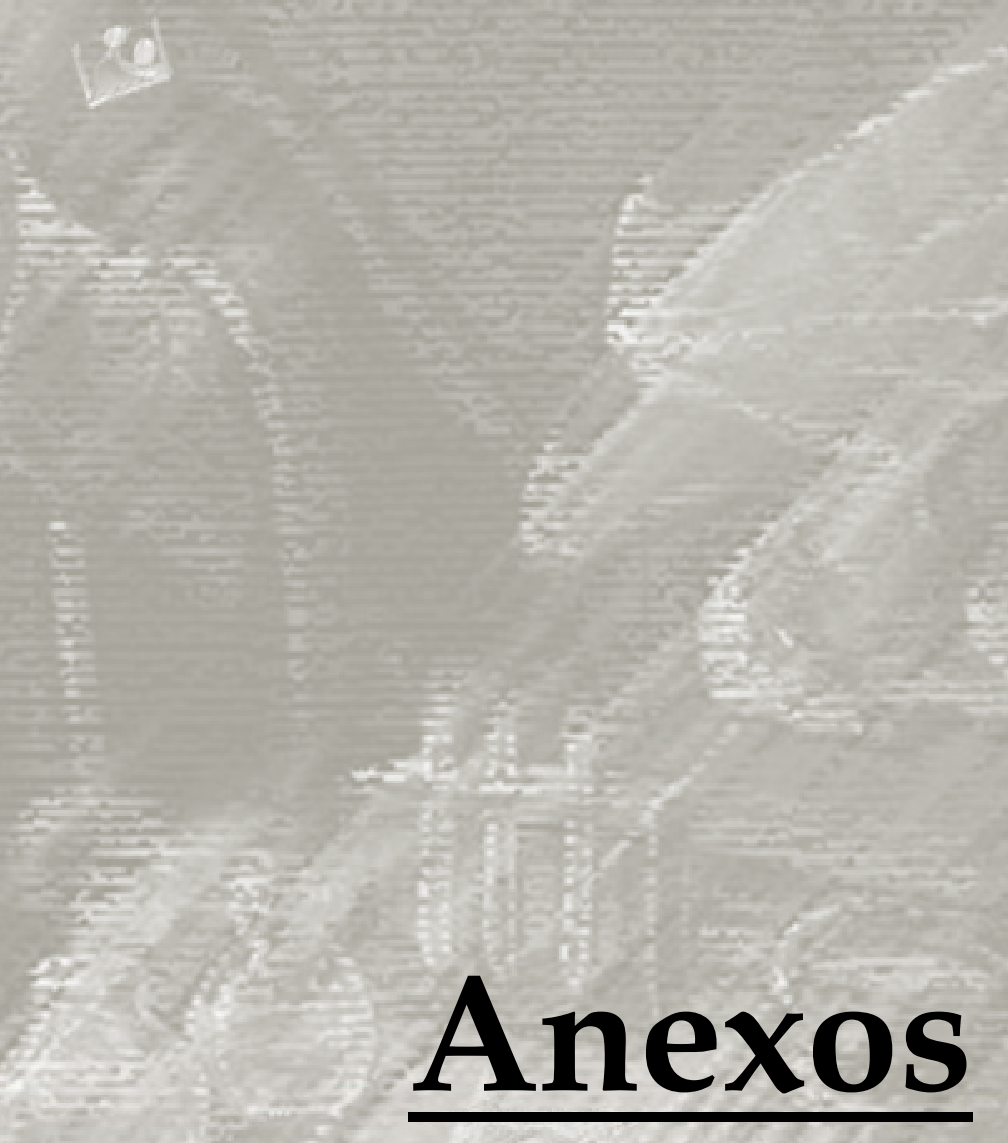





\section{ANEXO A - Parecer da Comissão de Ética em Experimentação Animal da FOB/USP}

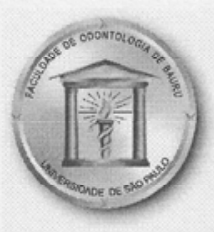

\section{Universidade de São Paulo \\ Faculdade de Odontologia de Bauru}

Al. Dr. Octávio Pinheiro Brisolla, 9-75 - Bauru-SP - CEP 17012-901 - C.P. 73 PABX (0XX14)235-8000 - FAX (0XX14)223-4679

Comissão de Ética no Ensino e Pesquisa em Animais

Fone: (14)3235-8356

e-mail: mferrari@fob.usp.br

CEEPA-PROC. $N^{\circ} 15 / 2007$

Bauru 17 de setembro de 2007.

Senhor Professor,

O projeto de pesquisa encaminhado a esta Comissão de Ética no Ensino e Pesquisa em Animais, denominado "Papel da quimiocina MIP1 $\alpha$ na imunimodulação da severidade da doença periodontal experimental", de autoria de Carlos Eduardo Palanch, sob sua orientaçăo foi enviado ao relator para avaliação.

O parecer do Relator aprovando o projeto foi aceito em reunião desta Comissão realizada no dia 13 de setembro de 2007.

Atenciosamente,

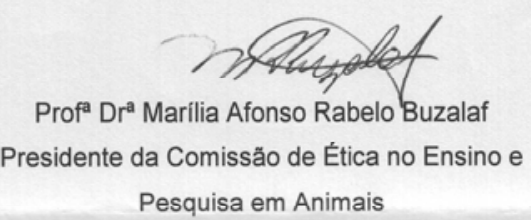

Prof. Dr. Gustavo Pompermaier Garlet

Docente do Departamento de Ciências Biológicas 



\section{ANEXO B - Sequência dos Primers}

Sequencia dos primers e propriedades do produto de amplificação

\begin{tabular}{|c|c|c|c|c|}
\hline Alvo & $\begin{array}{l}\text { Sequencia primer sense } \\
\text { Sequencia primer anti-sense }\end{array}$ & $\mathrm{tA}\left({ }^{\circ} \mathrm{C}\right)$ & $\operatorname{tM}\left({ }^{\circ} \mathrm{C}\right)$ & $\mathrm{bp}$ \\
\hline TNF- $\alpha$ & $\begin{array}{l}\text { AAGCCTGTAGCCCATGTTGT } \\
\text { CAGATAGATGGGCTCATACC }\end{array}$ & 56 & 79 & 330 \\
\hline IL-10 & $\begin{array}{l}\text { AGATC TCCGAGATGC CTTCA } \\
\text { CCGTGGAGCAGGTGAAGAAT }\end{array}$ & 58 & 85 & 307 \\
\hline IFN-Y & $\begin{array}{l}\text { ATGAAATATACAAGTTATATCATG } \\
\text { TGTTTCGAGGTCGAAGAGCATCCC }\end{array}$ & 58 & 77 & 501 \\
\hline MIP-1 $1 \alpha$ & $\begin{array}{l}\text { TTCTGCTGACAAGCTCACCCT } \\
\text { ATGGCGCTGAGAAGACTTGGT }\end{array}$ & 60 & 79 & 322 \\
\hline MIP-1 $\beta$ & $\begin{array}{l}\text { CCCACTTCCTGCTGTTTCTCCGCG } \\
\text { GAGGAGGCCTCTCCTGAAGT }\end{array}$ & 60 & 80 & 238 \\
\hline RANTES & $\begin{array}{l}\text { TTCCCTGTCATCGCTTGCTCT } \\
\text { CGGATGGAGATGCCGATTTT }\end{array}$ & 60 & 81 & 433 \\
\hline RANKL & $\begin{array}{l}\text { CAGAAGATGGCACTCACTGCA } \\
\text { CACCATCGCTTTCTCTGCTCT }\end{array}$ & 65 & 73 & 203 \\
\hline OPG & $\begin{array}{l}\text { GGAACCCCAGAGCGAAATACA } \\
\text { CCTGAAGAATGCCTCCTCACA }\end{array}$ & 57 & 77 & 225 \\
\hline MMP-1 & $\begin{array}{l}\text { TGGACCTGGAGGAAATCTTGC } \\
\text { AGAGTCCAAGAGAATGGCCGA }\end{array}$ & 58 & 79 & 155 \\
\hline MMP-13 & $\begin{array}{l}\text { AGAGATGCGTGGAGAGTCGAA } \\
\text { AAGGTTTGGAATCTGCCCAGG }\end{array}$ & 65 & 85 & 162 \\
\hline MMP-2 & $\begin{array}{l}\text { CTGATGGCACCCATTTACACCT } \\
\text { GATCTGAGCGATGCCATCAAA }\end{array}$ & 60 & 82 & 186 \\
\hline TIMP-1 & $\begin{array}{l}\text { ACTGCAGGATGGACTCTTGCA } \\
\text { TTTCAGAGCCTTGGAGGAGCT }\end{array}$ & 30 & 82 & 206 \\
\hline TIMP-3 & $\begin{array}{l}\text { TTCTCAGCGAGGATGGCACTT } \\
\text { AAACACGGTTCAGGATGCTGG }\end{array}$ & 60 & 81 & 200 \\
\hline iNOS & $\begin{array}{l}\text { CGTCATTTCTGTCCGTCTCT } \\
\text { TTGCTGGCTGATGGCTGGCG }\end{array}$ & 56 & 82 & 390 \\
\hline $\begin{array}{l}\text { A. } \\
\text { actinomycetemcomitans }\end{array}$ & $\begin{array}{l}\text { ATGCCAACTTGACGTTAAAT } \\
\text { AAACCCATCTCTGAGTTCTTCTTC }\end{array}$ & 60 & 78 & 557 \\
\hline$\beta$-actina & $\begin{array}{l}\text { ATGTTTGAGACCTTCAACA } \\
\text { CACGTCAGACTTCATGATGG }\end{array}$ & 56 & 75 & 495 \\
\hline
\end{tabular}

tA: Temperatura de annealing, tM: Temperatura de Melting; bp: pares de base do produto de amplificação 